SERVIÇO DE PÓS-GRADUAÇÃO DO ICMC-USP

Data de Depósito: $\quad 22.09 .2003$

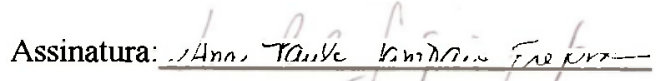

\title{
GENSMAC-SOF: um método numérico para simular escoamentos incompressíveis de fluidos de segunda ordem
}

José Laércio Doricio

Orientador: Prof. Dr. Murilo Francisco Tomé

Dissertação apresentada ao Instituto de Ciências Matemáticas e de Computação - ICMC-USP, como parte dos requisitos para obtenção do título de Mestre em Ciências de Computação e Matemática Computacional.

USP - São Carlos

Setembro/2003 
A Comissão Julgadora:

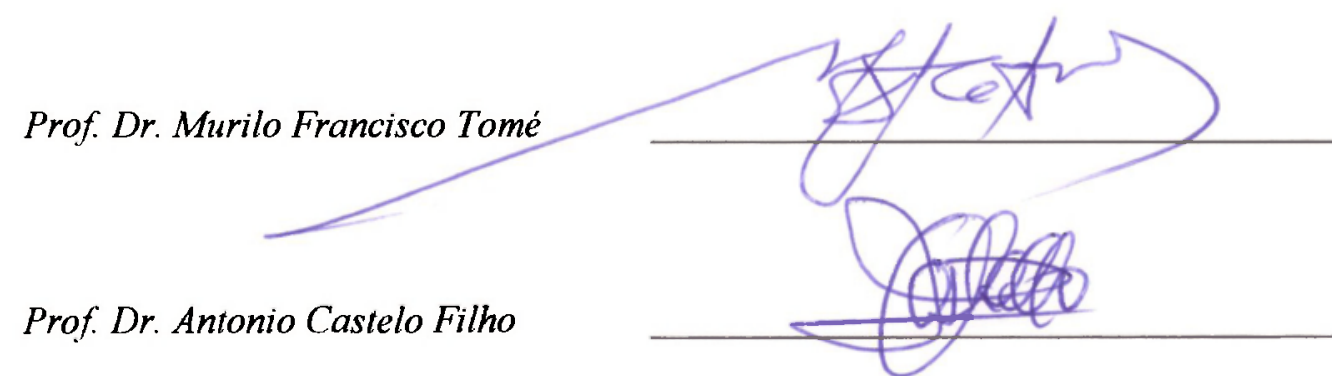

Profa. Dra. Mônica Feijó Naccache Mutlowacide 


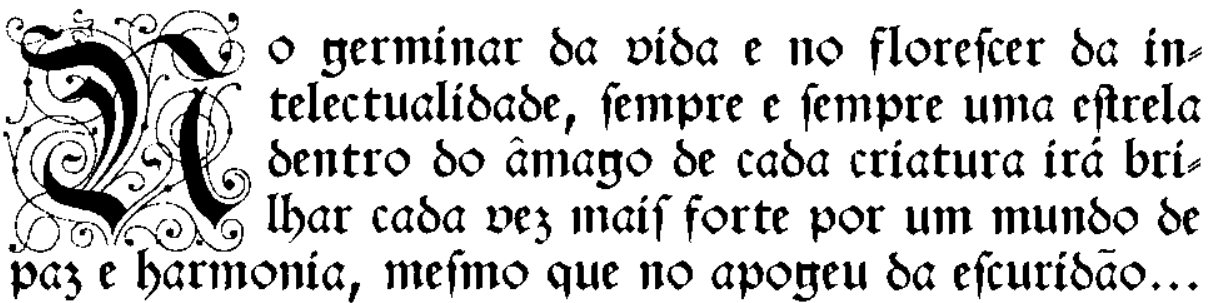

Aos Mens Pais 


\title{
Agradecimentos
}

\begin{abstract}
Principalmente a Deus o a meus pais Nair Vasques Doricio e Dalvo Doricio pela ajuda e incentivo em todos os momentos.

Ao meu orientador Prof. Dr. Murilo F. Tomé pelo incentivo, amizade c colaboração durante a realização desse trabalho.

Em especial aos professores, Dr. Roberto R. Paterlini, Dr, Adalberto P. Bergamasco o Dr. José Alberto Cuminato, e aos meus amigos Renato Hallal, Isaias Torres, Robson T. S. de Oliveira Jr., Luís Felipe, Gerson F. Silva, Marcelo (Japa), Toninho e Venezucla pola amizade, colaboração, incentivo e momentos de descontração.
\end{abstract}

Aos demais professores e amigos da LSP e da LFSCar. 


\section{Resumo}

Esse trabalho apresenta um método numérico para simular escoamentos visco-elásticos com superfícies livres de fluidos de Segunda Ordem. As equacioes goventintes são resolvidas através de una ténica de diferenças finitas em uma malha diferenceiada bascarla (em um método similar ao SMAC(Simplified-Marker-And-Cell). Partículas marcadoras săo utilizadas para representar a superficie livre do fluido. Detalhes completos para a aproximação das tensões na superfície livre são dados. São apresentados resultados numéricos demonstrando a capacidade desta nova técnica para resolver escoamentos visco-elásticos com superfícies livres de fluidos de Segunda Ordem para vários problemas. Fornecemos resultados muméricos sobre a simulação do inchamento do extrudado e sobre a contração 4: 1. Além disso, são apresentados resultados refêrentes à validaçāo e convergència do método numérico descnvolvido nesse trabalho. 


\section{Abstract}

This work is concened with the numerical simulation of viscoelastic free surface flows of a Second Order fluid. The governing equations are solved by a finite difference techicque based on a SMAC(Simplified-Marker-And-Cell) type method. A staggered grid is employed and marker particles are used to represent the fluid free surface. lull details for the approximation of the free surface stress conditions are given. Numerical results demonstrating the capabilities of this new technique in solving viscoelastic free surface flows of a Second Order Huid are presented for a number of problems involving transient. free surface flows. In particular, the numerical simulation of the extrudate swell and the flow on a $4: 1$ contraction are presented for various values of the Deborah number. In addition, validation and convergence results are given. 


\section{Sumário}

$\begin{array}{ll}\text { Agradecimentos } & \text { ii }\end{array}$

Resumo iii

Abstract iv

Sumário $\quad$ v

Lista de Símbolos vii

Lista de Figuras $\quad x$

Lista de Tabelas $\quad$ xii

1 Introdução 1

1.1 Aspectos Gerais . . . . . . . . . . . . . . . . 1

1.2 Organização da Tese . . . . . . . . . . . . . . . 3

2 Equações Governantes 4

2.1 Equaçoes Covernantes em Coordenadas Cartesianas . . . . . . . . . . 6

2.2 Forma Adimensional das Equaçōes Governantes . . . . . . . . . . 8

2.3 Condições de Contorno para Injetores, Fjetores e Contornos Rígidos . . . 9

2.4 Condiçoes de Contorno nas Superfícies Livres . . . . . . . . . . 10

3 Método Numérico $\quad 11$

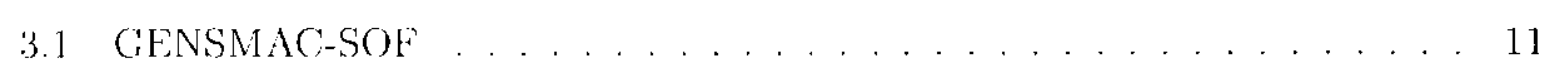

3.2 Algoritmo Computacional . . . . . . . . . . . . . . . 13 
4 Discretização das Equações $\quad 15$

4.1 Dominio Computacional . . . . . . . . . . . . . . 15

4.2 Discretização das Equaçoes Governantes . . . . . . . . . . . . 16

4.2 .1 Cálculo das Derivadas do Tensor não- Newtoniano . . . . . . 18

4.2 .2 Discretização do Tensor não-.evewtoniano . . . . . . . . . . . . 20

4.3 Discretização dos Termos Convectivos . . . . . . . . . . . . . . 21

4.4 Aproximação das Condições de Contorno na Superfície Livre . . . . . . . 25

4.5 Controle do Passo no Tempo . . . . . . . . . . . . . . . . . . 29

4.6 Movimento das Particulas . . . . . . . . . . . . . . . 30

5 Validação do Método Numérico 31

5.1 Validação no Canal . . . . . . . . . . . . . 31

6 Resultados Numéricos $\quad 42$

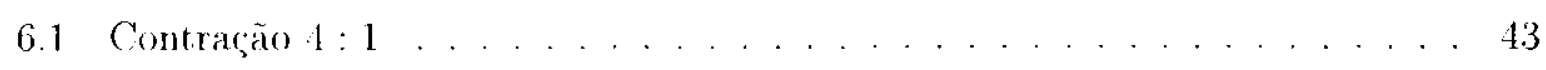

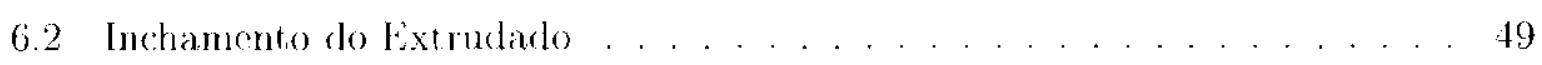

7 Conclusōes e Recomendações $\quad 57$

$\begin{array}{lc}\text { Referências Bibiográficas } & \mathbf{5 8}\end{array}$

Anexo A: Métodos de Runge-Kutta i

Anexo B: Linhas de Corrente iv

Anexo C: Ambiente FreeFlow vii 


\section{Lista de Símbolos}

\begin{tabular}{|c|c|}
\hline Símbolo & Descrição \\
\hline$u$ & vetor volocidade \\
\hline$x$ & vetor posiçăo \\
\hline$\underline{9}$ & vetor de aceleração gravitacional \\
\hline$\underline{n}$ & vetor normal unitário \\
\hline$\underline{u}_{n}$ & componente normal do vetor velocidade \\
\hline$\underline{u}_{t}$ & componente tangencial do vetor velocidade \\
\hline$x_{n}$ & componente normal do vetor posição \\
\hline$\underline{x}_{t}$ & componente tangencial do vetor posição \\
\hline$\stackrel{\pi}{=}$ & tensor de tensäo total \\
\hline$\underline{I}$ & tensor de tensão extra \\
\hline$\underline{d}$ & rensor taxa de deformação) \\
\hline$\stackrel{d}{-n}_{n}$ & tensor taxa de deformação de ordem $n$ \\
\hline$\Phi$ & tensor de tensão näo-Nowtoniano \\
\hline$\underline{I}$ & tensor unitário \\
\hline$u$ & componente do vetor velocidade na direção $x$ \\
\hline$v$ & componente do vetor velocidade na direção y \\
\hline$g_{x}$ & componente do vetor acelera(̧äo gravitacional direção $x$ \\
\hline$y_{y}$ & componente do vetor aceleração gravitacional direção $y$ \\
\hline$\rho$ & massa específica do fluido \\
\hline$p$ & pressão rolativa \\
\hline$\eta_{0}$ & viscosidado dinânica inicial do fluido \\
\hline$\eta$ & viscosidade dinâmica do fluido \\
\hline
\end{tabular}


Lista de Simboles

\begin{tabular}{|c|c|}
\hline Símbolo & Descrição \\
\hline$\lambda_{2}$ & primeiro parâmetro reológico năo-Newtoniano SOF \\
\hline$\lambda_{4}$ & segundo parâmetro reológico não-Newtoniano SOF \\
\hline$\Psi_{1}$ & primeiro coeficiente de diferença de tensões normais \\
\hline$\Psi_{2}$ & segundo coeficiente de diferença de tensōes nomais \\
\hline$N 1$ & primeira diferenca de tensōes normais \\
\hline$\sqrt{2}$ & segunda diferença de tensōes normais \\
\hline$\tau_{x I}: \tau_{y y}$ & tensão extra normal \\
\hline$\tau_{x y}$ & tensäo extra cisalhante \\
\hline$d_{x x} \odot d_{y y}$ & taxa de deformação normal \\
\hline$d_{x y}$ & taxa de deformação cisalhante \\
\hline$\Phi_{x x} \odot \Phi_{y y}$ & tensão não-Newtoniana normal \\
\hline$\Phi_{x y}$ & tensão não-Newtoniana cisalhante \\
\hline U & valor de referência para a velocidade \\
\hline$L$ & valor de referencia para o comprimento \\
\hline$g$ & constante gravitacional \\
\hline Re & número de Reynolds \\
\hline De & número de Deborah \\
\hline $\operatorname{Fr}$ & número de: Froude \\
\hline$t$ & variável temporal \\
\hline$\underline{\underline{u}}$ & vetor velocidade intermediária \\
\hline$\delta x$ & largura da célula na direção do eixo $x$ \\
\hline$\delta y$ & largura da célula na direção do cixo $y$ \\
\hline$\delta t$ & tamanho do passo no tempo \\
\hline$S_{R}$ & parâmetro adimensional para die swell \\
\hline$S_{r}$ & taxa de inchamento para o die swell \\
\hline$\nabla$ & operador gradiente \\
\hline$\nabla$ & operador divergente \\
\hline$\nabla \times$ & operador rotacional \\
\hline$\nabla^{2}$ & operador laplaciano \\
\hline
\end{tabular}




\begin{tabular}{ll} 
Lista de Símbolos \\
Símbolo & Descrição \\
\hline$\frac{D}{D t}$ & operador derivada substancial \\
$O^{T}$ & operador transposta do um tensor \\
$\zeta$ & fator de controle do passo no tempo \\
\hline
\end{tabular}




\section{Lista de Figuras}

4.1 Cólula Computarional. . . . . . . . . . . . . . . . 15

4.2 Domínio Computacional. . . . . . . . . . . . . . . . 16

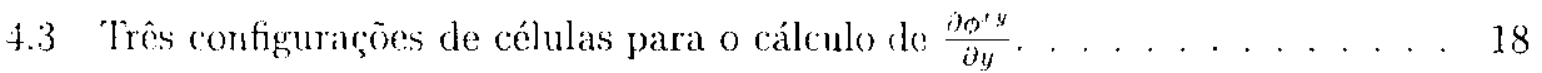

1.1 Trôs configuraçôes de células para o cálculo de $\frac{\partial \Phi^{*}}{\partial y} \ldots \ldots$. . . . . . . . . 19

$4.5 \quad$ Três configurações de cólulas para $\frac{\partial u}{\partial y} \ldots \ldots \ldots \ldots 20 \ldots \ldots 2 \ldots \ldots$

4.6 Fstêncil utilizado para calcular $\phi_{A} \odot \phi_{B} \ldots \ldots \ldots \ldots \ldots \ldots \ldots \ldots \ldots$

4.7 Células de superfície livre com apenas una face em contato com uma célula vazia. . . . . . . . . . . . . . . . . . . . . . . . 25

1.8 Células de superfície livre com duas faces adjacentes em contato com células vazias. . . . . . . . . . . . . . . . . . . . . 27

5.1 Descrição do modelo computacional para a canal-21) . . . . . . . 31

5.2 Resultados numéricos para a componente u em $t=0.1$ s e $t=0.515 \mathrm{~s} . \quad$. 34

5.3 Resultados muméricos para a componente v em $t=0.1 \mathrm{~s}$ e $t=0.545 \mathrm{~s} . .31$

5.4 Resultados numéricos para o ternsor $\tau^{x x} \mathrm{em} l=0.1 \mathrm{~s} \mathrm{e} t=0.545 \mathrm{~s} \ldots \ldots .35$

5.5 Resultados numéricos para o tensor $\tau^{x y} \mathrm{~cm} t=0.1$ s e $t=0.545 \mathrm{~s} \ldots \ldots .35$

5.6 Resultados numéricos para o tensor $\tau^{y y}$ em $t=0.1 \mathrm{~s}$ e $t-0.545 \mathrm{~s} \ldots \ldots 36$

5.7 Resultados muméricos para $\mathrm{N} 1 \mathrm{em} t=0.1 \mathrm{set}=0.545 \mathrm{~s} \ldots \ldots . \ldots 36$

5.8 liesultados na maiha $M_{1}$ : velocidade $u$, componente $\tau^{x x}$ e $\tau^{x y} \mathrm{~cm} x=7.5 \mathrm{~cm} .37$

5.9 Resultados na malha $M_{1}$ : velocidade $u$, componente $\tau^{r x}$ e $\tau^{-x y} \mathrm{~cm} x=15.0 \mathrm{~cm} .37$

5.10 Resultados na malha $M_{2}$ : velocidade $u$, componente $\tau^{x x}$ e $\tau^{x y}$ erm $x-7.5 \mathrm{~cm} .38$

5.11 Resultados na malha $M_{2}$; velocidade $u$, componente $\tau^{x x} \mathrm{e} \tau^{x y}$ em $x=15.0 \mathrm{~cm} .38$

5.12 Resultados na malha $H_{3}$ : velocidade $u$, componente $\tau^{x x}$ o $\tau^{x y} \mathrm{~cm} x=7.5 \mathrm{~cm} .39$

j.13 Resultados na malha $M_{3}$ : velocidade $u$, componente $\tau^{x x}$ e $\tau^{x y}$ em $x-7.5 \mathrm{~cm} .39$ 
6.1 Modelo para a simulação da contração $4: 1 \ldots \ldots . \ldots . \ldots . \ldots 43$

6.2 Resultados numéricos: $R_{\mathrm{e}}=1.0 \mathrm{e} \mathrm{De}=0,0.2,0.4,0.6 .0 .8,1.0,1.2 \mathrm{e} 1.4 .44$

6.3 Resultados numéricos: $\operatorname{Re}=0.1$ e $\mathrm{De}=0,0.2,0.4,0.6,0.8,1.0,1.2$ e 1.4 .45

6.4 Componente da velocidade n para $\mathrm{Re}=1.0 \mathrm{e} \mathrm{t}=2.0 \mathrm{~s} \mathrm{com}$ De $=0 \mathrm{e} 1.2$. . 46

6.5 Componente da velocidade v para $R_{\mathrm{c}}=1.0 \mathrm{e} \mathrm{t}=2.0 \mathrm{~s} \mathrm{com}$ De $=0 \mathrm{e} 1.2 .47$

6.6 Tensão $\tau^{x x}$ para $\mathrm{Re}=1.0 \mathrm{e} \mathrm{t}=2.0 \mathrm{~s}$ com De $=0$ e $1.2 \ldots \ldots 47$

6.7 Tensão $\tau^{x y}$ para $\operatorname{Re}=1.0$ e t $-2.0 \mathrm{~s}$ com De $=0$ e $1.2 \ldots \ldots \ldots 47$

6.8 Tensão $\tau^{y y}$ para $R e=1.0 \mathrm{et}=2.0 \mathrm{~s}$ com $\mathrm{De}=0 \mathrm{e} 1.2 \ldots \ldots 48$

6.9 Diferença de tensão normal $\mathrm{N} 1: \mathrm{Re}=1.0 \mathrm{et}=2.0 \mathrm{~s}$ com De $=0 \mathrm{e} 1.2 \ldots 48$

6.10 . Vodelo para a simulação do inchamento do extrudado. . . . . . . . . 19

6.11 Componente u $\mathrm{cm} t=0.9 \mathrm{~s}$ para $\mathrm{De}=0,0.2,0.4 \mathrm{e} 0.6 \ldots \ldots . \ldots 50$

6.12 Componente v em $t=0.9 \mathrm{~s}$ para $\mathrm{De}=0,0.2,0.400 .6 \ldots \ldots \ldots$. 31

6.13 Componente $\tau^{x x}$ em $t=0.9 s$ para $\mathrm{De}=0,0.2,0.4$ e $0.6 \ldots \ldots \ldots 2$

6.14 Componente $\tau^{x y}$ em $t=0.9 \mathrm{~s}$ para De $=0,0.2,0.4$ e $0.6 \ldots \ldots .53$

6.15 Componente $\tau^{y y} \mathrm{~cm} t=0.9 s$ para $D e=0,0.2,0.4$ e $0.6 \ldots \ldots . \ldots 1$

6.16 Diferença de tensão normal N1 em $t=0.9 \mathrm{~s}$ para $\mathrm{Do}=0,0.2,0.4$ c $0.6 . \quad$. $5 \overline{5}$

6.17 Taxa de inchamento do problema de inchamento do extrudado . . . . . 56 56

1 Esquema para o cálculo da função de corrente ............ v 


\section{Lista de Tabelas}

5.1 Erro relativo para veriticar a convergéncia do método numérico. . . . . . 40

5.2 Ordem de convergencia do método numérico. . . . . . . . . . . . . 41 


\section{Introdução}

\subsection{Aspectos Gerais}

() estudo de métodos numéricos para simular fenomenos que envolvam o escoamento de Aludos com ou sem troca de calor tem se intensificado a pós o surgimento dos computadores digitais a partir dos anos de 1950. Com o avanço da informática a simula(ção de fenomenos complicados tem se tornado cada vez mais eficiente permitindo a implementação de métodos numéricos para simular escoamentos cuja equação constitutiva é altanente näo linear.

Muitos líquidos na natureza e na indústria não podem ser descritos eficientementer atraves dos modelos de fluides viscosos o lineares, tais como os modelos Newtoniano o Newtoniano Generalizado, devido à presença de diferença de terıóos normais e aos efeitos năo lincares que esses modelos são incapazes de predizer. Para resolver esse problema foram dessenvolvidas novas equações constitutivas capazes do predizer essas informações. Dentre essas equações constitutivas podemos destacar o modelo linear de Maxwell, o modelo de Jeffreys, o modelo convectivo de Maxwell, os modelos para fluidos ordenados, entre outros, conferir Bird et al. [1987]. Podemos classificar essas equações constitutivas nos seguintes grupos: Newtoniano, Newtoniano Generalizado, Visco-elástico linear, Viscoelástico não-linear.

A principal vartagem dos fuidos Newtonianos e Newtonianos generalizados é que esses modelos descrevem eficientemente os efeitos viscosos, porém os efeitos clásticos năo 
podem ser descritos por esses modelos. Esse problema foi resolvido através dos modelos visco-elásticos lineares que são capazes de descrever esses efeitos clásticos. Um exemplo de modelo visco-elástico linear é o modelo linear de Maxwell. Apesar dos modelos viscoelásticos lineares descreverem os efeitos elásticos, eles são incapazes de descrever os efoitos não-lineares produzidos pela diferença de tensões normais. Uma tentativa para resolver esse problema foi o desenvolvimento dos modelos visco-elásticos não-lineares, cujo marco foi os modelos para fluidos ordenados, tal como fluiclos de Segunda e Terceira Ordem, conforme Bird ot al. [1987]. Esses modelos são capazes de descrever com precisão os efeitos não-lineares em escoamentos onde o tensor taxa de deformação e suas derivadas no tempo são pecpuenos, contudo não podem descrever os efeitos de rolaxação de tensóes, conforme Bird et al. [1987] a Gast et al. [1999].

Recentemente, o grupo de pescuisa em Matemática Aplicada do ICMC-USP de São Carlos desenvolveu um ambiente de simulação de escoamentos incompressiveis com superfícies livres denominado Free Flow-2D, conferir Oliveira [1999]. Atualmente, o ambiente de simulação FreeFlow-2D permite a simulação dos seguintes tipos de escoamentos bidimensionais': Newtoniano, Newtoniano Generalizado (incluindo Bingham, Power-Law e Cross-Model) e Oldroyd-B. O objetivo desse trabalho é desenvolver um método numérico para simular escoamentos bidimensionais de fluidos de Segunda Ordem e implementálo no ambiente FreeFlow-2D. O método desenvolvido pode ser aplicado a escoamentos confriados e escoamentos com superfícies livies. As equaçoes governantes são resolvidas atravós da técnica de diferenças finitas sobre uma malha diferenciada baseadia em um método similar au nétodo SMAC(Simplified-Marker-And-Cell), conferir Amsden at al. [1970]. Para validar o método numérico são apresentadas três simulações: a simulação do escoanento em um canal bidimensional, a simulação do inchamento do extrudado, conferir Mitsoulis [1999] e Liang o Özetkin [1999], e a simulação da contração $4: 1$ para escoamentos confinados, conferir Nigen a Walters [2002]. O primeiro problema é utilizado para validar quantitativamente o método numérico e os últimos dois problemas são utilizados para validar o método numérico qualitativannente, devido à açāo dos efeitos clásticos nesses problemas. Apresentaremos também resultados referêntes à convergência do método numérico.

\footnotetext{
1 Para mais detalhes sobre o ambiente de simulação Freeflow-2D, consultar anexo C no final dessa tese.
} 


\subsection{Organização da Tese}

O desenvolvimento desse trabalho segue a descrição abaixo.

- Capítulo 1: Introduçào e organização desse trabalho.

- Capítulo 2: As equações governantes na forma dimensional c adimensional para escoamentos incompressíveis de fluidos de Segunda Ordem são apresentadas juntamente com as condiçoes de contorno.

- Capítulo 3: Apresentamos um método numérico para resolver escoamentos de fluidos de Segunda Ordem.

- Capítulo 4: Discretizamos, em detalhes, as equaçōes governantes através do métorho de diferenças finitas em uma mallia diferenciada.

- Capítulo 5: A lasse de validação do método numérico será discutida. Apresentaremos os resultados do escoamento em um canal.

- Capítulo 6: Os resultados numéricos para a contração 4: 1 e para o problema de inchamento do extrudado são apresentados.

- Capítulo 7: Apresentamos as conclusões desse trabalho e as recomendações para trabalhos futuros. 


\section{Equações Governantes}

As equações governantes para escoamento incompressível em regime laminar, transiente e isotérmico são a equação de conservação de quantidade de movimento e a equação de conservaçăo de massal que podem ser escritas respectivamente como:

$$
\begin{gathered}
\rho \frac{\mathcal{D}}{\mathcal{D} t} \underline{u}=\nabla p+\nabla \cdot \underline{\underline{\tau}}+\rho \underline{\underline{g}}, \\
\nabla \cdot \underline{u}=0,
\end{gathered}
$$

onde $\rho$ é a massa específica do fluido, $g$ é o vetor de accleraçăo gravitacional, $u(x, t)$ é o campo de volocidades, $p(\underline{x}, t)$ é o campo de pressão e $\underline{\underline{\tau}}(\underline{x}, t)$ é o tensor de tensão extra. Todavia, é neccessario uma equação constitutiva para calcular $\underline{\underline{\tau}}$ : que define a classe do escoamento. Para escoamentos Newtonianos a equação constitutiva é:

$$
\underline{\underline{\tau}}=\eta_{0} \stackrel{d}{\underline{d}}
$$

onde $\eta_{0}$ é a constante que representa o coeficiente de viscosidade ${ }^{2}$ do fluido e $\underline{\underline{d}}$ é o tensor taxa de deformaçăo definido por:

$$
\underline{d}=\nabla \underline{u}+(\nabla \underline{u})^{T},
$$

Alguns autores denominam a equação de conservação de quantidade de movimento e a equação de conservação de massa cono equação de momentum e equação da continuidade, rospectivamente. ${ }^{2} 0$ coeficiente de viscusidade tambóm é conhecido na literatura como viscosidade dinanica 
O trabatho desenvolvido objetiva resolver escoamentos incompressiveis de fluidos de Segunda Orem (SOF). A equação constitutiva para o modelo SOF se origina do truncanento do modelo de Expansão em Movinento-Retardado (EMR) nos termos de? segunda ordem, ver Bird et, al. [1987]. O nodelo EMR expressa o tensor de tensão extra como um polinômio em relação aos tensores taxi de deformação de ordem $n$, definidos pela fórmula recursiva $(2.5)$.

$$
\begin{aligned}
& \underline{d}_{=1}-\underline{d}_{=} \\
& \underline{d}_{n+1}=\frac{\mathcal{D}}{\mathcal{D} t} \underline{\underline{d}}_{n}-\left[\left(\nabla \underline{u}^{T} \cdot \underline{\underline{d}}_{n}+\underline{d}_{n} \cdot \nabla \underline{u}\right] .\right.
\end{aligned}
$$

A equasão constitutiva E.MR ${ }^{1}$ expandida até os termos de terceira ordem é dada pela equação (2.6), onde $b_{1}, b_{2}, b_{11}$, etc. são denominados parâmetros materiais do fluido

$$
\begin{aligned}
\underline{\tau}=b_{1} \underline{\underline{d}}_{1}+b_{2} \underline{\underline{d}}_{2}+b_{11}\left(\underline{\underline{d}}_{1} \cdot \underline{\underline{d}}_{1}\right)+b_{3} \underline{\underline{d}}_{3}+ & \\
& b_{12}\left(\underline{\underline{d}}_{1} \cdot \underline{\underline{d}}_{2}+\underline{\underline{d}}_{2} \cdot \underline{\underline{d}}_{1}\right)+b_{1: 11}\left(\underline{\underline{d}}_{1}: \underline{\underline{d}}_{1}\right) \underline{\underline{d}}_{1}+\ldots
\end{aligned}
$$

conforme Bird et al. [1987]. Ao truncá-la nos termos de primeira ordem obtemos a equaçăo constitutiva para fluidos Newtonianos. Analogamente, ao tuncá-la nos termos de segunda ordem obtemos a equação constitutiva para fluidos de Scgunda Ordem e assim sucessivamente são obtidos os fluidos ordenados. Para simplificar a notação, vamos escrever a equação constitutiva SOF utilizando o esquema Oldroyd-8 conforme apresentado em Bird ct al. [1987]. Fazendo $b_{1}=\eta_{0}, b_{2}=\eta_{0} \lambda_{2}, b_{11}=\eta_{0} \lambda_{4}$ nla equaçăo (2.6) e considerando somente os temos de segunda ordem obtemos:

$$
\underline{\underline{\tau}}=\eta_{0} \stackrel{d}{\underline{d}}+\eta_{0} \lambda_{4} \quad(\underline{\underline{d}} \cdot \underline{\underline{d}})+\eta_{0} \lambda_{2} \stackrel{d}{\underline{d}}_{2},
$$

onde $\eta_{0}, \lambda_{2}$ e $\lambda_{4}$ são constantes definidas como a viscosidade dinâmica inicial, o primeiro parâmetro reológico relacionado à primeira diferença de tensões normais e o segundo As equaçoes constitutivas geradas a partir do truncamento do modelo EMR săo conhecidas como equaçöes constitutivas para fluidos ordenados, conforme Bird et al. [1987]. 
parâmetro reológido do fluido relacionado à segunda diferença de tensöes normais respectivamente. O parâmetro $\eta_{0}$ está relacionado aos efeitos viscosos e os parámetros $\lambda_{2}$ e $\lambda_{4}$ estão rolacionados aos efeitos de diferença de tensões normais

Quando o escoamento é cisalhante em regime permauente, as funções materiais para o modelo SOF, conforme Bird et al. [1987], são dadas por:

$$
\begin{aligned}
& \eta=\frac{\eta_{12}}{d_{12}}=\eta_{0}, \\
& \Psi_{1}=\frac{N_{1}}{d_{12}^{2}}=\frac{\tau_{11}-\tau_{22}}{d_{12}{ }^{2}}=-2 \eta_{0} \lambda_{2}, \\
& \Psi_{2}-\frac{N_{2}}{d_{12}{ }^{2}}-\frac{\tau_{22} \cdots \tau_{33}}{d_{12}{ }^{2}}=\eta_{0} \lambda_{4},
\end{aligned}
$$

onde $N_{1}$ e $N_{2}$ são a primeira a a segunda diferencas de tensóes normais, $\Psi_{1}$ e $\Psi_{2}$ são o primeiro e o segundo coeficientes de diferenca de tensós normais.

\subsection{Equações Governantes em Coordenadas Carte-}

\section{sianas}

Nesse trabalho consideraremos escoamentos bidimensionais com superfícies livres em coordenadas cartesianas. Nesse sistema de coordenadas, utilizaremos as seguintes definições para o gradiente do vetor $\underline{u}$ e para o tensor taxa de deformaçảo $\underline{d}$ :

$$
\nabla \underline{u}=\left[\begin{array}{ll}
\frac{\partial u}{\partial x} & \frac{\partial v}{\partial x} \\
\frac{\partial u}{\partial y} & \frac{\partial u}{\partial y}
\end{array}\right] \quad e \quad \underline{\underline{d}}=\left[\begin{array}{cc}
2 \frac{\partial u}{\partial x} & \frac{\partial u}{\partial y}+\frac{\partial v}{\partial x} \\
\frac{\partial u}{\partial y}+\frac{\partial v}{\partial x} & 2 \frac{\partial v}{\partial y}
\end{array}\right]
$$

Utilizando as definiçōes acima $c$ a equação da conservaçăo de massa, o tensor $\underline{\underline{d}} \cdot \underline{\underline{d}}$ é dado por:

$$
\underline{\underline{d}} \cdot \underline{\underline{d}}=\left[\begin{array}{cc}
4\left(\frac{\partial u}{\partial x}\right)^{2}+\left(\frac{\partial u}{\partial y}+\frac{\partial v}{\partial x}\right)^{2} & 0 \\
0 & 4\left(\frac{\partial v}{\partial y}\right)^{2}+\left(\frac{\partial u}{\partial y}+\frac{\partial v}{\partial x}\right)^{2}
\end{array}\right] .
$$

e os tensores $(\nabla \underline{u})^{T} \underline{\underline{d}}$ e $\underline{d} \nabla \underline{u}$ sāo dados por: 


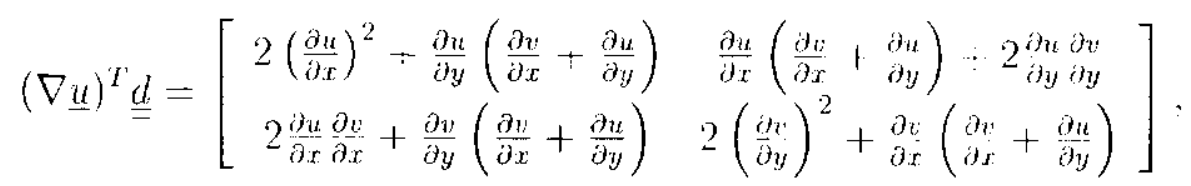

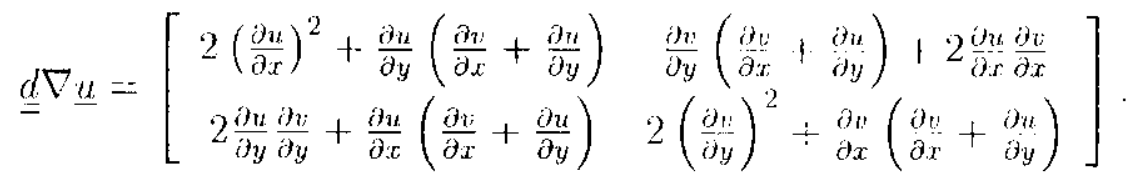

Ltilizando (2.11)-(2.14), as componentes da equaçăo constitutiva (2.7) podem ser escritas na forma:

$$
\begin{aligned}
& \tau^{x x}=\eta_{0}\left(d^{x x}+\Phi^{x x}\right), \\
& \tau^{x y}=\eta_{0}\left(d^{x y}+\Phi^{x y}\right) \\
& \tau^{y y}=\eta_{0}\left(d^{y y}+\Phi^{y y}\right) .
\end{aligned}
$$

onde as componentes do tensor taxa de deformação săo dadas por:

$$
d^{x x}=2 \frac{\partial u}{\partial x}, \quad d^{x y}=\frac{\partial u}{\partial y}+\frac{\partial v}{\partial x}, \quad d^{y y}=2 \frac{\partial v}{\partial y},
$$

e as componentes do tensor $\underline{\underline{\Phi}}$ são:

$$
\begin{aligned}
& \Phi^{x x}=\eta_{0} \lambda_{1}\left[4\left(\begin{array}{l}
\partial u \\
\partial x
\end{array}\right)^{2}+\left(\frac{\partial u}{\partial y}+\frac{\partial v}{\partial x}\right)^{2}\right]-\eta_{0} \lambda_{2}\left[-\frac{\mathcal{D} d^{x x}}{\mathcal{D} t}+4\left(\frac{\partial u}{\partial x}\right)^{2}+2 \frac{\partial u}{\partial y}\left(\frac{\partial u}{\partial y}+\frac{\partial v}{\partial x}\right)\right], \\
& \Phi^{x y}=2 \eta_{0} \lambda_{2}\left(. \frac{\mathcal{D} d^{x y}}{\mathcal{D} t}+\frac{\partial u}{\partial x} \frac{\partial v}{\partial x}+\frac{\partial u}{\partial y} \frac{\partial v}{\partial y}\right) \\
& \Phi^{y y}=\eta_{0} \lambda_{4}\left[4\left(\frac{\partial v}{\partial y}\right)^{2}+\left(\frac{\partial u}{\partial y}+\frac{\partial v}{\partial x}\right)^{2}\right]-\eta_{0} \lambda_{2}\left[-\frac{\mathcal{D} d^{y y}}{\mathcal{D} t}+4\left(\frac{\partial v}{\partial y}\right)^{2}+2 \frac{\partial v}{\partial x}\left(\frac{\partial u}{\partial y}+\frac{\partial v}{\partial x}\right)\right]
\end{aligned}
$$

Assumiremos que $\underset{\mathcal{D} t}{\stackrel{D}{=}}=0$. De acordo com Bird et al. [198i]], o segundo coeficiente de diferença de tensões normais é, em módulo, bem menor que que o primeiro, em geral, $\left|\lambda_{4}\right| \approx ! \frac{1}{10} \lambda_{2} !$. Considerando esse fato e que o escoamento é bidimensional, nós podemos assumir que $\lambda_{4}=0$. Ltilizando as hipóteses acima, as componentes do tensor $\underline{\underline{\Phi}}$ se reduzem a:

$$
\begin{aligned}
& \Phi^{r x}=\cdots \eta_{0} \lambda_{2}\left[4\left(\frac{\partial u}{\partial x}\right)^{2}+2 \frac{\partial u}{\partial y}\left(\frac{\partial u}{\partial y}+\frac{\partial v}{\partial x}\right)\right] \\
& \Phi^{x y}=-2 \eta_{0} \lambda_{2}\left(\frac{\partial u}{\partial x} \frac{\partial v}{\partial x}+\frac{\partial u}{\partial y} \frac{\partial v}{\partial y}\right) \\
& \Phi^{y y}=-\eta_{0} \lambda_{2}\left[4\left(\frac{\partial v}{\partial y}\right)^{2}+2 \frac{\partial v}{\partial x}\left(\frac{\partial u}{\partial y}+\frac{\partial v}{\partial x}\right)\right] .
\end{aligned}
$$


Introduzindo as equaçoes (2.15)-(2.17) na rquaçăo de quantidade de movinento (2.1) e fazendo uso da equação de conservação de massa (2.2) obtemos:

$$
\begin{aligned}
& \frac{\partial u}{\partial t}+\frac{\partial u^{2}}{\partial x}+\frac{\partial u v}{\partial y}=-\frac{\partial p}{\partial x}+\frac{1}{\rho}\left(\frac{\partial^{2} u}{\partial x^{2}}+\frac{\partial^{2} u}{\partial y^{2}}+\frac{\partial}{\partial x} \Phi^{x x}+\frac{\partial}{\partial y} \Phi^{x y}\right)+\underline{g}_{x} \\
& \frac{\partial v}{\partial t}+\frac{\partial u v}{\partial x}+\frac{\partial v^{2}}{\partial y}=-\frac{\partial p}{\partial y}+\frac{1}{\rho}\left(\frac{\partial^{2} v}{\partial x^{2}}+\frac{\partial^{2} v}{\partial y^{2}}+\frac{\partial}{\partial x} \Phi^{x y}+\frac{\partial}{\partial y} \Phi^{y y}\right)+\underline{g}_{y}
\end{aligned}
$$

A equação de conservação de massa (2.2) em coordenadas cartesianas é dada por:

$$
\frac{\partial u}{\partial x}+\frac{\partial v}{\partial y}=0
$$

\subsection{Forma Adimensional das Equações Governantes}

P'ara adimensionar as equaçoes governantes vamos utilizar os valores de referência $U, L$ e g para a velocidade, para o comprimento e para o campo gravitaciunal, respectivamente. As seguintes variáveis adimensionais são ntilizadas:

$$
u=U \bar{u}, v=U \bar{v}, x=L \bar{x}, y-L \bar{y}, t=\frac{L}{U} i, \underline{g}=g \underline{g}, p=\rho U^{2} \ddot{p} .
$$

Utilizando (2.28), a equação de conservaçăo de culantidade de movimento toma a seguinte forma adimensional' ${ }^{1}$ :

$$
\begin{aligned}
& \frac{\partial u}{\partial t}+\frac{\partial u^{2}}{\partial x}+\frac{\partial u v}{\partial y}=-\frac{\partial p}{\partial x}+\frac{1}{R e}\left(\frac{\partial^{2} u}{\partial x^{2}}+\frac{\partial^{2} u}{\partial y^{2}}+\frac{\partial}{\partial x} \Phi^{x x}+\frac{\partial}{\partial y} \Phi^{x y}\right)+\frac{g}{F r^{2}} \\
& \frac{\partial v}{\partial t}+\frac{\partial u v}{\partial x}+\frac{\partial v^{2}}{\partial y}=-\frac{\partial p}{\partial y}+\frac{1}{R e}\left(\frac{\partial^{2} v}{\partial x^{2}}+\frac{\partial^{2} v}{\partial y^{2}}+\frac{\partial}{\partial x} \Phi^{x y}+\frac{\partial}{\partial y} \Phi^{y y}\right)+\frac{g_{y}}{F r^{2}}
\end{aligned}
$$

que pode se escrita na forma vetorial abaixo:

$$
\frac{\partial u}{\partial t}=-\nabla p+\underline{N}(\underline{u})
$$

onde $N(\underline{u})$ tem como componentes:

$$
\begin{aligned}
& N_{1}=-\frac{\partial u^{2}}{\partial x}-\frac{\partial u v}{\partial y}+\frac{1}{R e}\left(\frac{\partial^{2} u}{\partial x^{2}}+\frac{\partial^{2} u}{\partial y^{2}}+\frac{\partial^{2} \Phi^{x x}}{\partial x^{2}}+\frac{\partial^{2} \Phi^{x y}}{\partial y^{2}}\right)+\frac{g}{F r^{2}} \\
& N_{2}=-\frac{\partial u v}{\partial x}-\frac{\partial v^{2}}{\partial y}+\frac{1}{R e}\left(\frac{\partial^{2} v}{\partial x^{2}}+\frac{\partial^{2} v}{\partial y^{2}}+\frac{\partial^{2} \Phi^{x y}}{\partial x^{2}}+\frac{\partial^{2} \Phi^{y y}}{\partial y^{2}}\right)+\frac{\underline{g} y}{F r^{2}} .
\end{aligned}
$$

\footnotetext{
1 As barras foram omitidas de cima das variáveis para simplificaçăo de notação.
} 
As componentes dia equarão constitutiva tomam a seguinte forma:

$$
\begin{aligned}
& \tau^{x x}=\frac{1}{R e}\left(d^{x x}+\Phi^{x x}\right) \\
& \tau^{x y}=\frac{1}{R e}\left(d^{x y}+\Phi^{x y}\right) \\
& \tau^{y y}=\frac{1}{R e}\left(d^{y y}+\Phi^{y y}\right)
\end{aligned}
$$

A equaçà de consorvaçà de massa toma a seguinte forma:

$$
\frac{\partial u}{\partial x}+\frac{\partial y}{\partial y}=0
$$

Nas equaçoes (2.34)-(2.36) as componentes do tensor taxa de deformação $\underline{d}$ o do tensor näo-Newtoniano $\underline{\Phi}$ säo dadas por:

$$
\begin{gathered}
d^{x x}=2 \frac{\partial u}{\partial x}, \quad d^{n y}=\frac{\partial u}{\partial y}+\frac{\partial u}{\partial x}, \quad d^{y y}-2 \frac{\partial v}{\partial y} \\
\Phi^{x: x}=-D e\left[4\left(\frac{\partial u}{\partial x}\right)^{2}+2 \frac{\partial u}{\partial y}\left(\frac{\partial u}{\partial y}+\frac{\partial v}{\partial x}\right)\right], \\
\Phi^{x y} \quad \cdots \quad-2 D e\left(\frac{\partial u \partial v}{\partial x}+\frac{\partial u}{\partial x} \frac{\partial y}{\partial y}\right) \\
\Phi^{y y}=-D e\left[4\left(\frac{\partial y}{\partial y}\right)^{2}+2 \frac{\partial v}{\partial x}\left(\frac{\partial u}{\partial y}+\frac{\partial v}{\partial x}\right)\right] .
\end{gathered}
$$

onde $R e=\frac{e^{\prime} L}{\eta_{0}}, D e=\frac{\lambda_{2} L}{l}$ e Fr $-\frac{V}{\sqrt{g} L}$ säo o número de Roynolds, o número de Deborah e o número de Froude, respectivamente.

\subsection{Condiçōes de Contorno para Injetores, Ejetores e Contornos Rígidos}

A condição de contorno uilizada para a velocidade é a condição de não-escorregamento $\underline{u}(x, t)=0$ nos contornos rígidos. Se considerarmos contornos rígidos paralelos ao (ixo $x$, temos:

$$
\frac{\partial u}{\partial x}=0, \quad \frac{\partial v}{\partial x}=0, \quad \frac{\partial v}{\partial y}=0
$$


Introduzindo as clerivadas (2.42) nas equaçöes constitutivas (2.34)-(2.36), a condiçäo de contorno para a componente $\Phi^{x y}$ do tensor não-Newtoniano $\Phi$ é dada por $\Phi^{r y}=0$.

Na fronteira de injeção utilizamos as seguintes condięóse de contorno para a velocidade: $\underline{u}_{n}=f(y)$ e $\underline{u}_{t}=0$, onde $\underline{u}_{n}$ e $\underline{u}_{t}$ denotam a velocidade normal e a velocidade tangencial ao injetor. respectivamente. Por exemplo, considerando uma fronteira de injecão paralela ao eixo $x$, temos:

$$
\frac{\partial u}{\partial x}=0, \quad \frac{\partial y}{\partial y}=0
$$

Introduzindo as derivadas (2.43) nas cquaçoes constitutivas, obtemos $\Phi^{x y}=0$ na fronteira do injegrão.

Nas fronteiras de ejeção utilizamos a condição $\frac{\partial \underline{u}}{\partial n}=0$ e $p(\underline{x}, t)=0$. Nesse caso, pode ser mostrado clue a componente $\Phi^{x y}$ é dada por $\Phi^{x y}=0$.

\subsection{Condições de Contorno nas Superfícies Livres}

As condiçöes de contorno aplicadas nas superfícies livres são as seguintes:

$$
\begin{aligned}
& \underline{n} \cdot \underline{\underline{\pi}} \cdot \underline{n}=0, \\
& \underline{m} \cdot \underline{\underline{\pi}} \cdot \underline{n}=0,
\end{aligned}
$$

onde $\underline{n}-\left(n_{x}, n_{y}\right)$ e $\underline{m}=\left(-n_{y}, n_{x}\right)$ são os vetores unitários normal e tangencial à superficio livre respectivamente, $\underline{\underline{\pi}}=-p \underline{I}-\underline{\tau}$ é o tensor de tensão total e I ́ o tensor unitário

Utilizando o fato que $n$ e $\underline{m}$ são unitários e ortogonais, as condições $(2.44)$ e $(2.45)$ podem ser escritas como:

$$
\begin{aligned}
& p-\frac{1}{R e}\left[\Phi^{x x} n_{x}^{2}+\Phi^{y y} n_{y}^{2}+2 n_{x} n_{y}\left(\Phi^{x y}+d^{x y}\right)\right]=0, \\
& \left(d^{x: x}-d^{y y}+\Phi^{x x}-\Phi^{y y}\right) n_{x} n_{y}+\left(d^{x y}+\Phi^{x y}\right)\left(n_{x}^{2}-n_{y}^{2}\right)=0 .
\end{aligned}
$$




\section{Método Numérico}

\subsection{GENSMAC-SOF}

Para resolver as equaçóses $(2.29),(2.30),(2.37)$ e (2.39)-(2.41) vamos utilizar uma metodologia similar àquela apresentada por Tomé ct al. [1996]

Suponhamos que são conhecidas as volocidades $\underline{u}\left(\underline{x}, t_{n}\right)$ e a pressão $p\left(\underline{x}, t_{n}\right)$ iniciais, e também as condições de contorno para a velocidade e para a pressão. A velocidade $u\left(x, t_{n+1}\right)$ e a pressão $p\left(\underline{x}, t_{n+1}\right)$, onde $t_{n+1}=t_{n}+\delta t$, são calculadas como segue.

Consideramos una pressão inicial que satisfaz a equação da pressão na superfície livre (2.46). Seja $\check{\mu}\left(\underline{x}, t_{n}\right)=p\left(\underline{x}, t_{n}\right)$, cntão calculamos um campo de velocidade intermediária $\underline{\underline{u}}\left(\underline{x}, t_{n+1}\right)$ atraves da equação abaixo:

$$
\frac{\partial \underline{\underline{u}}}{\partial t}--\nabla \tilde{p}+\underline{N}(\underline{u})
$$

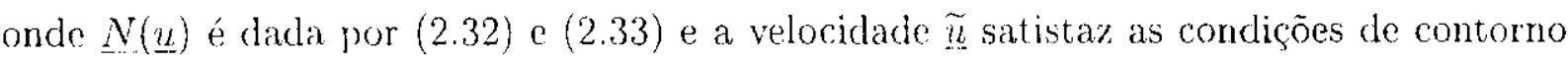
apropriadas para a velocidade $\underline{u}$. Subtraindo a equação (3.1) da equação (2.31) obtemos:

$$
\frac{\partial(\underline{u}-\underline{\tilde{u}})}{\partial t}--\nabla(p-\tilde{p}) .
$$

Aplicando o rotacional em ambos os lados desta equaria obtemos:

$$
\nabla \times\left[\frac{\partial\left(\underline{u}_{-}-\tilde{u}\right)}{\partial t}-\underline{-}\right]=0
$$


eprmutando os operadores obtemos:

$$
\frac{\partial}{\partial t}[\nabla \times(u-\underline{\tilde{u}})]=0
$$

J)a equação (3.3) podemos conchuir que $\nabla \times(\underline{u}-\underline{\tilde{u}})=f(x)$ para algum $f(x)$ com $\left.t \in t^{\prime} t_{n}, t_{n+1}\right]$. Como $\underline{u}=\underline{\tilde{u}} \mathrm{em} t=t_{n} \operatorname{temos} \nabla \times \underline{u}=\nabla \times \underline{\tilde{u}}$ em $t=t_{n}$. Portanto $f(\underline{x})=0$.

Decorrente deste fato, $\nabla \times(\underline{u}-\underline{\tilde{u}})=0$ para $t \in\left[t_{n}, t_{n+1}\right]$, mostrando que a vorticidade associada à $\underline{u}\left(x, t_{n+1}\right)$ e $\underline{u}\left(\underline{x}, t_{n+1}\right)$ sào as mesmas. Porém $\widetilde{u}\left(x, t_{n+1}\right)$ năo satisfaz $\nabla \cdot \underline{\tilde{u}}=0$. Seja $\psi\left(\underline{x}, t_{n+1}\right)$ uma função escalar tàl que:

$$
\underline{u}\left(\underline{x}, t_{n+1}\right)-\underline{\widetilde{u}}\left(\underline{x}, t_{n+1}\right)=-\nabla \psi\left(x, t_{n+1}\right) .
$$

Aplicando o divergente a ambos os lados da equação (3.4) e impondo conservaçăo de massa para $\underline{u}\left(\underline{x}, t_{n}, 1\right)$, obtemos:

$$
\nabla^{2} \psi\left(\underline{x}, t_{n+1}\right)=\nabla \cdot \underline{\tilde{u}}\left(\underline{x}, t_{n+1}\right)
$$

As condições de fromleira adequadas para a equação (3.j) são:

$$
\begin{gathered}
\psi=0, \\
\frac{\partial \psi}{\partial \underline{n}}=0,
\end{gathered}
$$

com (3.6) aplicada em suyerficies livres e com (3.7) aplicarda nos contornos rígidos.

Substituindo (3.4) em (3.2) obtemos:

$$
\frac{\partial}{\partial t}\left(\cdots \nabla \psi\left(\underline{x}, t_{n+1}\right)\right)=-\nabla\left(p\left(\underline{x}, t_{n+1}\right)-\widetilde{p}\left(\underline{x}, t_{n+1}\right)\right),
$$

implicando em:

$$
\frac{\partial}{\partial t}\left(b\left(\underline{x}, t_{n+1}\right)\right)-p\left(\underline{x}, t_{n+1}\right)-\tilde{p}\left(\underline{x}, t_{n+1}\right)
$$

Ao discretizarmos a equação acima através de diferenças progressivas no tempo obtemos:

$$
\frac{\psi\left(\underline{x}, t_{n+1}\right)-\psi\left(\underline{x}, t_{n}\right)}{\delta t}=p\left(\underline{x}, t_{n+1}\right) \cdots \tilde{p}\left(\underline{x}, t_{n+1}\right)
$$


onde $\delta$ t é o passo no tempo. Como $\underline{u}\left(\underline{x}, t_{n}\right)=\underline{\widetilde{u}}\left(\underline{x}, t_{n}\right)$, então através de $(3.1)$ vemos que $\nabla \psi\left(\underline{x}: t_{n}\right)=0$. Decorrente desse fato, $\psi\left(\underline{x}, t_{n}\right)$ ć constante. Considerando $\psi\left(x, t_{n}\right)=0 \mathrm{em}$ (3.8), obtemos a equação para a pressão:

$$
p=\widetilde{p}+\frac{\psi\left(\underline{x}, t_{n+1}\right)}{\delta t}
$$

\subsection{Algoritmo Computacional}

Passo 1: Scja $n=0$ e $\widetilde{p}\left(\mathrm{x}, t_{0}\right)$ um campo de pressäo inicial que satisfaz a condição de contorno para a pressão na superfície livre. Esse campo de pressão fí calculado de forma que a çuação (2.44) scja satisfeita na superfície livre.

Passo 2: Calculamos $\Phi^{x x}\left(\underline{x}, t_{n}\right), \Phi^{x y}\left(\underline{x}, t_{n}\right)$ e $\Phi^{y y}\left(\underline{x}, t_{n}\right)$ explicitamente através das equaçòes (2.39)-(2.41).

Passo 3: Utilizando os tensores calculados anteriormente, a velocidade intermediária $\widetilde{u}\left(\underline{x}, t_{n+1}\right)$ é calculada através das seguintes equações:

$$
\begin{aligned}
& \frac{\partial \tilde{u}}{\partial t}+\frac{\partial u^{2}}{\partial x}+\frac{\partial u v}{\partial y}=\frac{1}{R e}\left(\nabla^{2} u+\frac{\partial \Phi^{x \cdot s}}{\partial x}+\frac{\partial \Phi^{x y}}{\partial y}\right)+\frac{\underline{g}_{x}}{F r^{2}} \\
& \frac{\partial \tilde{v}}{\partial t}+\frac{\partial u v}{\partial x}+\frac{\partial v^{2}}{\partial y}=\frac{1}{R e}\left(\nabla^{2} v+\frac{\partial \Phi^{x y}}{\partial x}+\frac{\partial \Phi^{y y}}{\partial y}\right)+\frac{\underline{g}_{y}}{F r^{2}}
\end{aligned}
$$

As equaçōes diferenciais ordinárias (3.10) e (3.11) são resolvidas utilizando métodos de Runge-Kuttia explícitos'.

Passo 4: Resolvemos a equação de Poisson abaixo para determinarmos $\psi\left(x, t_{n+1}\right)$ :

$$
\nabla^{2} \psi\left(\underline{x}, t_{n+1}\right)=\nabla \cdot \underline{\widetilde{u}}\left(\underline{x}, t_{n-1}\right) .
$$

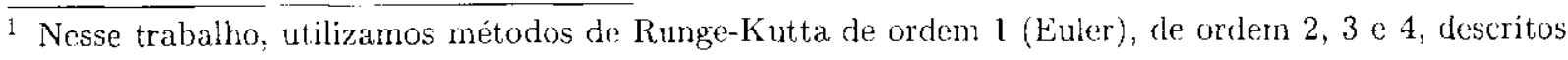
no anexo A. 
Passo 5: Calculamos a velocidade final $\underline{u}\left(\underline{x}, t_{n+1}\right)$ através da equação:

$$
\underline{u}\left(\underline{x}, t_{n+1}\right)=\underline{\widetilde{u}}\left(\underline{x}, t_{n+1}\right)-\nabla \psi\left(\underline{x}, t_{n+1}\right) .
$$

Passo 6: A pressão é calculada por meio da seguinte equação

$$
p\left(x, t_{n+1}\right)=\tilde{p}\left(x, t_{n}\right)+\frac{\psi\left(x, t_{n+1}\right)}{\delta t}
$$

Passo 7: Atualizamos a posição das partículas marcadoras. Essas partículas são geradas nos injetores sendo injetadas para dentro do domínio para representar o fluido, fornecendo meios de visualização do escoamento e obtenção da orientação da superfície livre. As partículas marcadoras são movidas para suas novas posições através da solução das seguintes equaçoes pelo método de Euler explícito:

$$
\frac{\partial x}{\partial t}-u \quad e \quad \frac{\partial y}{\partial t}=v
$$

Passo 8: Se $t_{n+1}<t_{\text {find }}$ façamos $n=n+1$ e voltamos ao passo 1, caso contrário terminamos o algoritmo 


\section{Discretização das Equações}

\subsection{Domínio Computacional}

Para resolvermos as equaçoos (2.39)-(2.41), (3.10), (3.11), (3.12), (3.13) e (3.14) utilizamos o método de diferenças finitas em uma malha diferenciada ${ }^{1}$, cuja pressāo e tensão são calculadas no centro da célula e as componentes da velocidade nos pontos médios de cada aresta, conforme podemos observar na figura (4.1).

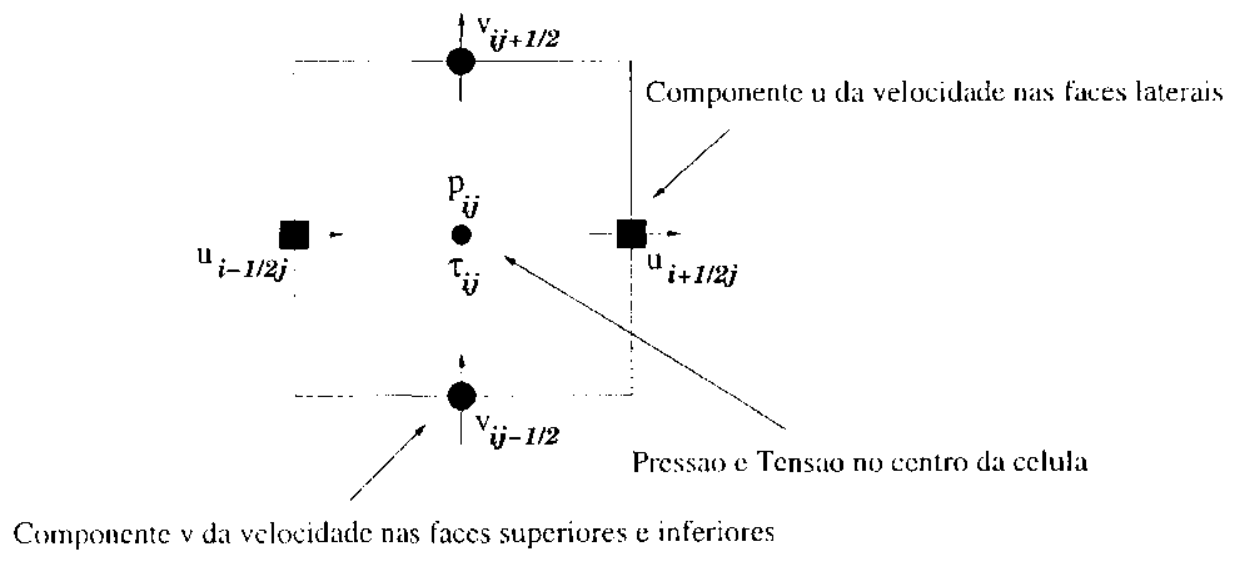

Figura 4.1: Cólula Computacional.

Como o fluido está em movimento, precisamos identificar o fuido e a posiçào da superfície livre na malha, para isso, as células da malha são classificadas como segue:

1 Esse tipo de mallia foi escollido por permitir um methor acoplamento entre a velocidade e a pressão, foi introduzida por Harlow e Wolsh [1965] 
1. VAZIA (F): Sĩo células que não contém fluido.

2. CHelA (sigla: F): Sän células que estão cheias de fluido. Essas células não possinem fares com contato com faces de células vazias.

3. SUPFIRFICIE (S): São células que contém fluido e possuem pelo menos uma face em contato com uma face de célula vazia

4. INJETOR (I): São células que definem a fronteira de injeção.

5. FiJTOR (O): São cólulas que definem a fronteira de ejeção.

6. CONTORNo (B): São cólulas que definem a localizaçäo da fronteira rígida.

A figura (1.2) mostra uma configuração de células em uma malha computacional, nela polemos observar todos os tipos de células o sua distribuição definindo o domínio do fluirlo.

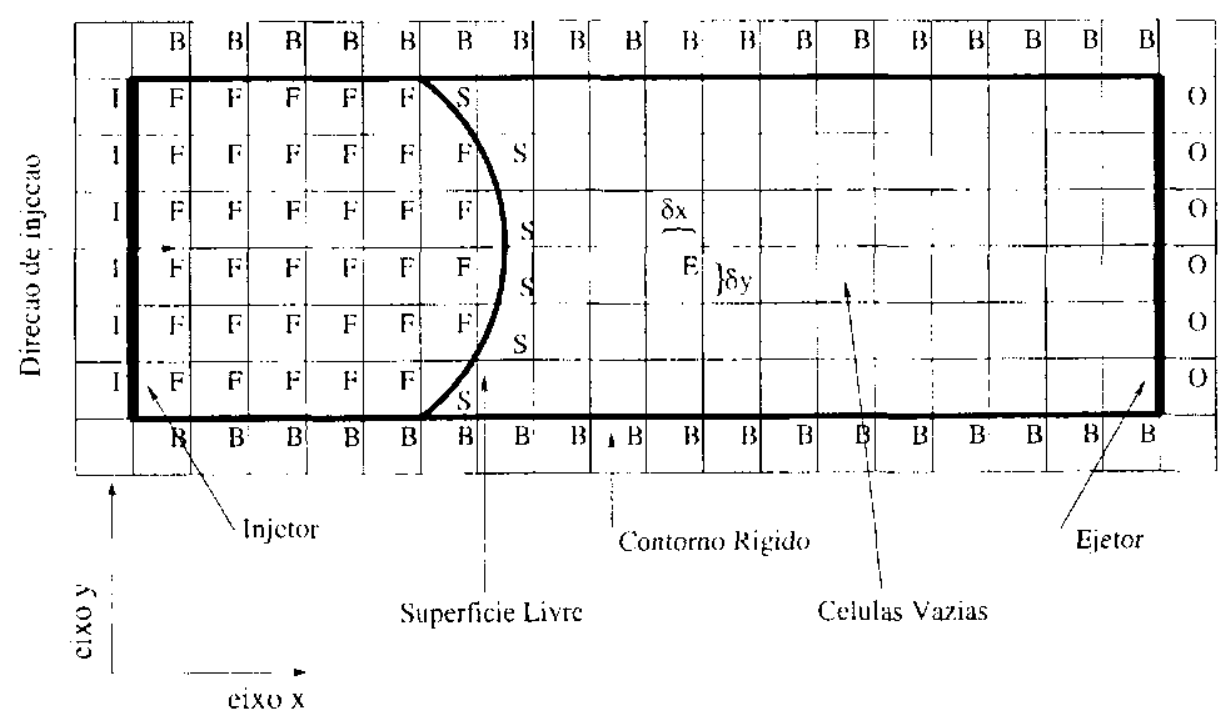

Figura 4.2: Domínio Computacional.

\subsection{Discretização das Equações Governantes}

Para discretizarmos as equaçoses de quantidade de movimento intermediárias (3.10) (3.11) vamos ntilizar a aproximação por diferenças centrais para as derivadas espaciais 
e a aproximação por diferenças progressivas para as derivadas temporais. A equação de quantidade de movimento (3.10) á discretizada no ponto $\left(i+\frac{1}{2}, j\right)$ das células, encquanto que a equação $(3.11)$ é discretizada no ponto $\left(i, j+\frac{1}{2}\right)$. Procedendo dessa forma, a equação de quantiklade de movimento intermediária (3.10) pode ser escrita como:

$$
\begin{aligned}
& \tilde{u}_{i+\frac{1}{2}, j}^{n+1}=\widetilde{u}_{i+\frac{1}{2}, j}^{n}+\delta t\left[-\left(\frac{\tilde{p}_{i+1, j}-\tilde{p}_{i, j}}{\delta x}\right)-\left.\operatorname{CONV}(u)\right|_{i+\frac{1}{2}, j}+\right. \\
& \frac{1}{\operatorname{Re}}\left(\frac{u_{i+\frac{3}{2}, j}-2 u_{i+\frac{1}{2}, j}+u_{i-\frac{1}{2}, j}}{\delta x^{2}}\right)+ \\
& \left.\frac{1}{R e}\left(\left.\frac{u_{i+1, j+1}-2 u_{i+\frac{1}{2}, j}+u_{i \cdots, 2, j} 1}{\delta y^{2}} \cdot \frac{\partial \Phi^{r} r}{\partial x}\right|_{i+\frac{1}{2}, j}+\left.\frac{\partial \Phi^{x y}}{\partial y}\right|_{i+\frac{i}{2}, j}\right)\right]+\frac{g_{x}}{F r^{2}} .
\end{aligned}
$$

Procedendo de forma análoga, a discretização da equação de quantidade de movimento intermediária (3.11) é dada por:

$$
\begin{aligned}
& \tilde{v}_{i, j+\frac{1}{2}}^{n, 1}=\widetilde{v}_{i, j, \frac{1}{2}}^{n}+\delta t\left[-\left(\frac{\widetilde{p}_{i, j+1}-\widetilde{p}_{i, j}}{\delta y}\right)-\left.\operatorname{CONV}(v)\right|_{i, j+\frac{1}{2}}+\right. \\
& \frac{1}{\operatorname{Re}}\left(\frac{v_{i+1, j+\frac{1}{2}}}{2 v_{i, j+\frac{1}{2}}+v_{i-1, j-\frac{1}{2}}}\right)+ \\
& \left.\frac{1}{\operatorname{Re}}\left(\frac{v_{i, j+\mathrm{L}_{2}^{3}}-2 v_{i, j+\frac{1}{2}}+v_{i, j \cdot \frac{1}{2}}}{\delta y^{2}}+\left.\frac{\partial \Phi^{x y}}{\partial x}\right|_{i, j+\frac{1}{2}}+\left.\frac{\partial \Phi^{y y}}{\partial y}\right|_{i, j+\frac{1}{2}}\right)\right]+\frac{g_{3 y}}{F r^{2}} .
\end{aligned}
$$

onde

$$
\left.\operatorname{CONV}(u)\right|_{i+\frac{1}{2}, j}=\left.\left(\frac{\partial u^{2}}{\partial x}+\frac{\partial u v}{\partial y}\right)\right|_{i, \frac{1}{2}, j} \quad \text { e }\left.\operatorname{CONV}(v)\right|_{i, j+\frac{1}{2}}=\left.\left(\frac{\partial u{ }^{\prime}}{\partial x}+\frac{\partial v^{2}}{\partial y}\right)\right|_{i, j+\frac{1}{2}}
$$

As derivadas do tensor não-Newtoniano $\frac{\partial \Phi^{x . c}}{\partial x}, \frac{\partial \Phi^{x y}}{\partial y}, \frac{\partial \Phi^{x y}}{\partial x}$ e $\frac{\partial \Phi^{y y}}{\partial y}$ são discutidas na sessão [4.2.1] e os termos convectivos (4.1) são tratados na sessão [4.3].

A equação de Poisson (3.12) é discretizada utilizando-se o operador laplaciano discreto com 5 pontos:

$\frac{\psi_{i+1, j}-2 \psi_{i, j}+\psi_{i-1, j}}{\delta x^{2}}+\frac{\psi_{i, j+1}-2 \dot{\psi}_{i, j}+\dot{\psi}_{i, j}-1}{\delta y^{2}}=\frac{\widetilde{u}_{i+\frac{1}{2}, j}-\widetilde{u}_{i-\frac{1}{2}, j}}{\delta x}+\frac{\widetilde{v}_{i, j+\frac{1}{2}}-\widetilde{v}_{i, j-\frac{1}{2}}}{\delta y}$.

Pode-se mostrar que a equação (4.2) corresponde a um sistema linear positivo definido e pentadiagonal para $\psi_{i, j}$. Para resolver esse sistema linear, empregamos o método dos gradientes conjugados como implementado en 'Tomé et al. [1994]. 
A volocidade final ó obticla rliscretizando-se a equaçào (3.13) nos respectivos nós:

$$
\begin{aligned}
& u_{i+1, j}^{n+1}=\widetilde{u}_{i+\frac{1}{2}, j}-\frac{\psi_{i+1, j}-\psi_{i, j}}{\partial x} \\
& v_{i, j+\frac{1}{2}}^{n-1}=\widetilde{v}_{i, j+\frac{1}{2}}-\frac{\psi_{i, j+1}-\psi_{i, j}}{\delta y} .
\end{aligned}
$$

O campo de pressão é obtido discretizando-se a equação (3.14) no centro das células:

$$
p_{i, j}=\widetilde{p}_{i, j}+\frac{\dot{\psi}_{i, j}}{\delta t}
$$

\subsubsection{Cálculo das Derivadas do Tensor não-Newtoniano}

A derivada $\frac{\partial \Phi^{r x}}{\partial x}$ é calculada no ponto $\left(i+\frac{1}{2}, j\right)$ através da aproximaçāo por diferenças centrais, conforme a equação (4.6). A derivada $\frac{\partial \Phi^{y y}}{\partial y}$ é calculada no ponto $\left(i, j+\frac{1}{2}\right)$ das células de forma análoga, conforme a equação (4.7).

$$
\begin{aligned}
&\left.\frac{\partial \Phi^{x x}}{\partial x}\right|_{i+\frac{1}{2}, j}= \frac{\Phi_{i+1, j}^{x x}-\Phi_{i, j}^{x x}}{\delta x} \\
&\left.\frac{\partial \Phi^{y y}}{\partial y}\right|_{i, j+\frac{1}{2}}=\frac{\Phi_{i, j+1}^{y y}-\Phi_{i, j}^{y y}}{\delta y}
\end{aligned}
$$

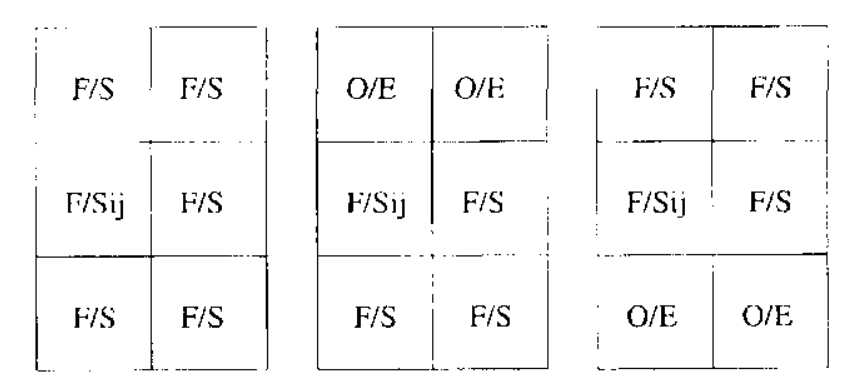

Figura 4.3: Três configuraçōes de células para o cálculo de $\frac{\partial \phi^{x:}}{\partial y}$.

A derivada $\frac{\partial}{\partial y} \Phi^{x y}$ é calculada no ponto $\left(i+\frac{1}{2}, j\right)$ das cólulas. Três casos são analisados, conforme figura (4.3). No primeiro caso, utilizamos a aproximação por diferenças centais, conforme a equação (4.8), no segundo caso utilizamos a aproximação por diferenças regressivas, conforme a equação (4.9) e no terceiro (aso utilizamos a aproximação por diferenças progressivas; conforme a equaçăo (4.10). 
- Primeriro caso:

$$
\begin{aligned}
\left.\frac{\partial \Phi}{\partial y}\right|_{i+\frac{1}{2}, j} ^{x y} & =\frac{\Phi_{i, \frac{2}{2}, j \cdot \frac{1}{2}}^{x y}-\Phi_{i+1, j}^{r y} \frac{1}{2}}{\delta y}, \\
\Phi_{i+\frac{1}{2}, j+\frac{1}{2}}^{x y} & =\frac{\Phi_{i, j}^{x y}+\Phi_{i+1, j}^{x y}+\Phi_{i, j+1}^{x y}+\Phi_{i+1, j+1}^{x y}}{4}, \\
\Phi_{i+\frac{1}{2}, j-\frac{1}{2}}^{x y} & =\frac{\Phi_{i, j}^{x y}+\Phi_{i+1, j}^{x y}+\Phi_{i, j-1}^{x y}+\Phi_{i+1, j \cdot 1}^{x y}}{4} .
\end{aligned}
$$

- Scgundo caso:

$$
\begin{gathered}
\left.\frac{\partial \Phi^{x y}}{\partial y}\right|_{i+\frac{1}{2}, j}-\Phi_{i-\frac{1}{2}, j}^{x y}-\Phi_{i+\frac{1}{2}, j}^{x y} \frac{1}{\delta y} \\
\Phi_{i+\frac{1}{2}, j}^{x y}=\frac{\Phi_{i, j}^{x y}+\Phi_{i+1, j}^{x y}}{2} e \Phi_{i+\frac{1}{2}, j}^{x y}=\frac{\Phi_{i, j}^{x y}+\frac{1}{2 y}+\Phi_{i+1, j}^{x y}}{2} .
\end{gathered}
$$

- Truceiro caso:

$$
\begin{gathered}
\left.\frac{\partial \Phi^{x y}}{\partial y}\right|_{i+\frac{1}{2}, j}=\frac{\Phi_{i+\frac{1}{2}, j+1}^{x y}-\Phi_{i+l_{2}, j}^{x y}}{\delta y} \\
\Phi_{i, \frac{1}{2}, j+1}^{x y}=\frac{\Phi_{i, j+1}^{x y}+\Phi_{i+1, j+1}^{x y y}}{2} e \Phi_{i+\frac{1}{2}, j}^{x y}=\frac{\Phi_{i, j}^{x y}+\Phi_{i+1, j}^{x y}}{2} .
\end{gathered}
$$

Quando a célula $(i, j)$ está en contato com células do injetor ou células do contorno rígido, de acordo com a figura (4.4), utilizamos a aproximação por diferenças centrais juntamente com as condiçōes de contorno para $\Phi^{x y}$ estudadas na sessão [2.3].

\begin{tabular}{|c|c|c|c|c|c|}
\hline $\mathrm{F} / \mathrm{S}$ & $\mathrm{F} / \mathrm{S}$ & $\mathrm{B} / \mathrm{I}$ & $\mathrm{B} / \mathrm{l}$ & $\mathrm{F} / \mathrm{S}$ & $\mathrm{F} / \mathrm{S}$ \\
\hdashline$-\mathrm{F} / \mathrm{Sij}$ & $\mathrm{F} / \mathrm{S}$ & $\mathrm{F} / \mathrm{Sij}$ & $\mathrm{F} / \mathrm{S}$ & $\mathrm{F} / \mathrm{S} \mathrm{ij}$ & $\mathrm{F} / \mathrm{S}$ \\
\hline $\mathrm{F} / \mathrm{S}$ & $\mathrm{F} / \mathrm{S}$ & $\mathrm{F} / \mathrm{S}$ & $\mathrm{F} / \mathrm{S}$ & $\mathrm{B} / \mathrm{I}$ & $\mathrm{B} / \mathrm{I}$ \\
\hline
\end{tabular}

Figura 4.4: Três configuraçöes de células para o cálculo de $\frac{\partial \text { try }}{\partial y}$.

A derivada $\frac{i j \Phi^{x y}}{\partial x}$ c calculada no ponto $\left(i \cdot j+\frac{1}{2}\right)$ e é obtida de forma análoga. 


\subsubsection{Discretização do Tensor não-Newtoniano}

As equações (2.39)-(2.41) são discretizadas no centro das células conforme podemos observar abaixo:

$$
\begin{aligned}
& \left.\Phi^{x x}\right|_{i, j}=-D e\left[1\left(\left.\frac{\partial u}{\partial x}\right|_{i, j}\right)^{2}+\left.2 \frac{\partial u}{\partial y}\right|_{i, j}\left(\left.\frac{\partial u}{\partial y}\right|_{i, j}+\left.\frac{\partial v}{\partial x}\right|_{i, j}\right)\right] . \\
& \left.\Phi^{x y}\right|_{i, j}=-2 D e\left(\left.\left.\frac{\partial u}{\partial x}\right|_{i, j} \frac{\partial v}{\partial x}\right|_{i, j}+\left.\left.\frac{\partial u}{\partial y}\right|_{i, j} \frac{\partial v}{\partial y}\right|_{i, j}\right) . \\
& \left.\Phi^{y y}\right|_{i, j}=-D e\left[4\left(\left.\frac{\partial u}{\partial y}\right|_{i, j}\right)^{2}+\left.2 \frac{\partial v}{\partial x}\right|_{i, j}\left(\left.\frac{\partial u}{\partial y}\right|_{i, j}+\left.\frac{\partial v}{\partial x}\right|_{i, j}\right)\right] .
\end{aligned}
$$

As derivadas na equanão acima são aproximadas como segue. Para calcular a derivada $\frac{\partial u}{\partial t}$ utilizamos o esquema de diferenças centrais, conforme a equação (4.11). A derivada $\frac{\partial y}{d y}$ é calculada de forma análoga, conforme equação (4.12).

$$
\begin{aligned}
& \left.\frac{\partial u}{\partial x}\right|_{2, j}=\frac{u_{i+\frac{1}{2}, j}-u_{i-\frac{1}{2}, j}}{\delta x} . \\
& \left.\frac{\partial v}{\partial y}\right|_{i, j}=\frac{u_{i, j} \cdot \frac{1}{2}-v_{i, j-\frac{1}{2}}}{\delta y} .
\end{aligned}
$$

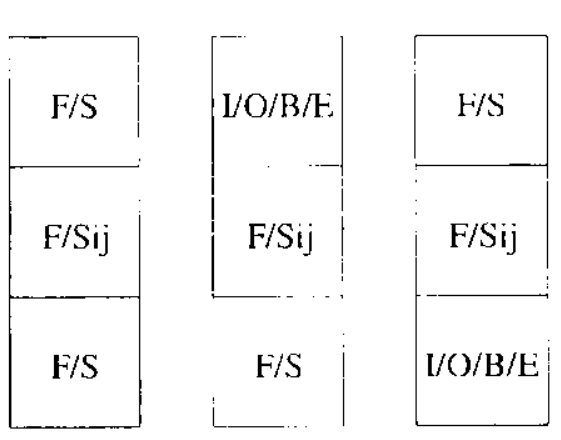

Figura 4.5: Três configurações de cólulas para $\frac{\partial u}{\partial y}$

A derivada $\frac{\partial u}{\partial y}$ é calculada utilizando-se um esquema misto. Para o caso que a célula com índice $(i, j)$ possui as faces $j+\frac{1}{2}$ e $j-\frac{1}{2}$ em contato com células cheias ou de superfície livre utilizamos o equema diferenças centrais: 


$$
\begin{gathered}
\left.\frac{\partial u}{\partial y}\right|_{i, j}=\frac{u_{i, j+\frac{1}{2}}-u_{i, j-\frac{1}{2}}}{\partial y}, \\
u_{i, j+\frac{1}{2}}=\frac{u_{i+\frac{1}{2}, j-1}+u_{i} \frac{1}{2}, j \cdot 1}{4}+u_{i+\frac{1}{2}, j}+u_{i-\frac{1}{2}, j} \\
u_{i, j-\frac{1}{2}}=\frac{u_{i+\frac{1}{2}, j}+u_{i-\frac{1}{2}, j-1}+u_{i+\frac{1}{2}, j}+u_{i-\frac{1}{2}, j}}{4} .
\end{gathered}
$$

Quando a face $j+\frac{1}{2}$ não está em contato com células cheias on de superfície livre utilizamos o esquema de diferenças regressivas:

$$
\begin{gathered}
\left.\frac{\partial u}{\partial y}\right|_{i, j}=\frac{u_{i, j}-u_{i, j-1}}{\partial y}, \\
u_{i, j}=\frac{u_{i+\frac{1}{2}, j}+u_{i-\frac{1}{2}, j}}{2} \text { e } u_{i, j}=\frac{u_{i+\frac{1}{2}, j-1}+u_{i-\frac{1}{2}, j} 1}{2} .
\end{gathered}
$$

Por outro lado, se a face $j-\frac{1}{2}$ não estiver em contato com células cheias ou de superfície livre utilizamos o esquema de diferenças progressivas:

$$
\begin{gathered}
\left.\frac{\partial u}{\partial y}\right|_{i, j}=\frac{u_{i, j+1}-u_{i, j}}{\delta y}, \\
u_{i, j+1}=\frac{u_{i \mid \frac{1}{2}, j+1}+u_{i-\frac{1}{2}, j-1}}{2} \text { e } u_{i, j}=\frac{u_{i+\frac{1}{2}, j}+u_{i-\frac{1}{2}, j}}{2} .
\end{gathered}
$$

Para calcular a derivada $\frac{\partial v}{\partial x}$ procedemos de forma análoga ao cálculo da derivada $\frac{\partial u}{\partial y}$.

\subsection{Discretização dos Termos Convectivos}

A forma através da qual as derivadas convectivas nas equaçóes de quantidade de movimento (3.10) e(3.11) são aproximadas requer uma atenção especial. Ésses termos são responsáveis por muitos fenômenos complexos nos escoamentos e são os principais causadores de dificuldades numéricas nas simulaçoons. Devido a esses fatores, várias técnicas de discretização têm sido desenvolvidas ao longo dos anos, conferir Varonos e Bergeles [1998]. No presente trabalho adotamos o esquema de alta ordem VONOS (Variable Order Non-Oscilatory Scheme), ver Varonos e Bergeles [1998].

A escolha do esquema VONOS para a discretização do termo convectivo é devido ao fato de que esquemas de alta ordem reduzem oscilações numéricas fisicanente incorretas 
ao mesmo tempo (que minimiza os efeitos da difusào numérica artificial. Ontros métodos como SMART, conferir Gaskell of al. [1988], c o esquema HLPA (Hybrid Linear Parabolic: Approximation), conferir Zhu [1992], poderiam ser utilizados.

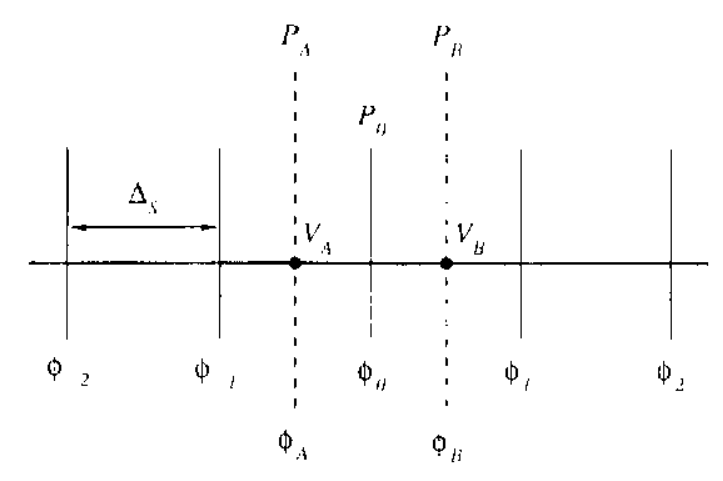

Figura 4.6: Estêncil utilizado para calcular $\phi_{A}$ e $\phi_{B}$.

Considerando a figura (4.6), onde $V_{A} \odot V_{B}$ são as velocidades convectivas nos pontos $P_{A}$ e $P_{B}$, respectivamente. Para calcularmos a derivada parcial da variável genérica $\phi$ em um ponto $P_{0}$, por exemplo $\frac{\partial \phi}{\partial s}$, onde $s$ é um dos eixos coordenados, podemos fazer a seguinte aproximação:

$$
\left.\frac{\partial \phi}{\partial s}\right|_{P_{0}}=\frac{\phi_{B}-\phi_{A}}{\Delta s} .
$$

Os valores de $\phi_{A}$ e $\phi_{B}$ são obtidos en termos dos valores vizinhos, $\phi_{-2}, \phi_{-1}, \phi_{0}, \phi_{1}$, $\phi_{2}$ e das clireçoons das velocidades convectivas $\left(V_{A}, V_{B}\right)$.

Fsquema VONOS:

$$
\begin{aligned}
\text { se } V_{B} \geq 0, \quad \phi_{B}= \begin{cases}\phi_{0}, & \text { se } \widehat{\phi}_{0} \notin[0,1] \\
10 \phi_{0}-9 \dot{\phi}_{-1}, & \text { se } \widehat{\phi}_{0} \in[0,3 / 74) \\
\frac{3}{8} \phi_{1}+\frac{6}{8} \phi_{0}-\frac{1}{8} \phi_{-1}, & \text { se } \widehat{\phi}_{0} \in[3 / 74,1 / 2) \\
1.5 \phi_{0}-0.5 \phi_{-1}, & \text { se } \widehat{\phi}_{0} \in[1 / 2,2 / 3) \\
\phi_{1}, & \text { se } \widehat{\phi}_{0} \in[2 / 3,1]\end{cases} \\
\text { se } V_{B}<0, \quad \phi_{H}= \begin{cases}\phi_{1}, & \text { se } \widehat{\phi}_{1} \notin[0,1] \\
10 \phi_{1}-9 \phi_{2}, & \text { se } \widehat{\phi}_{1} \in[0,3 / 74) \\
\frac{3}{8} \phi_{0}+\frac{6}{8} \phi_{1}-\frac{1}{8} \phi_{2}, & \text { se } \widehat{\phi}_{1} \in[3 / 74,1 / 2) \\
1.5 \phi_{1}-0.5 \phi_{2}, & \text { se } \widehat{\phi}_{1} \in[1 / 2,2 / 3) \\
\phi_{0}, & \text { se } \widehat{\phi}_{1} \in[2 / 3,1]\end{cases}
\end{aligned}
$$




$$
\begin{aligned}
\text { se } V_{A} \geq 0, \quad \phi_{A}- \begin{cases}\phi_{-1}, & \text { se } \widehat{\phi}_{-1} \notin[0,1] \\
10 \phi_{-1}-9 \phi_{2}, & \text { se } \widehat{\phi}_{-1} \in[0,3 / 74) \\
\frac{3}{8} \phi_{0}+{ }_{8}^{6} \phi_{-1}-\frac{1}{8} \phi_{-2}, & \text { se } \widehat{\phi}_{1} \in[3 / 74,1 / 2) \\
1.5 \phi_{-1}-0.5 \phi_{-2}, & \text { se } \widehat{\phi}_{-1} \in[1 / 2,2 / 3) \\
\phi_{0}, & \text { se } \widehat{\phi}_{1} \in[2 / 3,1]\end{cases} \\
\text { se } V_{A}<0, \quad \text { se } \widehat{\phi}_{0} \notin[0,1] \\
\phi_{A}= \begin{cases}\phi_{13}, & \text { se } \widehat{\phi}_{0} \in[0,3 / 74) \\
10 \phi_{0}-9 \phi_{1}, & \text { se } \widehat{\phi}_{0} \in[3 / 74,1 / 2) \\
\frac{3}{8} \phi_{-1}+\frac{6}{8} \phi_{0}-\frac{1}{8} \phi_{1}, & \text { se } \widehat{\phi}_{0} \in[1 / 2,2 / 3) \\
1.5 \phi_{0}-0.5 \phi_{1}, & \text { se } \widehat{\phi}_{0} \in[2 / 3,1] \\
\phi_{-1}, & \end{cases}
\end{aligned}
$$

onde $\widehat{\phi}_{i}, i=-1,0,1$, é definido em função das velocidades upstream $\left(\phi_{U}\right)$, remote-upstream $\left(\phi_{R}\right)$ e downstream $\left(\phi_{D}\right)$ no ponto $P_{A}$ \& $P_{B}$, isto é, de acordo com a direção da velocidade convectiva, :

$$
\widehat{\phi}_{i}=\frac{\phi_{l}-\phi_{R}}{\phi_{l}-\phi_{R}}
$$

Por excmplo, considendo o ponto $P_{A}$, como mostrado na figura (4.6), e supondo que a velocidade convectiva nesse ponto é positiva $\left(V_{A}>0\right)$, então os valores de $\phi_{D}, \phi_{C}$ e $\phi_{R}$ são dados por $\phi_{0}, \phi_{3}$ e $\phi_{-2}$, respectivamente.

Para implementarmos as expressōes acima consideramos o termo convectivo da equaçào (3.10) avaliado $\mathrm{cm}\left(i+\frac{1}{2}, j\right)$, dado por:

$$
\left.\operatorname{CONV}(u)\right|_{i+\frac{1}{2}, j}-\frac{\left.\partial u^{2}\right|^{2}}{\left.\partial x\right|_{i+\frac{1}{2}, j}}+\left.\frac{\partial(u v)}{\partial y}\right|_{i+\frac{1}{2}, j}
$$

As derivadas da ecplaçăo (4.16) podem ser aproximadas como segue:

$$
\begin{aligned}
& \left.\frac{\partial(u u)}{\partial x}\right|_{i+\frac{1}{2}, j}=\frac{\hat{u}_{i+1, j} u_{i+1, j}-\hat{u}_{i, j} u_{i, j}}{\delta x}
\end{aligned}
$$

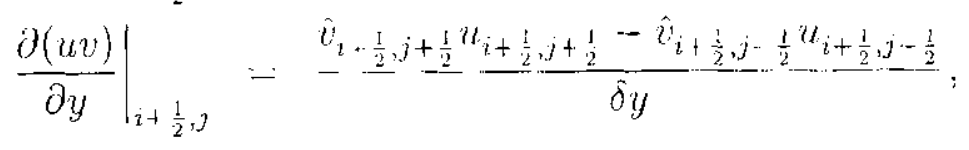

onde $\hat{u}$ e $\hat{v}$ são as velocidades convectivas a podem ser obtidas pelas médias dos valores vizinhos. As velocidades transportadas são calculadas através do esquema convectivo 
VONOS. Logo, as velocidades $u_{i, j} \mathrm{e} u_{2+1, j} \mathrm{em}(1.17)$ são obtidas de acordo com o seguinte procedimento. Seja $S_{i j}$ definido abaixo:

$$
S_{i, j}= \begin{cases}0, & \text { se } \hat{u}_{i, j} \geq 0 \\ 1, & \text { caso contrário }\end{cases}
$$

Aplicando o método VONOS à equação (4.17), obtemos:

$$
\begin{aligned}
& \widehat{\phi}_{i \cdot 1, j}=\left(1-S_{i+1, j}\right) \quad\left(\frac{u_{i+\frac{1}{2, j}}-u_{i-\frac{1}{2}, j}}{u_{i+\frac{3}{2}, j}-u_{i-\frac{1}{2}, j}}\right)+S_{i+1, j}\left(\frac{u_{i+\frac{3}{2}, j}-u_{i, \frac{5}{2}, j}}{u_{i+\frac{1}{2}, j}-u_{i+\frac{5}{2}, j}}\right) \\
& u_{i+1, j}=\left(1-S_{i+1, j}\right) \begin{cases}u_{i+\frac{1}{2}, j} & \text { se } \widehat{\phi}_{i+1, j} \notin[0,1] \\
10 u_{i+\frac{1}{2}, j}-9 u_{i-\frac{1}{2}, j} & \text { se } \widehat{\phi}_{i+1, j} \in[0,3 / 74) \\
\frac{3}{8} u_{i: \frac{3}{2}, j}+\frac{6}{8} u_{i+\frac{1}{2}, j}-\frac{1}{8} u_{i-\frac{1}{2}, j} & \text { se } \widehat{\phi}_{i+1, j} \subseteq[3 / 71,1 / 2) \\
1.5 u_{i+\frac{1}{2}, j}-0.5 u_{i-\frac{1}{2}, j} & \text { se } \widehat{\phi}_{i+1, j} \subset[1 / 2,2 / 3) \\
u_{i+\frac{3}{2}, j} & \text { se } \widehat{\phi}_{i+1, j} \in[2 / 3,1]\end{cases} \\
& +S_{i+1, j} \begin{cases}u_{i+\frac{3}{2}, j} & \text { se } \widehat{\phi}_{i+1, j} \not[0,1] \\
10 u_{i+\frac{3}{2}, j}-9 u_{i+\frac{5}{2}, j} & \text { se } \widehat{\phi}_{i+1, j} \in[0,3 / 71) \\
3 u_{i+\frac{1}{2}, j}+\frac{6}{8} u_{i-\frac{3}{2}, j}-\frac{1}{8} u_{i+\frac{5}{2}, j} & \text { se } \widehat{\phi}_{i+1, j} \subset[3 / 74,1 / 2) \\
1.5 u_{i+\frac{3}{2}, j}-0.5 u_{i+\frac{5}{2}, j} & \text { se } \widehat{\phi}_{i+1, j} \in[1 / 2,2 / 3) \\
u_{2+\frac{1}{2}, j} & \text { se } \widehat{\phi}_{i+1, j} \subset[2 / 3,1]\end{cases} \\
& \widehat{\phi}_{i, j}=\left(1-S_{i, j}\right) \quad\left(\frac{u_{i-\frac{1}{2}, j}-u_{i-\frac{3}{2}, j}}{u_{i+\frac{1}{2}, j}-u_{i-\frac{3}{2}, j}}\right)+S_{i, j}\left(\frac{u_{i+\frac{1}{2}, j}-u_{i+\frac{3}{2}, j}}{u_{i-\frac{1}{2}, j}-u_{i+\frac{3}{2}, j}}\right) \\
& u_{i, j}=\left(1-S_{i, j}\right) \quad \begin{cases}u_{i-\frac{1}{2}, 3} & \text { se } \widehat{\phi}_{i, j} \notin[0,1] \\
10 u_{i-\frac{1}{2}, j}-9 u_{i-\frac{3}{2}, j} & \text { se } \widehat{\phi}_{i, j} \in[0,3 / 74) \\
\frac{3}{8} u_{i+\frac{1}{2}, j}-\frac{6}{8} u_{i-\frac{1}{2}, j}-\frac{1}{8} u_{i-\frac{3}{2}, j} & \text { se } \widehat{\phi}_{i, j} \in[3 / 74,1 / 2) \\
1.5 u_{i-\frac{1}{2}, j}-0.5 u_{i-\frac{3}{2}, j} & \text { se } \widehat{\phi}_{i, j} \in[1 / 2,2 / 3) \\
u_{i+\frac{1}{2}, j} & \text { se } \widehat{\phi}_{i, j} \subset[2 / 3,1]\end{cases} \\
& +S_{i, j} \begin{cases}u_{i+\frac{1}{2}, j} & \text { se } \widehat{\phi}_{i, j} \notin[0,1] \\
10 u_{i+\frac{1}{2}, j}-9 u_{i+\frac{3}{2}, j} & \text { se } \widehat{\phi}_{i, j} \in[0,3 / 74) \\
\frac{3}{8} u_{i-\frac{1}{2}, j}+\frac{6}{8} u_{i+\frac{1}{2}, j}-\frac{1}{8} u_{i+\frac{3}{2}, j} & \text { se } \widehat{\phi}_{i, j} \in[3 / 71,1 / 2) \\
1.5 u_{i+\frac{1}{2}, j} \cdots 0.5 u_{i+\frac{3}{2}, j} & \text { se } \widehat{\phi}_{i, j} \in[1 / 2,2 / 3) \\
u_{i, \frac{1}{2}, j} & \text { se } \widehat{\phi}_{i, j} \in[2 / 3,1]\end{cases}
\end{aligned}
$$


As velocidarles tramsportadas da rquação (4.18) são obtidas de forma análoga ao procedimento acima.

\subsection{Aproximação das Condições de Contorno na Su- perfície Livre}

As condiçoes de contorno na superfície live (2.46) e (2.47) poden ser escritas como:

$$
\begin{aligned}
& p-\frac{1}{R e}\left[\Phi^{x x} n_{x}^{2}+\Phi^{y y} n_{y}^{2}+2 n_{x} n_{y}\left(\Phi^{x y}+d^{x y}\right)\right]=0 \\
& \left(d^{x x}-d^{y y}+\Phi^{x x}-\Phi^{y y}\right) n_{x} n_{y}+\left(d^{x y}+\Phi^{x y}\right)\left(n_{x}^{2}-n_{y}^{2}\right)=0
\end{aligned}
$$

Para aplicar essas condiçós, vamos supor que a malha é suficientemente fina de forma que a superficio live do fluido intersecta as células da malba em duas faces. Nesse caso, podemos aproximar a superfície livre através de superfícies horizontais, verticais ou inclinadas $45^{\circ}$, como segue:

1. Células de superficie livre com apenas uma face em contato com uma face de células vazias: Nesse caso, assumimos que a superfície livre é horizontal ou vertical. O vetor normal nessas células toma a forma $\underline{n}=( \pm 1,0)$ ou $\underline{n}=(0, \pm 1)$, do: acordo com a figura (4.7).

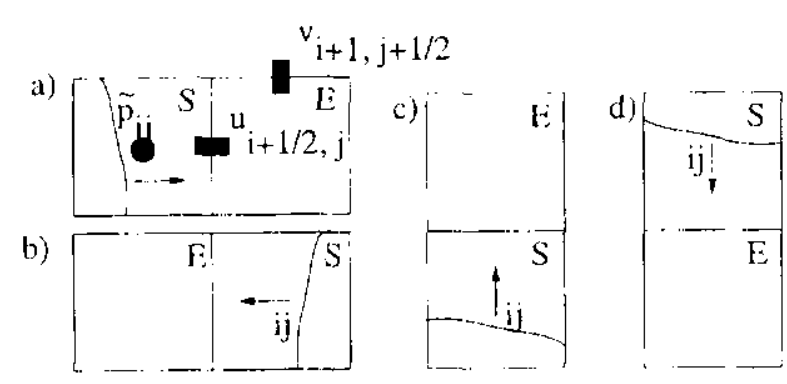

Figura 4.7: Células de superfície livre com apenas uma face em contato com uma célula vazial

As equaçós (2.46) e (2.47) nessas células se reduzem a:

$$
\begin{aligned}
& p-\frac{1}{R e}\left(\Phi^{x x} n_{x}^{2}+\Phi^{y y} n_{y}^{2}\right) \ldots 0 \\
& d^{x y}+\Phi^{x y}=0 .
\end{aligned}
$$


Considerando a figura (4.7a), observamos que ao calcular $\ddot{u}_{i+\frac{1}{2}, j}$ e $\tilde{v}_{i, j+\frac{1}{2}}$, utilizando

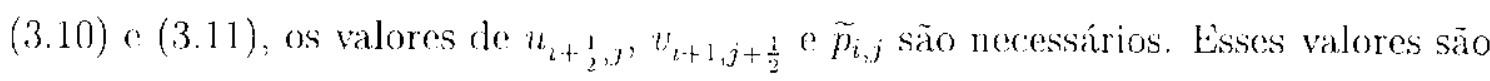
obtidos como segue:

- A velocidade $u_{i+\frac{1}{2}, j}$ é calculada através da equação da contimuidade aplicada no centro da célula de superfície livre, que fornece:

$$
u_{i+\frac{1}{2}, j}-u_{i \cdots \frac{1}{2}, j}-\frac{\delta x}{\delta y}\left(v_{i, j+\frac{1}{2}}-v_{i, j-\frac{1}{2}}\right) .
$$

- A velocidade $v_{i+1, j+\frac{1}{2}}$ é calculada aplicando a equação (4.20) na coordenada $\left(i+\frac{1}{2}, j+\frac{1}{2}\right)$ da malha, fornecondo:

$$
v_{i+1, j+\frac{1}{2}}=v_{i, j+\frac{1}{2}}-\left.\delta x \frac{\partial u}{\partial y}\right|_{i+\frac{1}{2}, j+\frac{1}{2}} \frac{\left(1-\left.2 D e \frac{\partial u}{\partial y}\right|_{i+\frac{1}{2}, j+\frac{1}{2}}\right)}{\left.\left.12 D e \frac{\partial u}{\partial x}\right|_{i+\frac{1}{2}, j+\frac{1}{2}}\right)},
$$

onde as derivadas $\frac{\partial u}{\partial y}, \frac{\partial u}{\partial x}$ sāo avaliadas através de diferenças centrais e a derivada $\frac{\partial v}{\partial y}$ é avaliada através do esquema de diferenças regressivas.

- A pressão $\widetilde{p}_{i j}$ é calculada através da equação (4.19) aplicada no ponto $(i, j)$, assim obtemos:

$$
\widetilde{p}_{i j}=\frac{1}{R e}\left(\left.d^{x x}\right|_{i, j}+\left.\Phi^{x x}\right|_{i, j}\right)
$$

\section{Células de superfície livre com duas faces adjacentes em contato com} faces de células vazias: Nessas cólulas, assumimos que a superfície livre faz um ângulo de $45^{\circ} \mathrm{com}$ os eixos coordenados. Nessas células, o vetor normal toma a forma $\underline{n}=\left( \pm \frac{\sqrt{2}}{2}, \pm \frac{\sqrt{2}}{2}\right)$. Por exemplo, se considerarmos a célula de superfície livre mostrada na figura $(4.8 \mathrm{a})$, tomamos $\underline{n}=\left(\frac{\sqrt{2}}{2}, \frac{\sqrt{2}}{2}\right)$. 

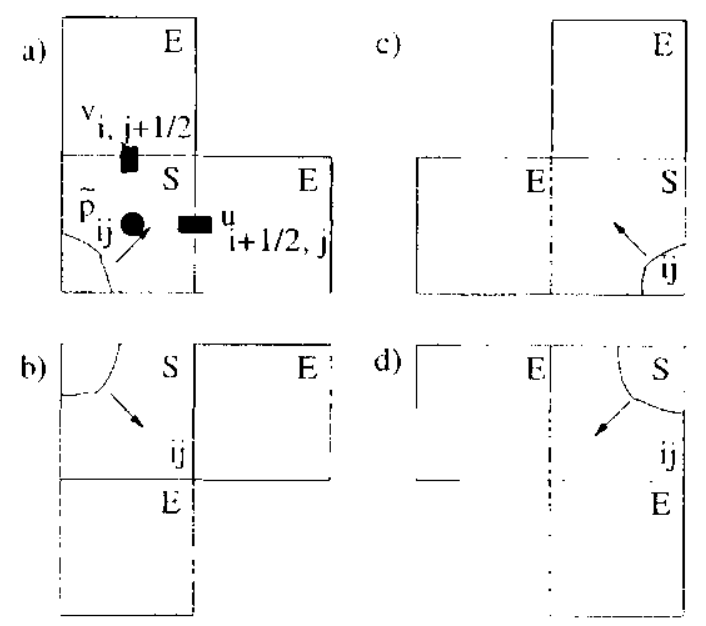

Figura 4.8: Células de superfície live com duas faces adjacentes em contato com células vazias.

Nesse caso, as equaçoes (2.46) e (2.47) tomam a forma:

$$
\begin{aligned}
& \tilde{p}=\frac{1}{2 R \cdot e}\left(\Phi^{x x}+\Phi^{y y}+2 \Phi^{x y}+2 d^{x y}\right) \\
& d^{x x}-d^{y y}+\Phi^{x x}-\Phi^{y y}=0
\end{aligned}
$$

As velocidades $u_{i+\frac{1}{2}, j}, \tau_{i, j+\frac{i}{2}}$ e $\widetilde{p}_{i, j}$ são calculadas como segue:

- Ltilizamos a equação (4.25) juntamente com a equação de conservação de massa (2.37) para calcular as volocidades $u_{i+\frac{1}{2} j}$ e $v_{i j+\frac{1}{2}}$. As equaçöes (4.25) e (2.37) formam um sisıcma de segunclo grau com duas equações a duas incógnitas, que pode ser resolvido através do método de substituição sob a hipótese de que $\delta x=\delta y$. Quando $\delta x \neq \delta y$ o sistema não linear gera quatro soluções, impossibilitando sua implementação computacional. Utilizando o vetor $\underline{n}=\left(\frac{\sqrt{2}}{2}, \frac{\sqrt{2}}{2}\right)$ e simplificando as equaçôes (4.25) e (2.37) obtemos o seguinte sistema:

$$
\begin{aligned}
& \frac{\partial v}{\partial y}-\frac{\partial u}{\partial x}+D e\left(\frac{\partial u}{\partial y}\right)^{2}-D e\left(\frac{\partial u}{\partial x}\right)^{2}=0 \\
& \frac{\partial u}{\partial x}+\frac{\partial v}{\partial y}=0
\end{aligned}
$$

onde as derivadas $\frac{\partial u}{\partial x}$ e $\frac{\partial h}{\partial y}$ são aproximadas através do método de diferenças centrais e as derivadas $\frac{\partial u}{\partial y}$ e $\frac{\partial y}{\partial x}$ são aproximadas através de diferenças regressivas. 
Resolvendo o sistema (4.26), obtemes os seguintes resiltados para a velocidade:

$$
\begin{aligned}
& u_{i+1 / 2, j}=\frac{1}{2}\left(\left(-6 \omega_{4} u_{i-1 / 2, j}-36 v_{1, j} 1 / 2{ }^{2}-6 \omega_{1} u_{i-1 / 2, j}+24 v_{2-1, j+1 / 2} u_{i-1 / 2, j}\right.\right. \\
& +24 v_{i-1, j 1 / 2} u_{i-1 / 2, j}-\omega_{1}^{2} \ldots 2 \omega_{1} \omega_{1}+8 \omega_{1} v_{i} 1, j+1 / 2+8 \omega_{1} v_{i-1, j-1 / 2}-12 \omega_{1} v_{i, j-1 / 2} \\
& -\omega_{4}^{2}+8 \omega_{4} v_{i-1, j \cdot 1 / 2}+8 \omega_{4} v_{2-1, j \cdots 1 / 2}-12 \omega_{4} v_{i, j-1 / 2}-16 v_{i-1, j+1 / 2}{ }^{2} \\
& -32 v_{i-1, j+1 / 2} v_{i-1, j} 1 / 2+48 v_{i-1, j+1 / 2} v_{i, j-1 / 2}-16 v_{i-1, j} 1 / 2^{2}+18 v_{i-1, j \cdots 1 / 2} v_{i, j-1 / 2}+\omega_{i 3}^{2} \\
& +2 \omega_{3} \omega_{2}-8 \omega_{33} u_{i+1 / 2, j-1}-8 \omega_{33} u_{i \cdot 1 / 2, j \cdot 1}+6 \omega_{33} u_{i-1 / 2, j}+\omega_{2}^{2}-8 \omega_{2} u_{i+1 / 2,1-1}
\end{aligned}
$$

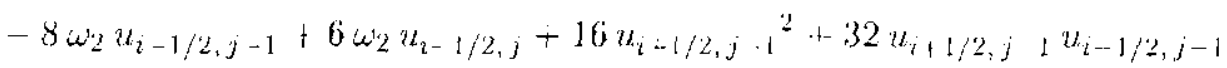

$$
\begin{aligned}
& \left.-24 u_{i+1 / 2, j-1} u_{i-1 / 2, j}+16 u_{i-1 / 2, j} 1^{2} \ldots 24 u_{i \cdot 1 / 2, j-1} u_{i-1 / 2, j}-36 u_{i-1 / 2, j} v_{i, j-1 / 2}\right) D_{c} \\
& \left.+32 u_{i-1 / 2, j} d y\right) /\left(\left(\cdots 3 \omega_{4}-3 \omega_{3}+12 u_{2} 1 / 2, j \cdot 1-18 u_{i, j-1 / 2}+12 \eta_{i-1, j \cdot 1 / 2}-3 \omega_{2}\right.\right. \\
& \left.\left.+12 v_{i-1, j-1 / 2}-3 \omega_{1}+12 u_{i+1 / 2, j \cdots 1}-18 u_{i-1 / 2, j}\right) D e-16 d y\right), \\
& \omega_{1}=v_{i-2, j+1 / 2}, \quad \omega_{2}=u_{i} \cdot 1 / 2, j \cdot 2, \quad \omega_{3}=u_{i-1 / 2, j-2} . \quad \omega_{4}-v_{i-2, j-1 / 2} .
\end{aligned}
$$

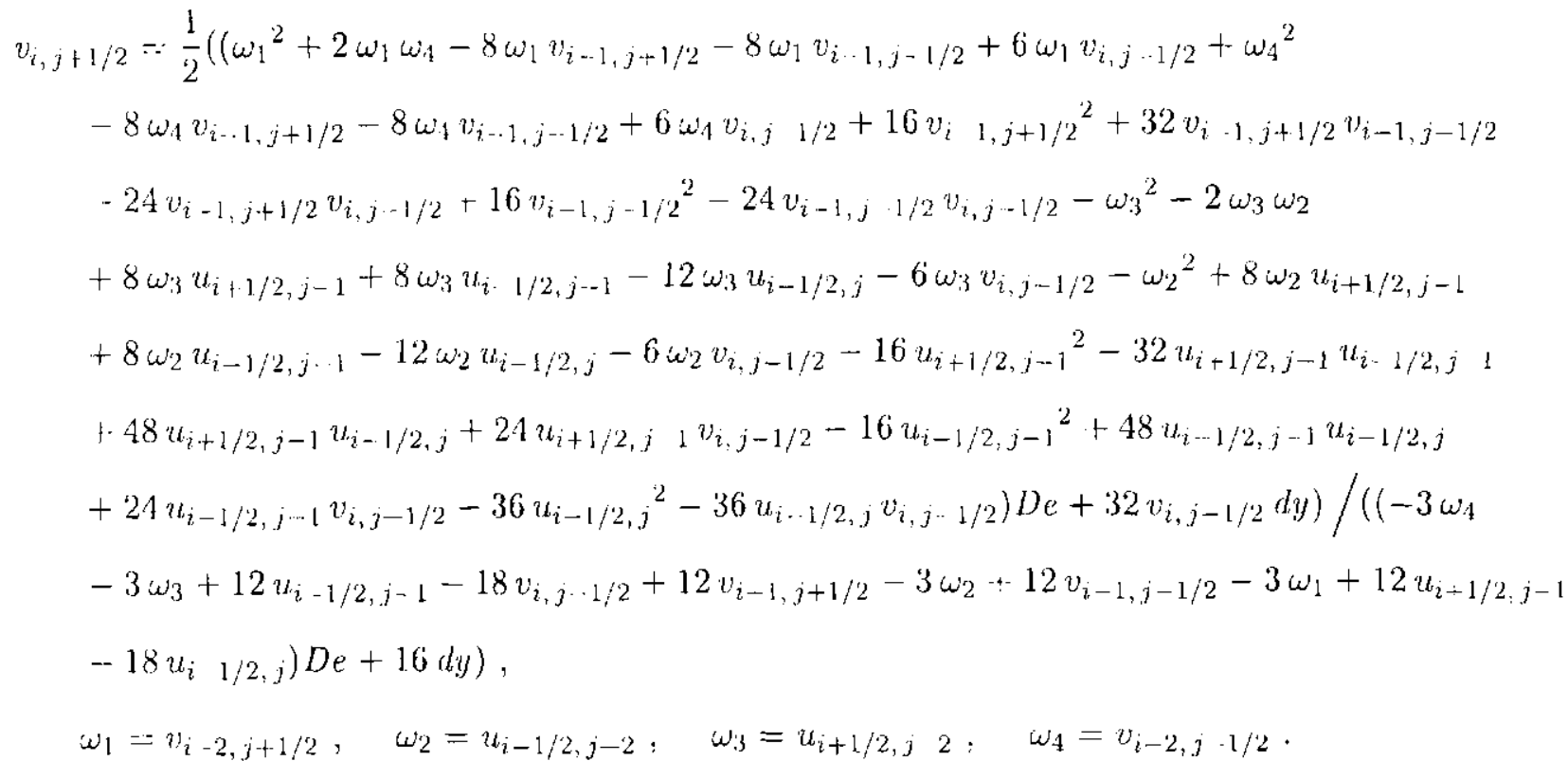

- A pressão $\tilde{p}_{i, j}$ é calculada através da equação (4.25) aplicarla no centro da cólula de superfície livre. Considerando o caso (4.8a), temos:

$$
\tilde{p}_{i . j}=\frac{1}{2} \frac{1}{R e} \cdot\left(\Phi^{\left.r x\right|_{i, j}}+\left.\Phi^{y y}\right|_{i, j}+\left.2 \Phi^{x y}\right|_{i, j}+\left.2 d^{x y}\right|_{i, j}\right)
$$


Para os outros casos da figura (4.8) procedemos de forma análoga.

3. Os casos que a célula de superfície possuem lados opostos en contato com lados de células vazias ou que possuem três on quatro lados em contato com células vazias são considerados casos degenerados. Nesses casos, uma das velocidades é calculada em função das outras de forma que a cquação da continuidade seja satisfeita e a pressão é dada por $\tilde{p}-0$. Quando esses tipos de configuração do células aparece. em um escoamento. isso indica que a malha de pontos deve ser refinada.

\subsection{Controle do Passo no Tempo}

Utilizamos um procedimento para calcular o tamanho do passo no tempo para todo ciclo computacional. Esse procedimento é baseado nas seguintes condiçōes de estabilidade escritas na forma adimensional, conferir Tomé et al. [1994] ou Fortuna [2000]:

1. Nenhuma partícula deve cruzar mais de uma célula em um dado intervalo de tempo. Esse critério á conhecido como condicão CFL. Assim, o valor de öt deve ser:

$$
\delta t_{1}<\min \left(\frac{\delta x}{|u|_{\text {max }}}, \frac{\delta y}{|v|_{\max }}\right)
$$

onde $|u|_{\max }|v|_{\max }$ são as velocidades máximas, em módulo, nas direções $x$ e $y$, respectivamente.

2. O termo difusivo da equação de quantidade de movimento exige que:

$$
\delta t_{2}<R e \frac{\delta x^{2} \delta y^{2}}{2 \delta x^{2}+2 \delta y^{2}}
$$

O valor de $\delta t$ adotado deve satisfazer, simultaneamente, as condiçoos $(4.28)$ e (4.29), portanto:

$$
\delta t=\zeta \min \left(\delta t_{1}, \delta t_{2}\right)
$$


onde $0<\zeta<1$ é um fator de segurança. Para fluidos de Segurda Ordem usamos $\zeta$ no intervalo $\left(\frac{1}{20}, \frac{1}{2}\right)$.

\subsection{Movimento das Partículas}

Utilizamos partículas marcadoras para representar o fluido. O objetivo principal dessas partículas é indicar a posição da superfície livre para determinar a configuração do fluido. As partículas são atualizadas no fim de cada passo no tempo fornecendo a dinâmica do movimento do fluido. A nova coordenada do fluido é encontrada resolvendo as seguintes equaçöes através do método de Euler, conferir Ralst.on [1965]:

$$
\frac{\partial x}{\partial t}=u \quad \text { e } \quad \frac{\partial y}{\partial t}=v
$$

As partículas são movilas de acordo com as seguintes equaçõos:

$$
\begin{aligned}
& x_{p}^{n+1}=x_{p}^{n}+u_{p} \delta t^{n+1}, \\
& y_{p}^{n+1}=y_{p}^{n}+v_{p} \delta t^{n+1} .
\end{aligned}
$$

onde $\left(x_{p}^{n}, y_{p}^{n}\right),\left(x_{p}^{n+1}, y_{p}^{n+1}\right)$ e $\delta t^{n+1}$ são a posiçāo atual da partícula, a nova posição e o passo no tempo atual, respectivamente. As velocidades $u_{p}$ e $v_{p}$ são calculadas através de uma interpolaçào bilinear envolvendo as quatro velocidades u e $v$ mais próximas. 
5

\section{Validação do Método Numérico}

As equaçōes de diferenças finitas descritas no capítulo anterior foram implementadas no sistema FreeFlow-2D $D^{1}$ para que possa ser cmpregado na simulação numérica de escoamentos de fluidos de Segunda Ordem. Na sessão [5.1] apresentamos a simulação do escoamento em un canal bidimensional com o objetivo de validar a implementaçào do método numérico desenvolvido nesse trabalho.

\subsection{Validação no Canal}

Para validar o método numérico vamos considerar o escoamento em um canal, conforme mostra a figura (5.1).

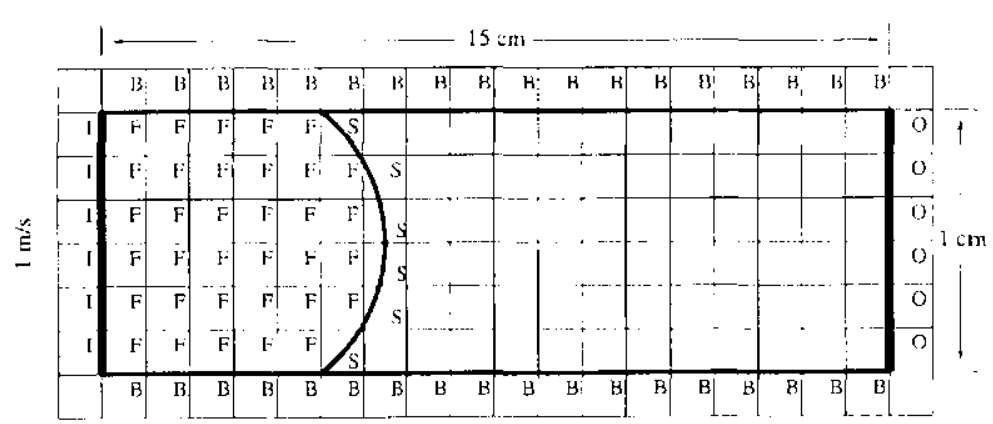

Figura 5.1: Descrição do modelo computacional para a ('anal-2I).

No injetor, vamos utilizar o perfil de velocidades parabólico, dado por:

1 Conferir anexo $\mathrm{C}$. 


$$
u(y)-u_{0}-\frac{4 u_{0}}{L^{2}}\left(y-\frac{L}{2}\right)^{2}
$$

onde $u_{0}=1 \mathrm{~m} / \mathrm{s}$ é a velocidade no injetor $L=1 \mathrm{~cm}$ é a largura do canal e $H=15 \mathrm{~cm}$ o o comprimento do canal. Substituindo $u_{0} \circ L$ na equação (5.1) obtemos o perfil de velocidade do injetor:

$$
u(y)=-4 y^{2}+4 y .
$$

A solução analítica para o perfil de velocidades no canal em regime permanente é dada pela pelas equaçóes abaixo, de acordo com Fortuna [2000]:

$$
\begin{aligned}
& u(y)=-\frac{1}{2 \eta_{0}} \frac{\partial p}{\partial x}\left(y L-y^{2}\right), \\
& \frac{\partial p}{\partial x}=-12 \frac{\eta_{0}}{L^{3}} \int_{0}^{L} u(y) d y .
\end{aligned}
$$

Utilizando as equações (5.3) e (5.4) juntamente com o perfil de velocidades no injetor (5.1): verificamos que o perfil de velocidades no canal é dado pela cquação (5.1).

Lim regime permanente, as equaçōes constitutivas (2.34), (2.35) e (2.36) se simplificamen:

$$
\begin{aligned}
\tau^{r x} & =-\frac{2 D e}{R e}\left(\frac{\partial u}{\partial y}\right)^{2}, \\
\tau^{x y} & =\frac{1}{R e} \frac{\partial u}{\partial y} \\
\tau^{y y} & =0 .
\end{aligned}
$$

As equaçoes (5.5) säo as soluções analíticas para as componentes do tensor de tensão extra quando a velocidade u é calculada através da equação (5.1). 
5. Vilidaçäo do Metodo Numérico

Para simular o problema (5.1), vamos utilizar os seguintes dados:

Escala de comprimento $L=0.01 \mathrm{~m}$

Escala de velocidade $U=1.0 \mathrm{~m} / \mathrm{s}$

Força de gravidade : $\underline{g}_{x} \therefore \underline{g}_{y}=0.0 \mathrm{~m} / \mathrm{s}^{2}$

Viscosidade $\eta / \rho=0.01 \mathrm{~m}^{2} / \mathrm{s}$

Tolerância para a soluçăo da cequação de Poisson $=10^{-8}$

Fator de controle de passo no tempo $\zeta=0.08$

$\lambda_{2}=0.0045$

Número de Reynolds - - 1.0

Número de Deborah $=0.45$

Para avaliar a convergencia do método apresentado, vamos utilizar tres malhas:

$M_{1} \rightarrow \delta x=\delta y=0.125 \mathrm{~cm},(8 \times 120)$ células:

$M_{2} \rightarrow \delta x-\delta y=0.0625 \mathrm{~cm},(16 \times 240)$ células;

$M_{3} \rightarrow \delta x=\delta y=0.03125 \mathrm{~cm},(32 \times 480)$ células.

O sistcma FreeFlow-2D simulou esse problema, utilizando as três malhas, até atingir o estado estacionário. Os resultados apresentados nas figuras (5.2)-(5.7) correspondem à simulação na malha $M_{3}$. A figura (5.2) mostra a distribuição de velocidade $u$ no canal nos tempos $t=0.1 \mathrm{se} t=0.545 \mathrm{~s}$. Podemos observar que no tempo $t=0.545 \mathrm{~s}$ as linhas de contorno estão paralelas mostrando que o estado estacionário foi atingido. As figuras (5.3)-(5.7) mostram, respectivamente, a configuração da velocidade $v$, da tensão normal $\tau^{x x}$, da tensão cisalhante $\tau^{x y}$, da tenssão nomal $\tau^{y y}$ e da primeira diferença de tensós normais $N 1$. Pode-se observar que os valores de $\tau^{x x}$ e $N 1$ estáa bem próximos. $A$ diferença entre $\tau^{x x}$ e $N 1$ se deve ao fato que $\tau^{y y}$ não ó nulo próximo ao injetor e à superfície livre, como pode ser observado na figura (5.6). 
5. Validação do Método Numérico

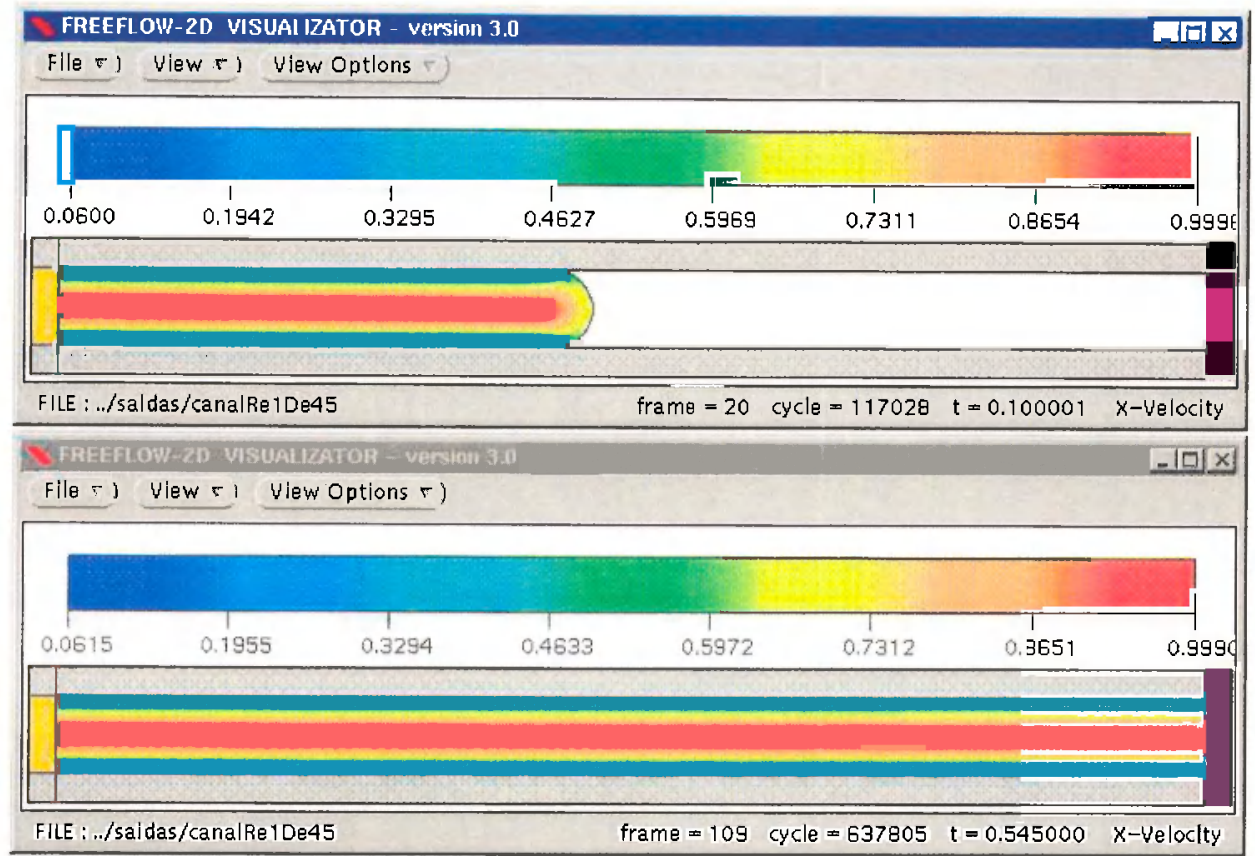

Figura 5.2: Resultados numéricos para a componente $\mathrm{u}$ em $t=0.1 \mathrm{~s}$ e $t=0.545 \mathrm{~s}$.

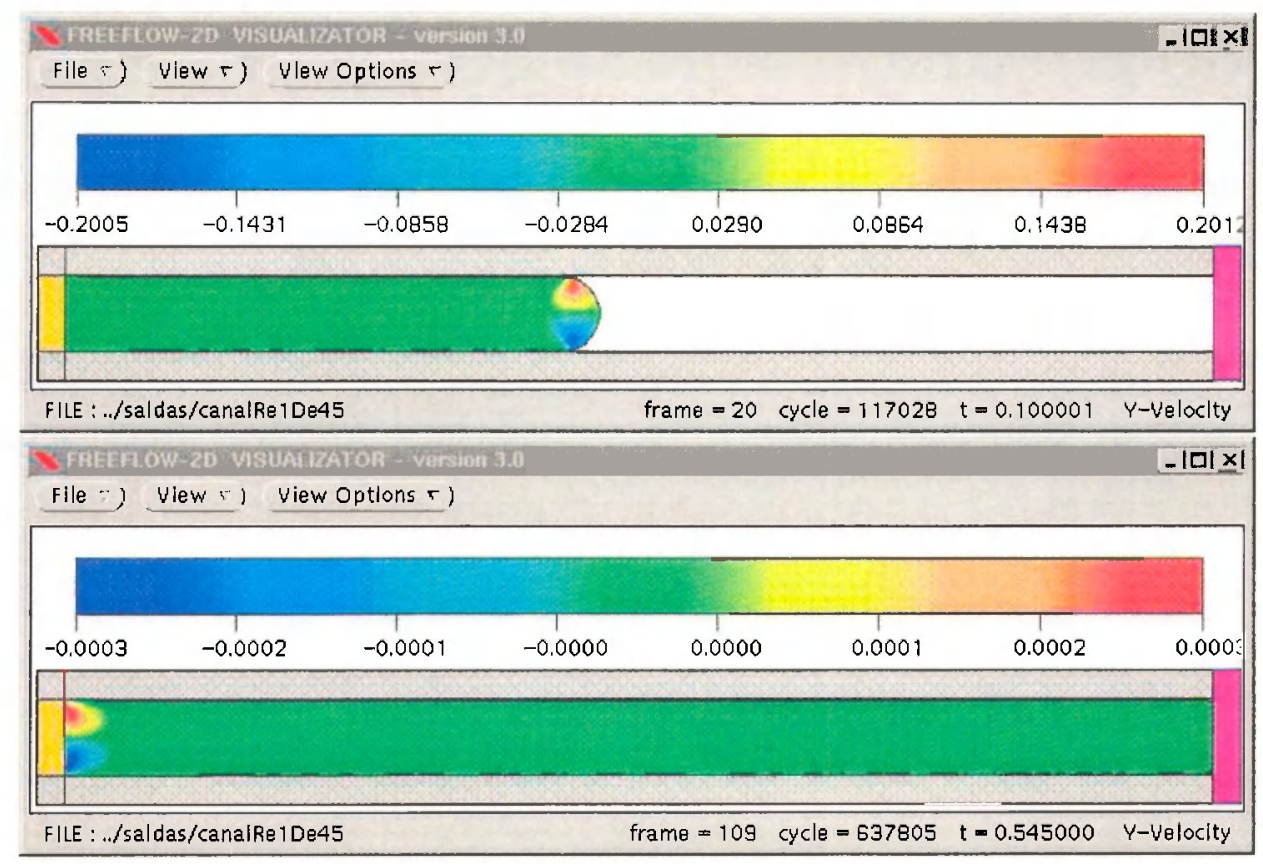

Figura 5.3: Resultados numéricos para a componente $\mathrm{v}$ em $t=0.1 \mathrm{~s}$ e $t=0.545 \mathrm{~s}$. 


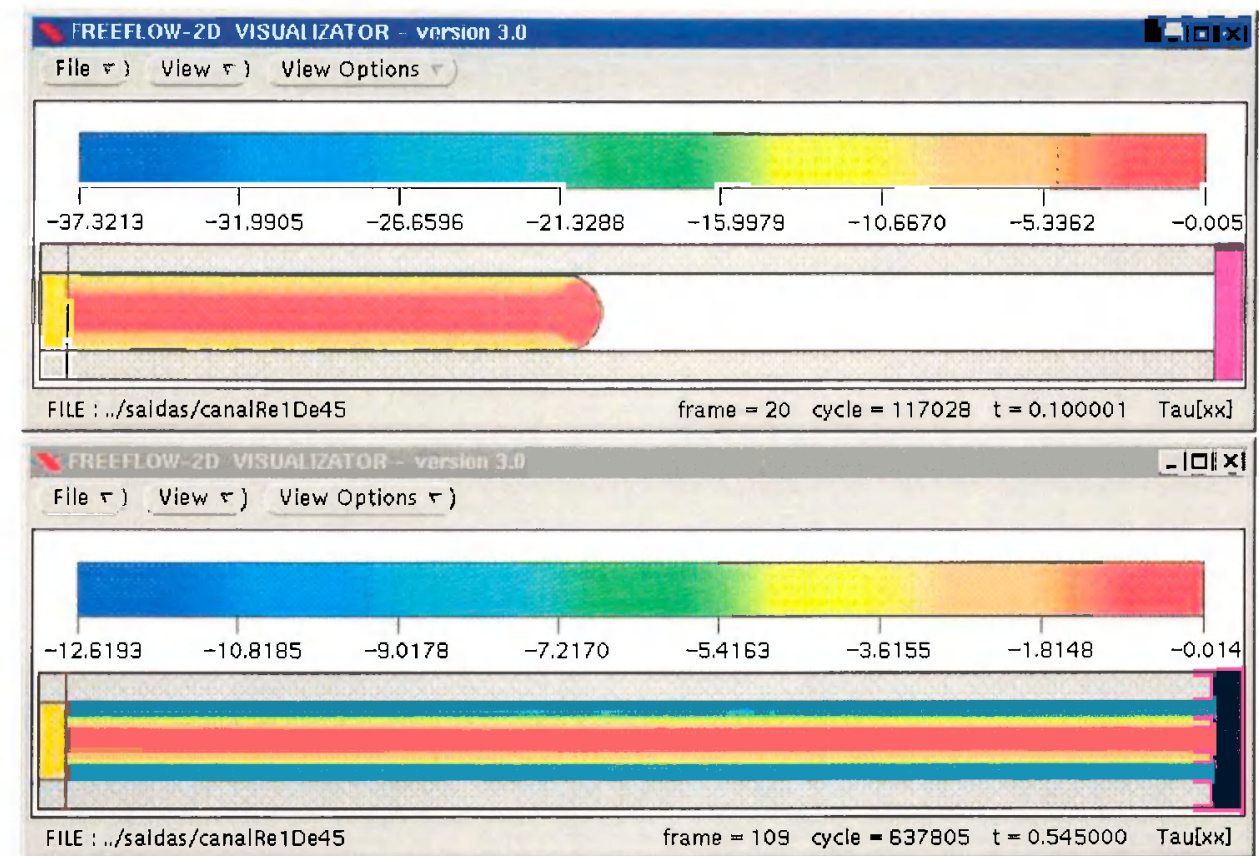

Figura 5.4: Resultados numéricos para o tensor $\tau^{x x}$ em $t=0.1 \mathrm{~s}$ e $t=0.545 \mathrm{~s}$.

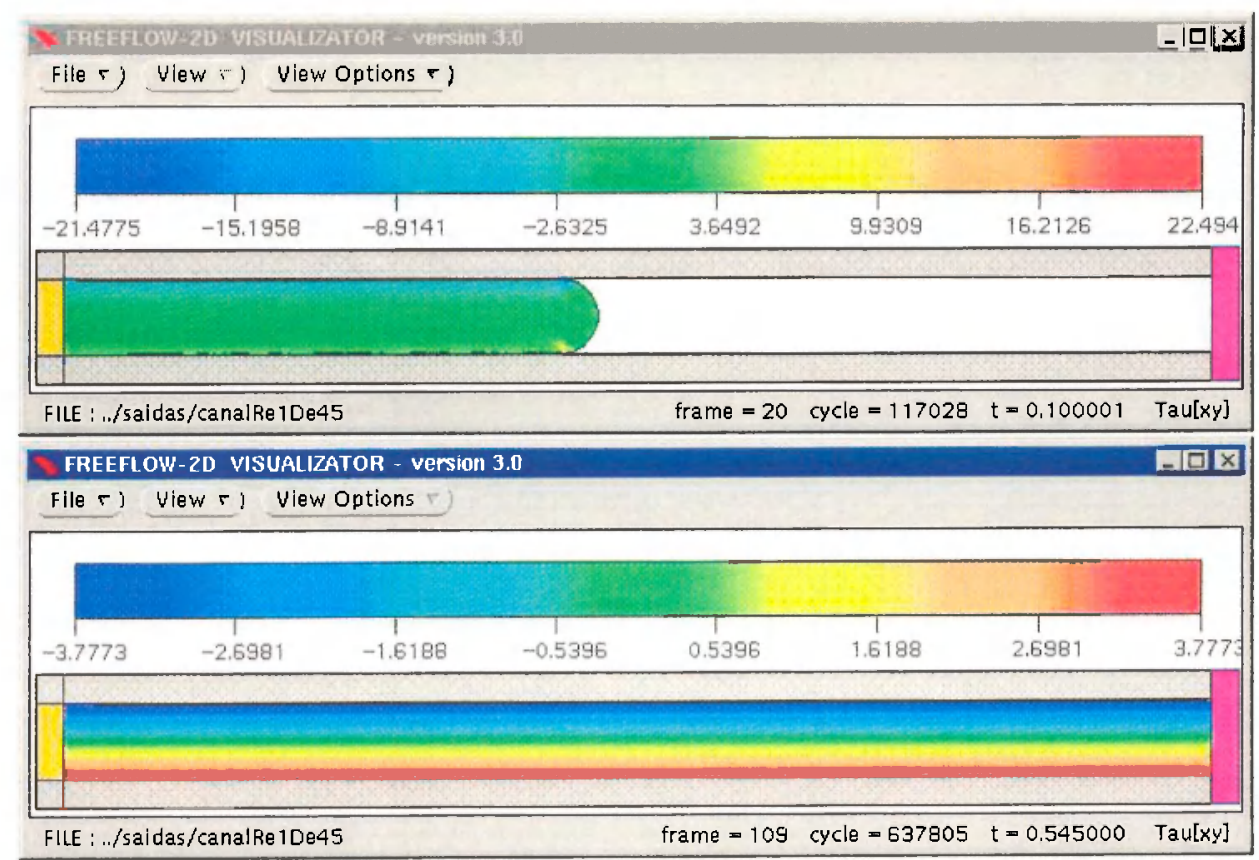

Figura 5.5: Resultados numéricos para o tensor $\tau^{x y}$ em $t=0.1 \mathrm{~s}$ e $t=0.545 \mathrm{~s}$. 


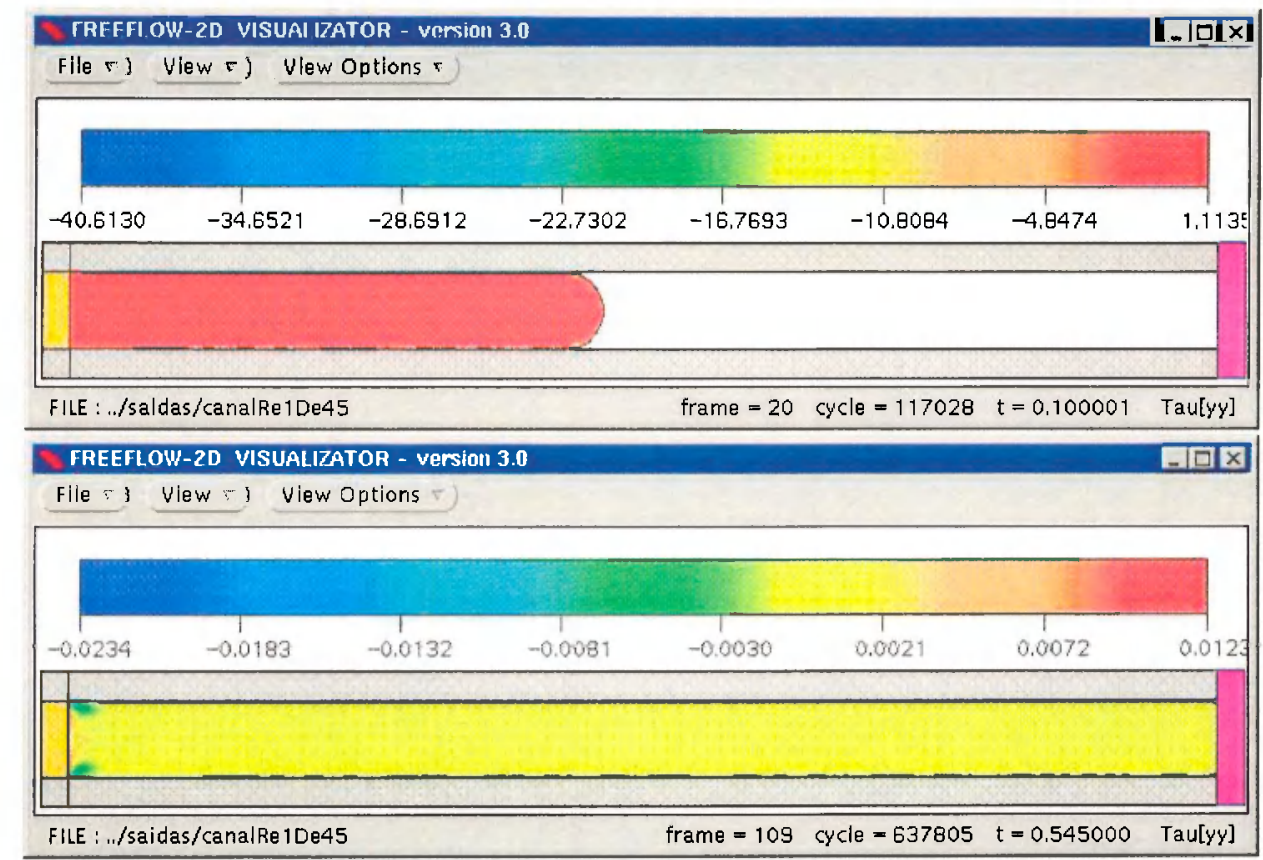

Figura 5.6: Resultados numéricos para o tensor $\tau^{y y}$ em $t=0.1 \mathrm{~s}$ e $t=0.545 \mathrm{~s}$.

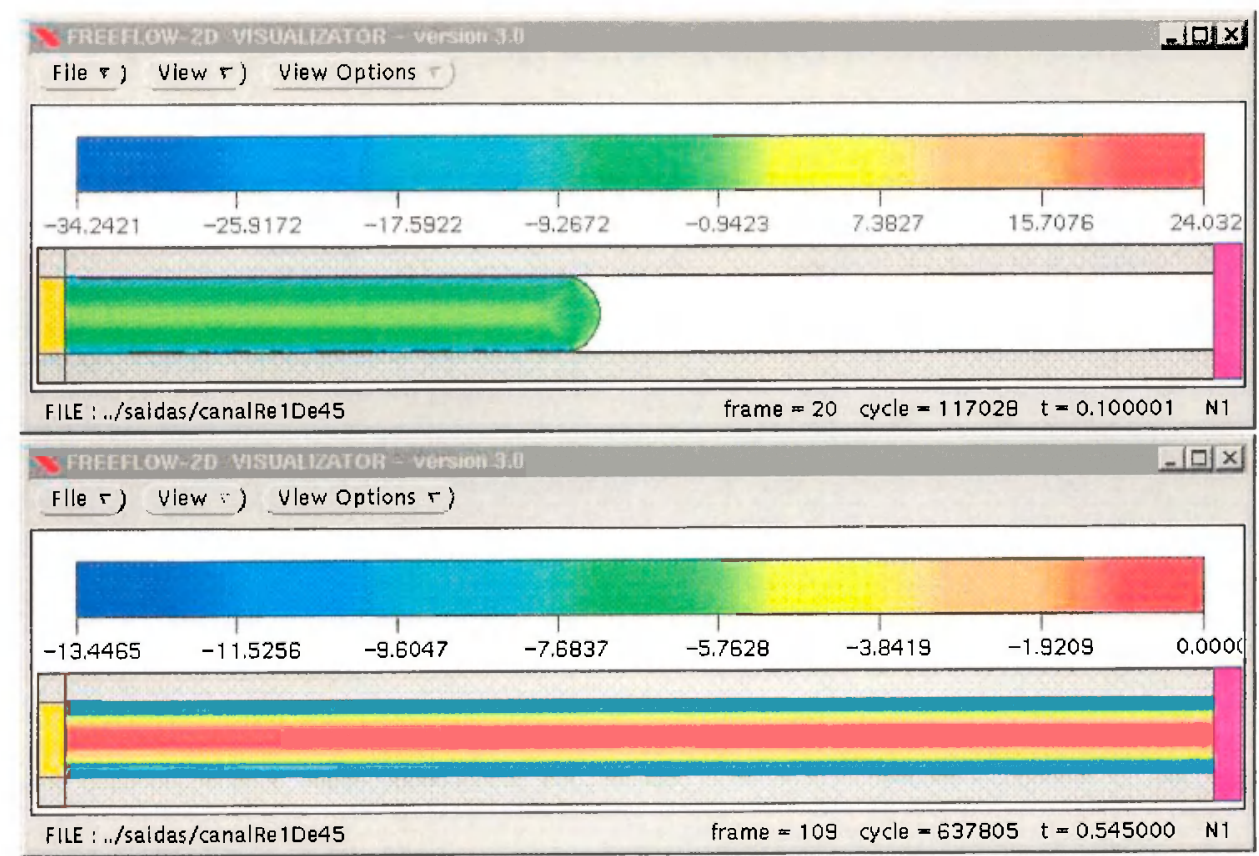

Figura 5.7: Resultados numéricos para N1 em $t=0.1 \mathrm{~s}$ e $t=0.545 \mathrm{~s}$. 
Nos gráficos das figuras (5.8)-(5.13) os resultados numóricos são representados pelos pontos discretos e os resultados analíticos, conforme as equações (5.1) e (5.5), pelas linhas contínuas. A componente da volocidade " e a componente da tensão tyy não foram inseridas no processo de validação pois ambas são nulas. Todos os resultados são adimensionais.

Os gráficos da figura (5.8) e da figura (5.9) correspondem ao corte do canal na direçāo $y$ nas coordenadas $x=7.5 \mathrm{~cm}$ e $x=15.0 \mathrm{~cm}$ para a malha $M_{1}$, respectivamente.
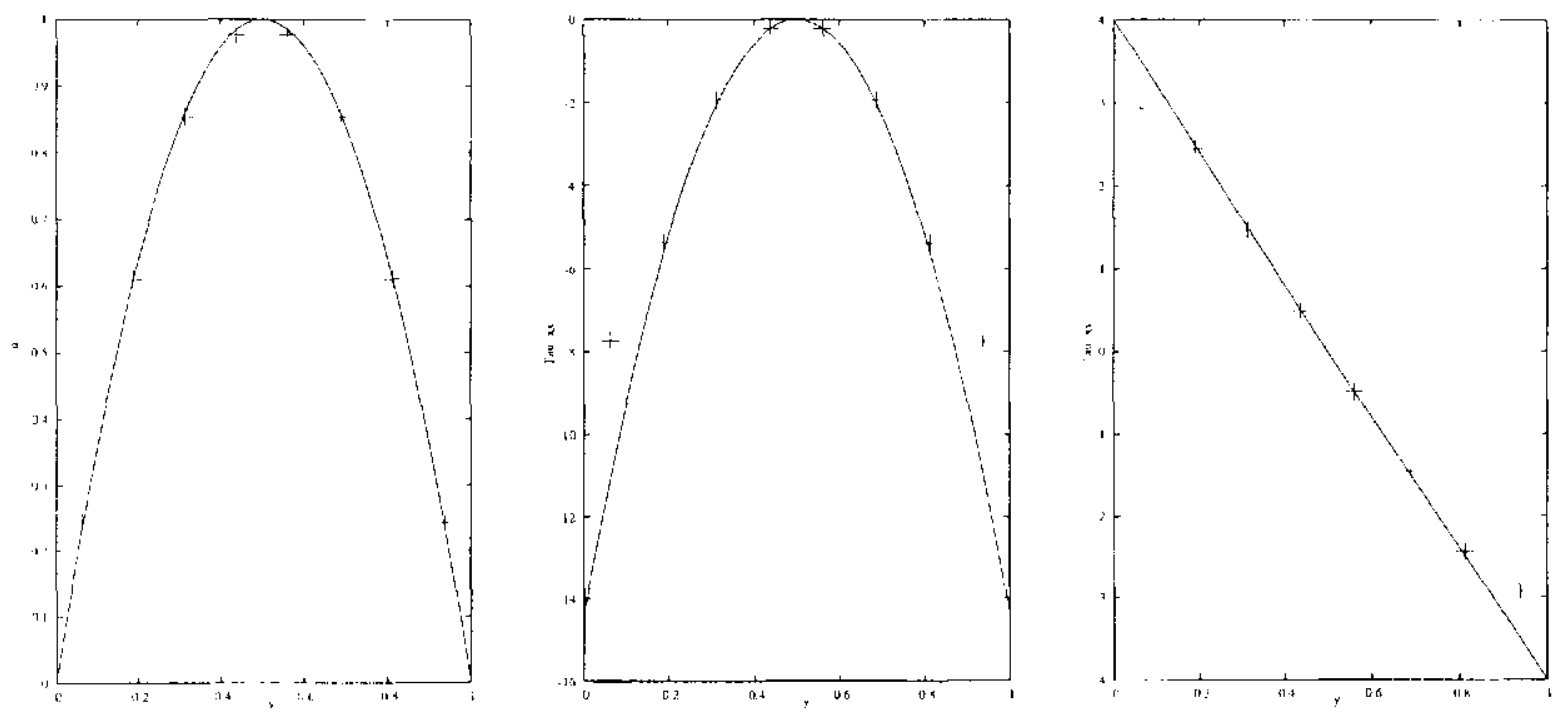

Figura 5.8: Resultados na malha $M_{1}$ : velocidade u, componente $\tau^{x x}$ e $\tau^{x y}$ em $x=7.5 \mathrm{~cm}$.
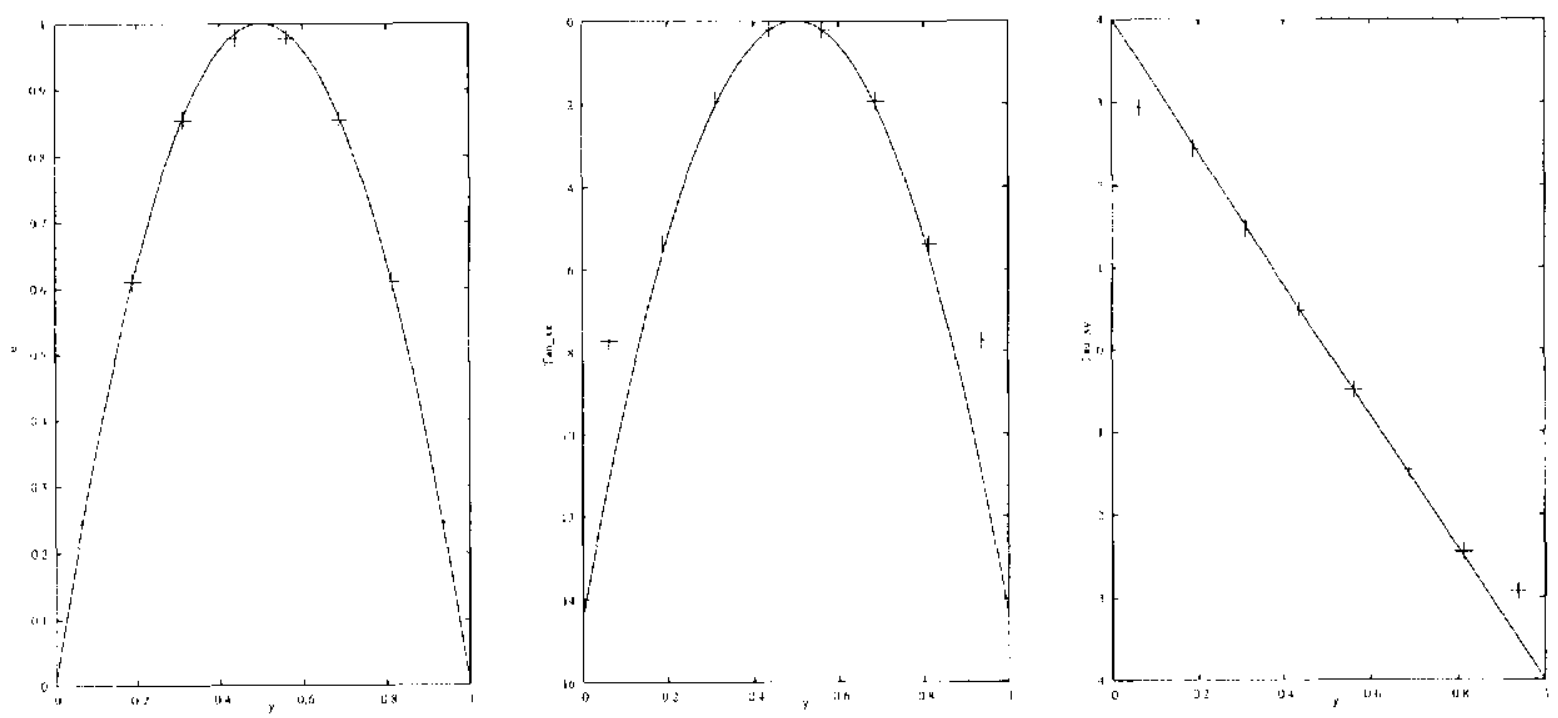

Figura 5.9: Resultados na malha $M_{1}$ : velocidade $u$, componente $\tau^{x x}$ e $\tau^{x y}$ em $x-15.0 \mathrm{~cm}$. 
Os gráficos (5.10) e (5.11) correspondem aos resultados obtidos para a velocidade? para a tensão nos planos $x=7.5 \mathrm{~cm}$ e $x=15.0 \mathrm{~cm}$ para a matha $M_{2}$.
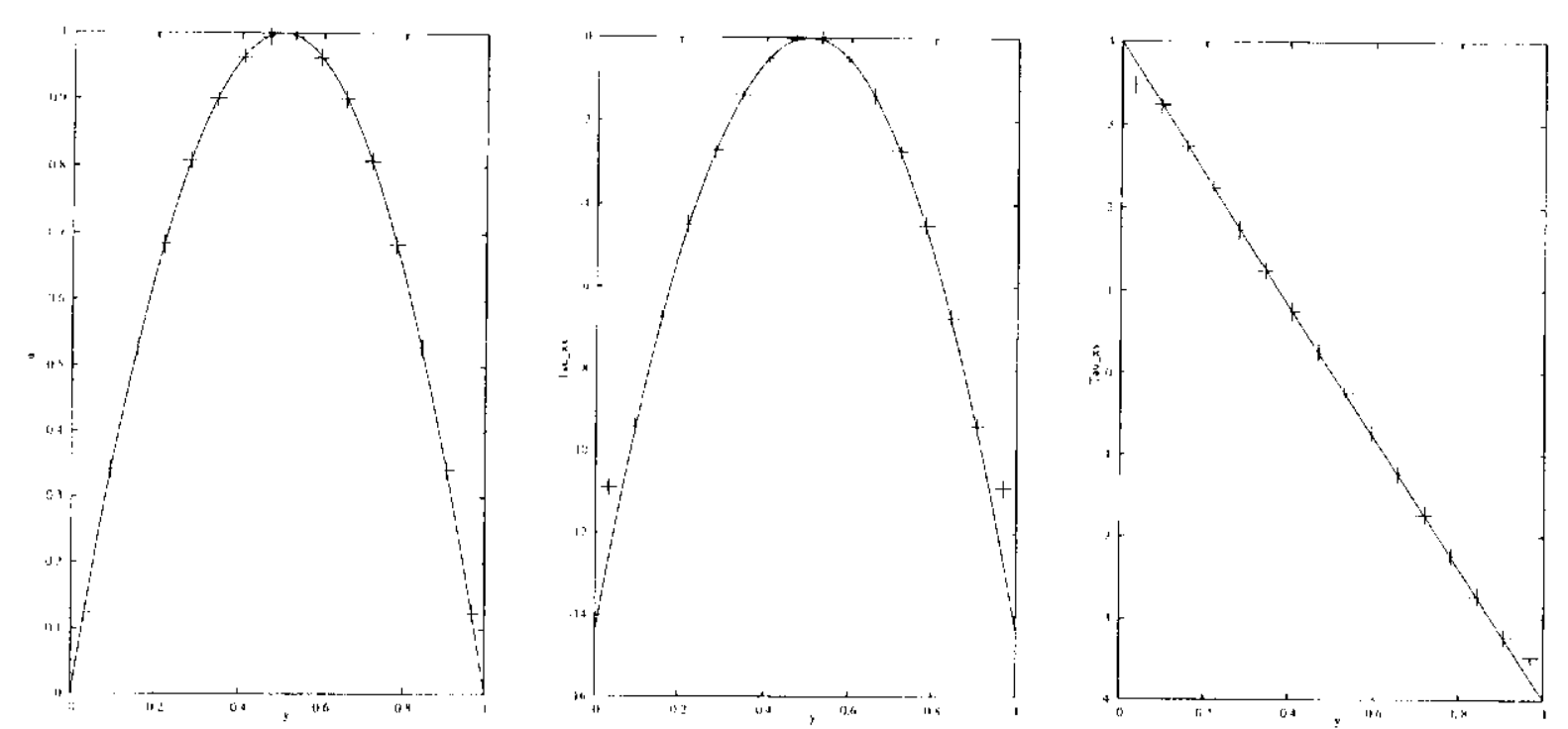

Figura 5.10: Resultados na malhat $M_{2}$ : velocidade $u$, componente $\tau^{x \cdot x}$ e $\tau^{x y} \mathrm{~cm} x-7.5 \mathrm{~cm}$.
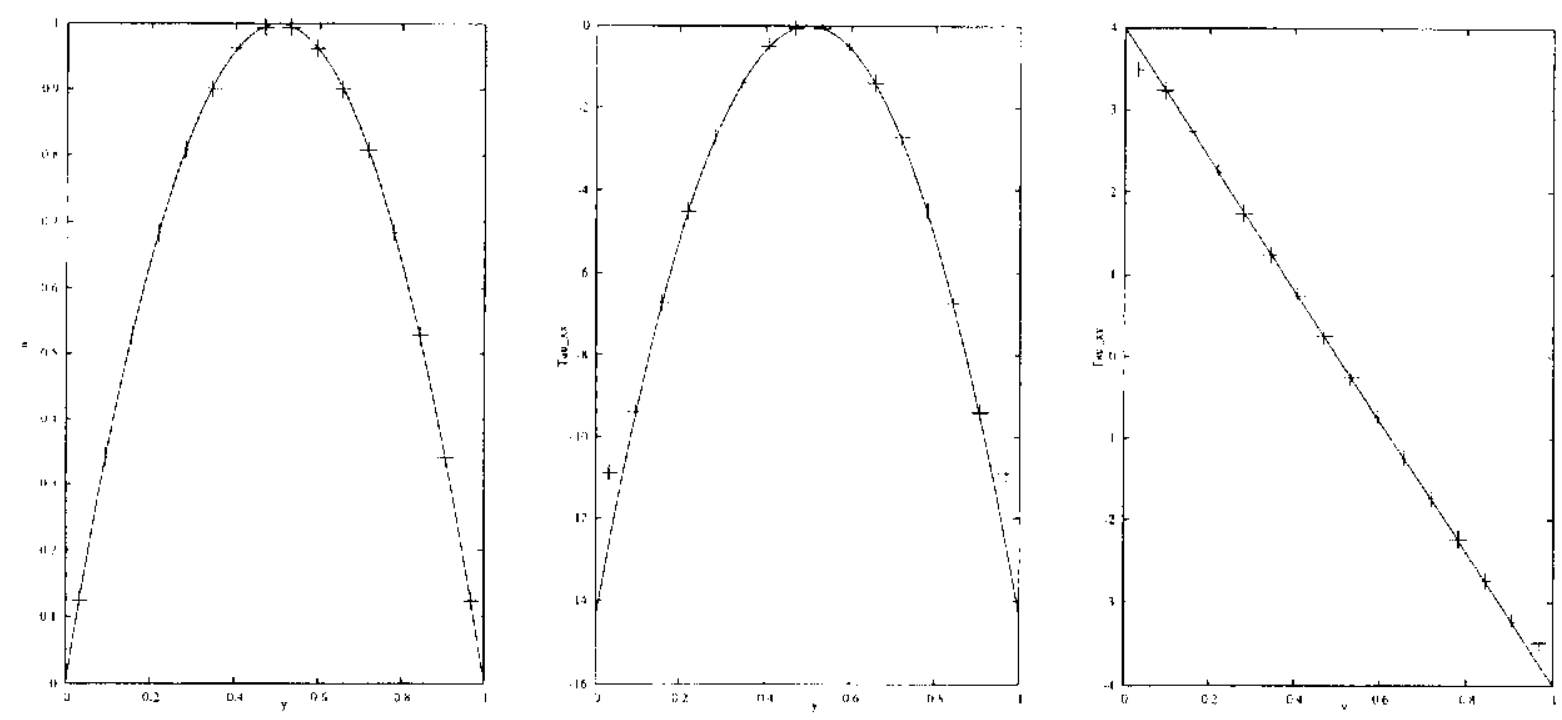

Figura 5.11: Resultados na malha $M_{2}$ : vclocidade $u$, componente $\tau^{x x}$ e $\tau^{x y}$ em $x=$ $15.0 \mathrm{~cm}$. 
() resultados obtidos para a malha $M_{3}$ no plano $x-7.5 \mathrm{~cm}$ podem ser observados nos gráficos da figura (5.12).
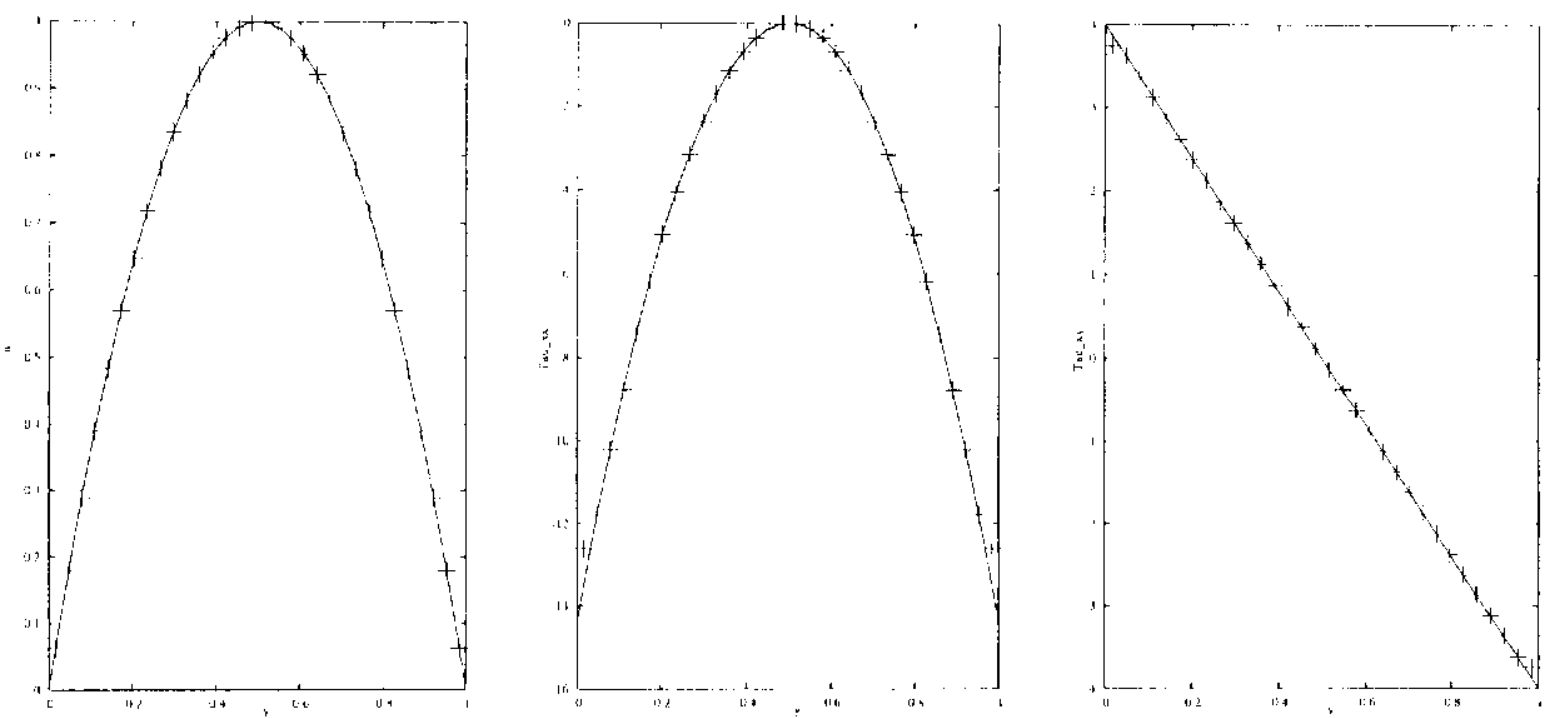

Figura 5.12: Resultados na malha $M_{3}$ : volocidade $u$, componente $\tau^{x x}$ e $\tau^{r y}$ em $r=7.5 \mathrm{~cm}$

Abaixo seguem os resultados obtidos para a malha fina no plano $x=15.0 \mathrm{~cm}$.
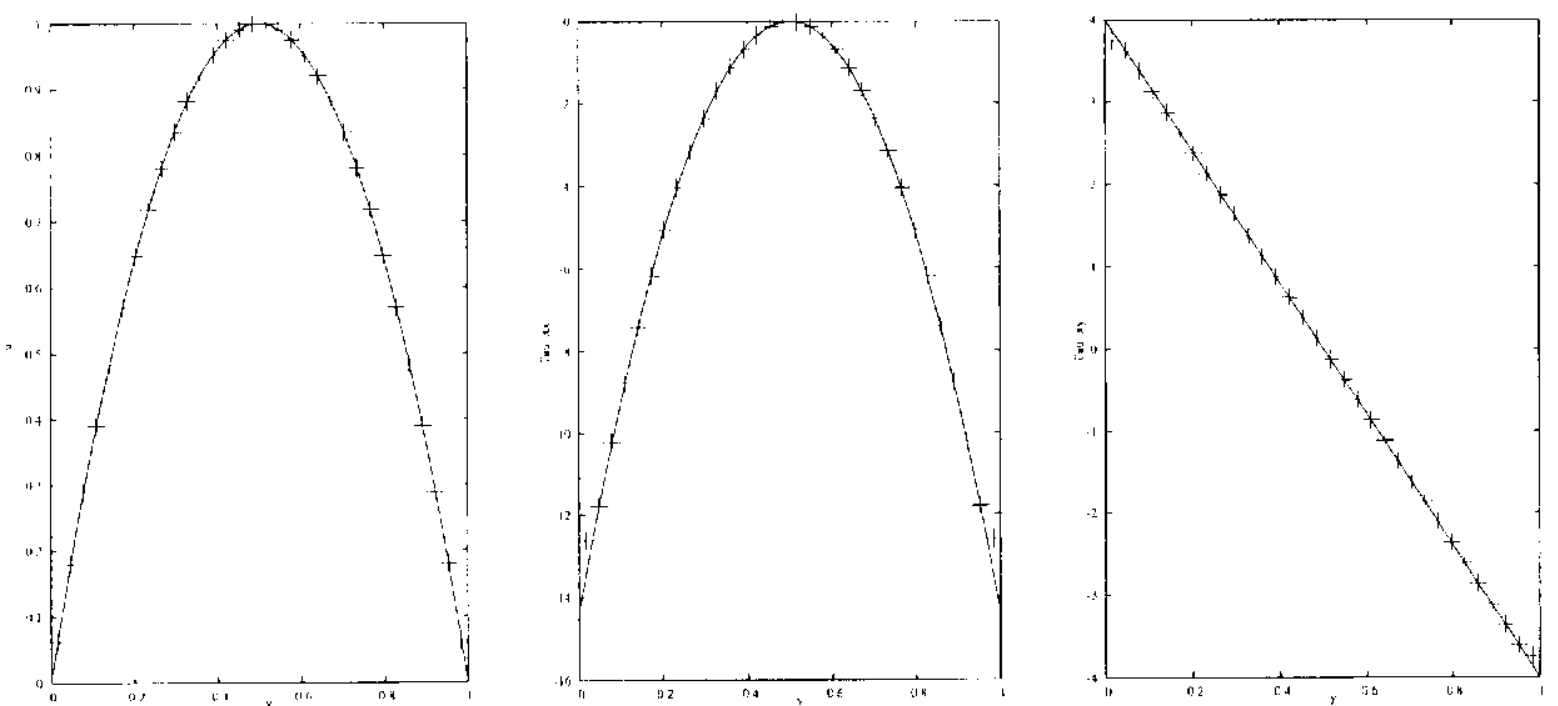

Figura 5. 13: Resultados na malha $M_{3}$ : velocidade $u$, componente $\tau^{x x}$ e $\tau^{x y}$ em $x=7.5 \mathrm{~cm}$ 
Podemos observar nos gráficos (5.8)-(5.13) que a velocirlacio u é bem aproximada. pelo método numérico. Contudo, o valor das lensöes $\tau^{r x}$ e. $\tau^{x y}$ en cólulas adjacentes às paredes do canal apresenta um erro significativo, esse erro aparece dovido à utilizaçäo do métodos de primeira ordem para aproximar as derivadas nessas células. Porém, no meio do canal, podemos ver que a solução numérica concorda bem com a solução exata. Os gráficos (5.8)-(5.13) também mostram que, com o refinamento da malha, o erro cometido em células adjacentes ao contorno rígido decai, mostrando a convergência do método numérico.

No cntanto, para demonstrammos a convergéncia do método numérico, devemos calcular o erro relativo entre a solução numérica e a solução analítica. Utilizaremos as seguintes expressões, que correspondem à roma $l_{2}$ :

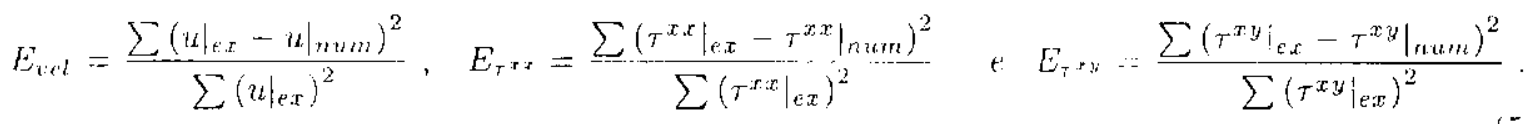

onde $\left.\right|_{\text {ex }}$ é a solução exata e $\left.\right|_{\text {num }}$ é a solução numérica.

Os crros obtidos utilizando as malhas $M_{1}, M_{2}$ e $M_{3}$, são mostrados na tabela $(5,1)$.

\begin{tabular}{|l|l|l|l|}
\hline Malhat & $E_{\text {vel }}$ & $E_{\tau^{x x}}$ & $E_{\tau^{x y}}$ \\
\hline$M_{1}$ & $7.9510^{-5}$ & $6.9210^{-2}$ & $1.5610^{-2}$ \\
$M_{2}$ & $5.5110^{-6}$ & $9.5210^{3}$ & $1.7410^{-3}$ \\
$M_{3}$ & $3.5510^{-7}$ & $1.2210^{-3}$ & $2.0210^{4}$ \\
\hline
\end{tabular}

Fabela 5.1: Erro relativo para verificar a convergècia do nétodo numérico.

Os resultados na tabela (5.1) mostram que o erro relativo diminui, com o refinamento da malha, na velocidade : nas tensōes. Esse comportamento mostra que o método numérico converge com o refinamento da malha.

A ordem de convergencia será calculada através dos resultados obtidos nas três malhas. O espaçanento entre essas malhas segue a regra: $h_{i+1}=\frac{1}{2} h_{i}$, com $i-1,2$. Supondo que a ordem de convergência do método numérico pode ser dada pela expressão $(5.7)$ 


$$
S_{h}\left(\underline{x}_{i}, t\right) \cdots S\left(\underline{x}_{1}, t\right)-c h_{i}^{n},
$$

onde e é um vetor que nã̃o depende de $h_{i}, S_{h_{i}}\left(\underline{x}_{i}, t\right)$ é a solução aproximada e $S\left(\underline{x}_{i}, t\right)$ é a solução exata, podemos calcular:

$$
\begin{aligned}
& \delta\left(S_{h_{i}}\right)=\left\|S_{h_{i}}\left(\underline{x}_{i}, t\right)-S\left(\underline{x}_{i}, t\right)\right\|=\|\underline{c}\| h_{i}^{n}, \\
& \delta\left(S_{h_{i+1}}\right)=\left\|S_{h_{i+i}}\left(\underline{x}_{i}, t\right)-S\left(\underline{x}_{i}, t\right)\right\|=\|\underline{c}\| h_{i+1}^{n} .
\end{aligned}
$$

Dividindo a equação (5.9) pola equaçào (5.8) e applicando o logarítmo, obtemos as seguintes expressões para a ordem de convergência, utilizando as malhas $M_{1}, M_{2}$ e $M_{3}$ :

$$
\begin{aligned}
& n_{1}=\frac{\log \frac{\delta\left(S_{M_{2}}\right)}{\delta\left(S_{M_{1}}\right)}}{\log \frac{1}{2}}, \\
& n_{2}=\frac{\log \frac{\delta\left(S_{M_{3}}\right)}{\delta\left(S_{M_{2}}\right)}}{\log \frac{1}{2}} .
\end{aligned}
$$

Os resultados fornecidos por (5.10) e (5.11) são mostrados na tabela (5.2).

\begin{tabular}{|l|l|l|l|}
\hline Equação utilizadà & $O(u)$ & $O\left(\tau^{x i x}\right)$ & $O\left(\tau^{r y y}\right)$ \\
\hline Equação (5.10) coln $M_{1} \circ M_{2}$ & $1.9691 / 7$ & 1.815898 & 1.973956 \\
Equação (5.11) com $M_{2} \circ M_{3}$ & 1.989068 & 1.920812 & 1.993293 \\
\hline
\end{tabular}

Tabela 5.2: Ordem de convergência do método numérico.

Os resultados da tabela (5.2) constatan que os dados têm a mesma ordem de grandeza, além disso os resultados indicam que o método numérico converge aproximadamente com ordem $O\left(h^{2}\right)$. Portanto, o método numórico está quantitativamente validado para o problema de escoamento de fluido de Segunda Orden em um canal com superfícies livres. 


\section{Resultados Numéricos}

Com o objetivo de verificarmos os efeitos causados pela diferença de tensöes normais em escoamentos do tipo SOF, analisaremos os resultados numéricos para a contração planar e para o problema de inchamento do extrudado, conferir trabalhos de Mitsoulis [1999], Gast et al. 1999], Nigen e Walters [2002] e Liang e Öretkin [1999]. Ademais, utilizaremos esses resultados para verificarmos a eficiencia do método numérico em resolver qualitativamentes os escoamestos com on sern superfície livre.

Muitos trabalhos realizados sobre a contração detêm atenção especial ao tamanho clos vórtices formados próximos à parede. O tamanho dos vórtices depende principalmente da geometria utilizada, da clasticidade do fluido (quantificada pelo múmero de Deborah) e das propriedades reológicas do fluido. O estudo desse problema procederá com a análise sobre a formação desses vórtices em escoamentos de fluidos de Segunda Ordem.

No problema de inchamento do extrudado, a expansäo do fluido ao deixar um orifício é ocasionada por dois fatores, segundo Cast et al. [1999]: o tamanho dessa expansāo é detcrminado pelas condiçoes do processo e pelas propriedades reológicas do fluido. As condiçoes do processo incluem a geometria do problema, a taxa de fluxo de massa e a temperatura. As propriedades reológicas do fluido incluem a viscosidade, a densidade, a primeira c a segunda diferenças de tensōes normais. Analisaremos a formação dessa expansão e compararemos os resultados com a teoria de Tanner, conferir Tanner [1970], e com o trabalho de Crochet e Keunnings, conferir Crochet et al. [1982]. 


\subsection{Contração $4: 1$}

A figura (6.1) mostra o modelo e as medidas do domínio para a contração $4: 1$.

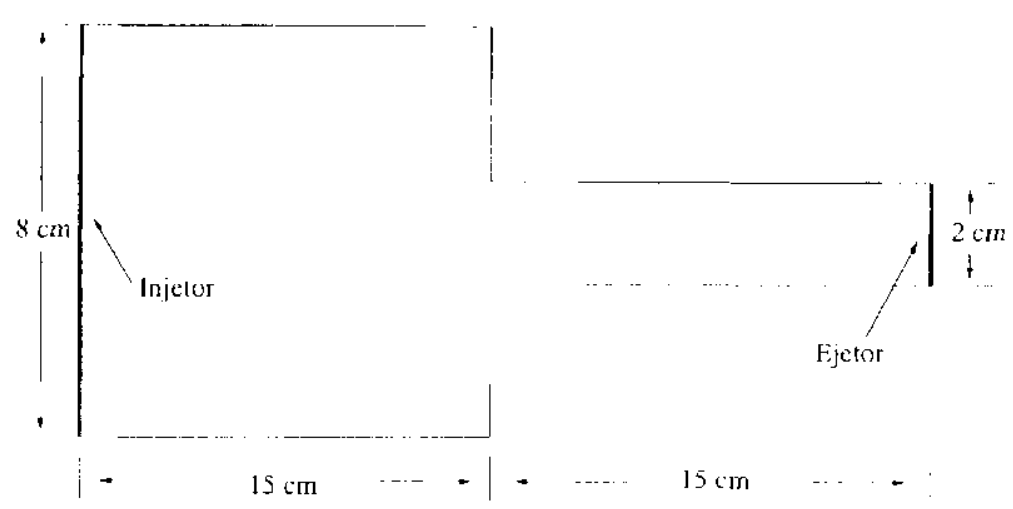

Figura 6.1: Modelo para a simulaçao da contraģäo $4: 1$.

Os seguintes dados foram utilizados no sistema Freeflow-21) para simular o problema da contração $4: 1$.

Escala de comprimento $L=0.01 \mathrm{~m}$

Escala de velocidade $U=1.0 \mathrm{~m} / \mathrm{s}$

Força gravitacional : $\underline{g}_{-x}=\underline{g}_{y}=0.0 \mathrm{~m} / \mathrm{s}^{2}$

Viscosidades $\eta / \rho=0.01 \mathrm{~m}^{2} / \mathrm{s} 00.1 \mathrm{~m}^{2} / \mathrm{s}$

Tolerancia para a solução da equação de Poisson $-10^{-8}$

Fator de controle de passo $\zeta=0.5$

$\lambda_{2}=0.0,0.002,0.004,0.006,0.008,0.01,0.012$ e $0.014 s$

Números de Reynolds $=1.0$ e 0.1

Números de Deborah $=0.0,0.2,0.4,0.6,0.8,1.0,1.2$ e 1.4

Walha: $\delta x=\delta y=0.12510^{-2} \mathrm{~m}, 64 \times 240$ células

Os resultados mostrados nas figuras (6.2)-(6.3) estão representados através de linhas de corrente ${ }^{1}$. Devido à propriedade de simetria da contraçäo, apenas a metade superior do domínio é mostrada.

$1 O$ calculo das linhas de corrente pode ser consultado no anexo $\mathrm{B}$ 

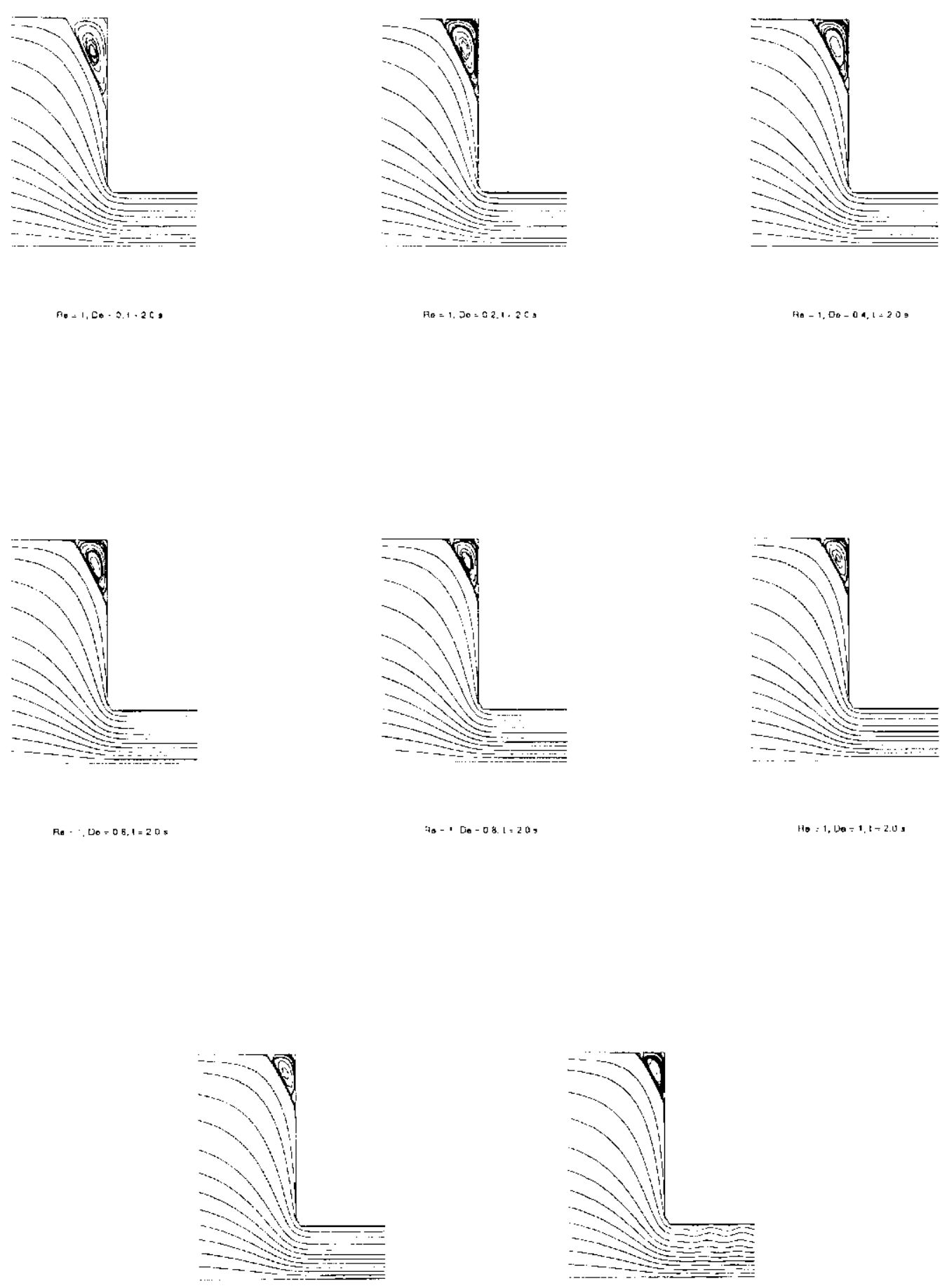

$P_{0}=1, D=12,1=20$

$F_{\theta 0}-1,00-14,1: 20$,

Figura 6.2: Resultados numéricos: $R e=1.0$ e De $=0,0.2,0.4,0.6,0.8,1.0,1.2$ e 1.4 

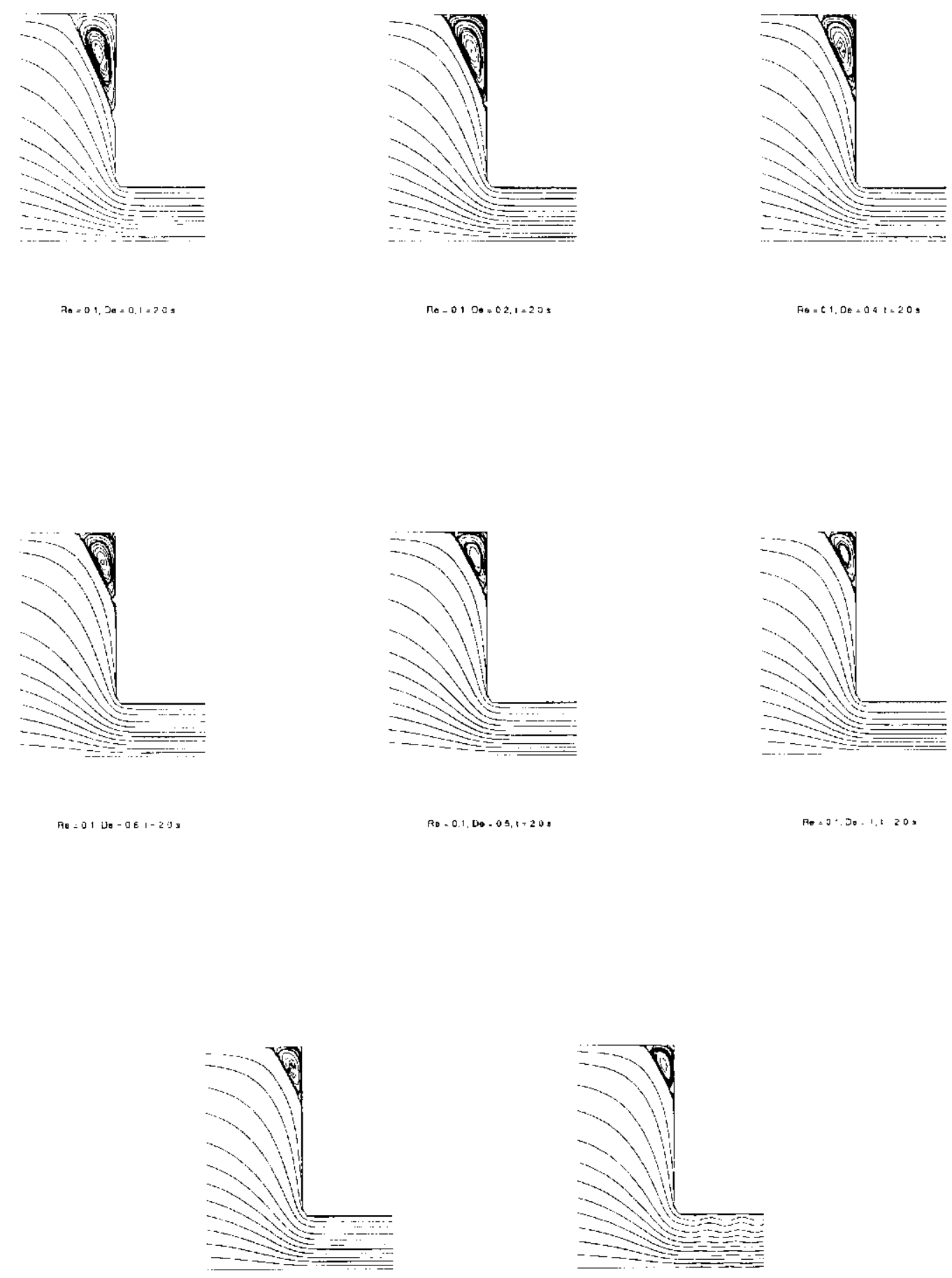

Figura 6.3: Resultados numéricos: $R c=0.1$ e $\mathrm{De}=0,0.2,0.4,0.6,0.8,1.0,1.2$ e 1.4 
Os resultados apresentados nas figuras (6.2) e (6.3) mostram que o tamanho do vórtice formado no canto da contração diminui com o aumento do número de Deborah e com a redução do número de Reynolds. Esse aumento foi previsto numericamente em Nigen e Walters [2002]. Essa redução do vórtice ocorre principalmente devido aos efeito elásticos gerados pela diferença de tensões normais do modelo SOF.

Imediatamente após a contração podemos observar um efeito de instabilidade do escoamento SOF quando $\mathrm{De}=1.4$, tanto para $\operatorname{Re}=1.0$ quanto para $\mathrm{Re}=0.1$, ver figuras (6.2) e (6.3). Essa instabilidade pode ser observada nas oscilações formadas nas linhas de corrente no canal com diâmetro menor. Essas oscilações se propagam até o ejetor. A equação constitutiva para fluidos SOF modela bem escoamentos cujo tensor taxa de deformação e suas derivadas são pequenos, conforme Bird et al. [1987]. A partir de De $=1.4$, a taxa de cizalhamento na quina juntamente com as tensões crescem rapidamente, inflingindo a restrição para escoamentos SOF. Acreditamos que esse é o motivo ao qual a simulação numérica apresenta essas oscilações.

Os resultados nas figuras (6.4)-(6.9) são referentes aos campos de velocidades $u$ e $v$ e às tensões $\tau^{x x}, \tau^{x y}$ e $\tau^{y y}$, assim como para a primeira diferença de tensões normais $N 1$ definida na equação (2.9), para $D e=0$ e $D e=1.2 \mathrm{com} R e=1.0$ em regime permanente.

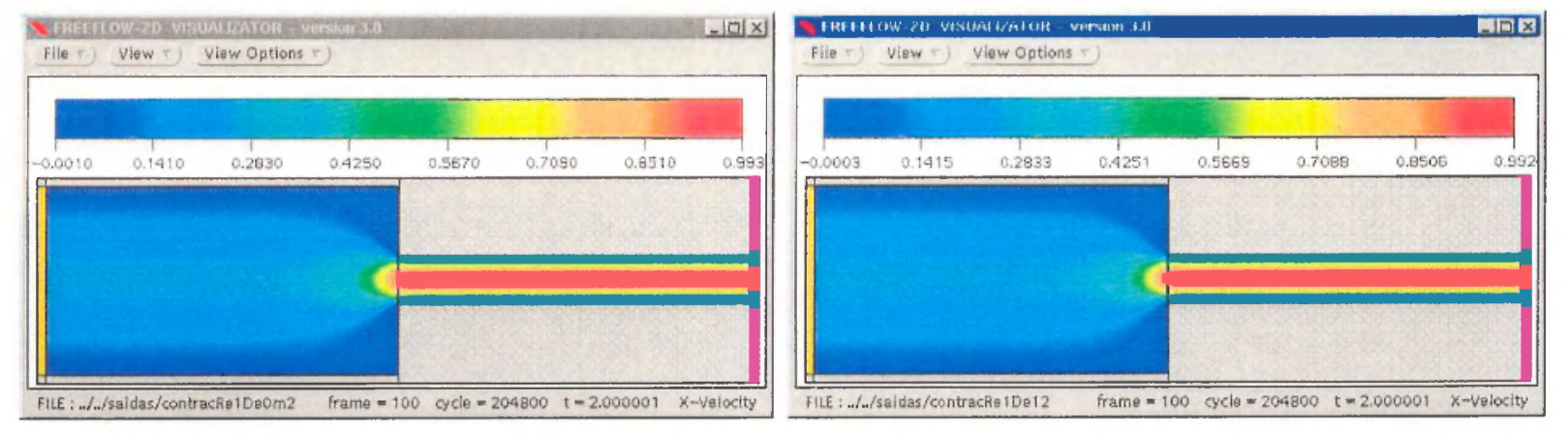

Figura 6.4: Componente da velocidade u para $R e=1.0$ e t $=2.0 \mathrm{~s}$ com $\mathrm{De}=0$ e 1.2 . 


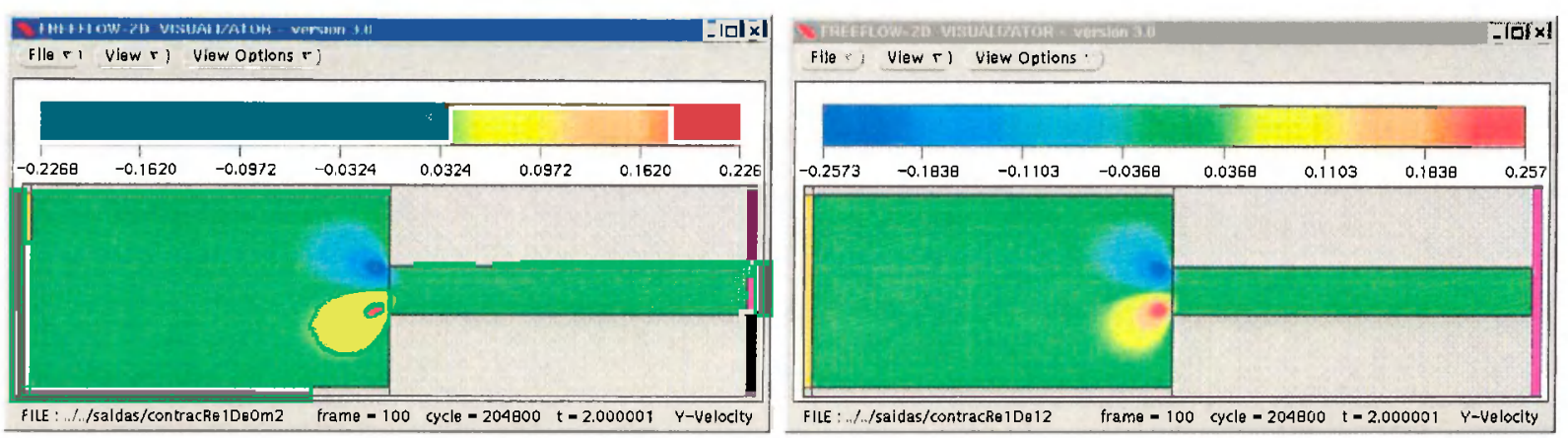

Figura 6.5: Componente da velocidade v para $\mathrm{Re}=1.0 \mathrm{e} \mathrm{t}=2.0 \mathrm{~s}$ com $\mathrm{De}=0$ e 1.2 .

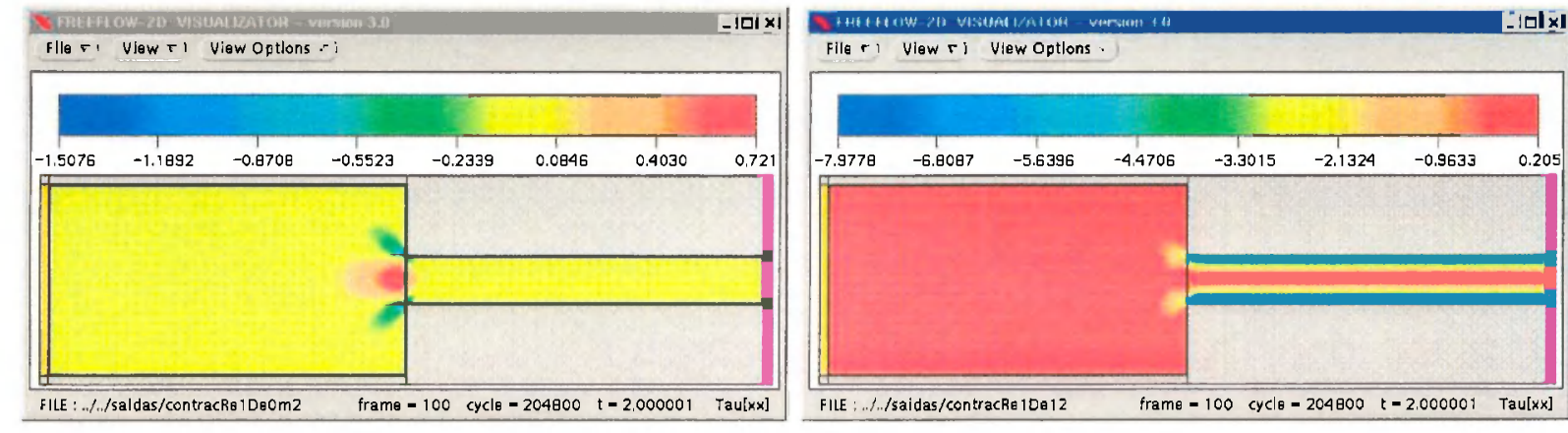

Figura 6.6: Tensao $\tau^{x x}$ para $\mathrm{Re}=1.0 \mathrm{e} \mathrm{t}=2.0 \mathrm{~s}$ com $\mathrm{De}=0$ e 1.2 .

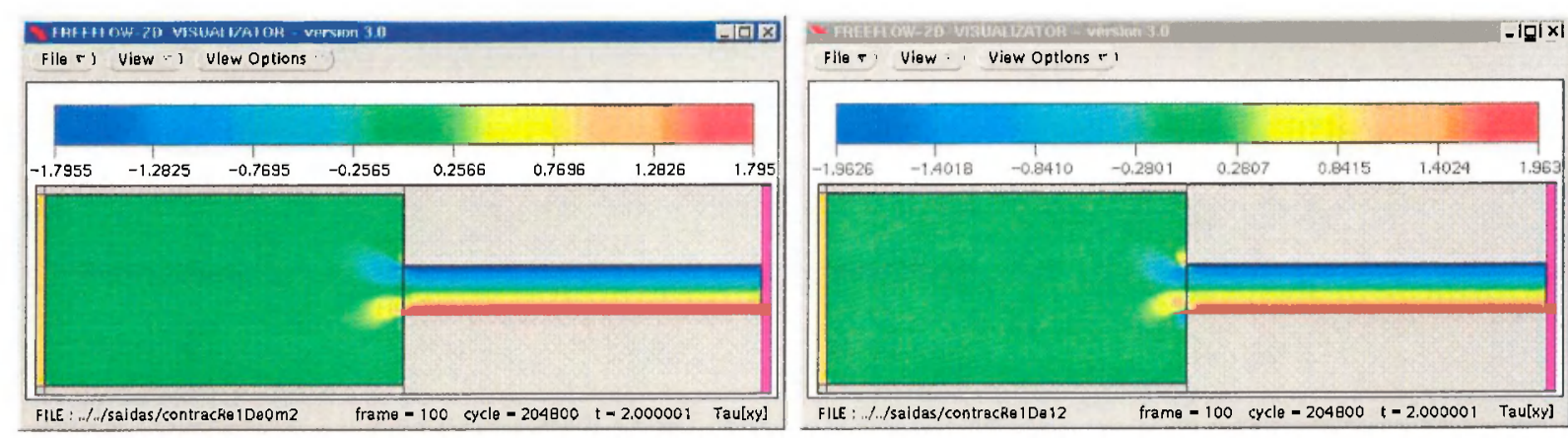

Figura 6.7: Tensão $\tau^{x y}$ para $\operatorname{Re}=1.0 \mathrm{e} t=2.0 \mathrm{~s}$ com $\mathrm{De}=0$ e 1.2 . 

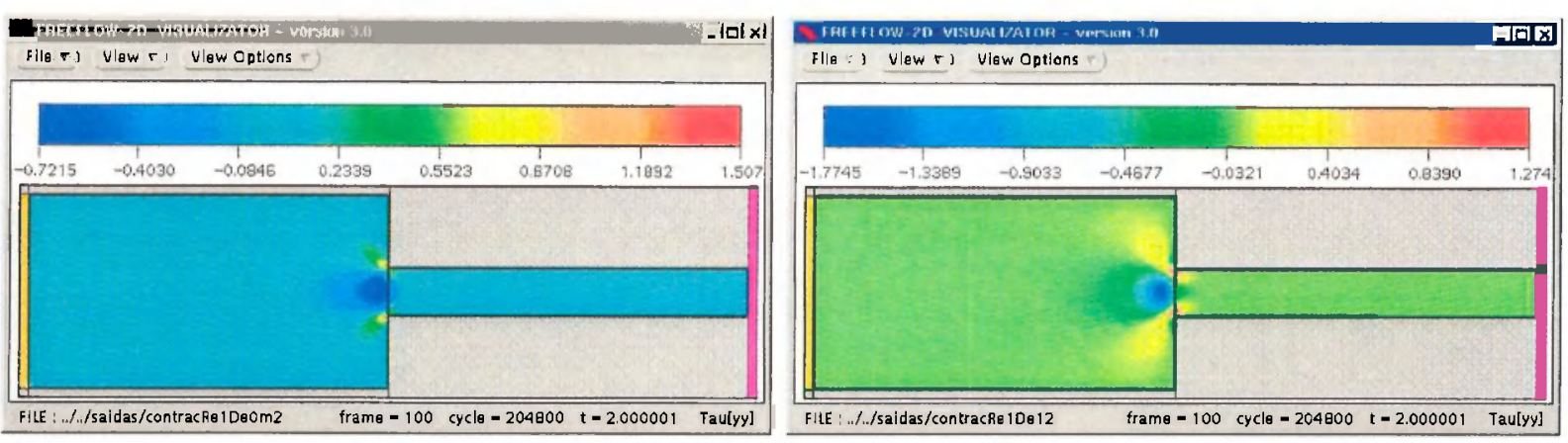

Figura 6.8: Tensão $\tau^{y y}$ para $\operatorname{Re}=1.0 \mathrm{e} \mathrm{t}=2.0 \mathrm{~s}$ com De $=0$ e 1.2 .
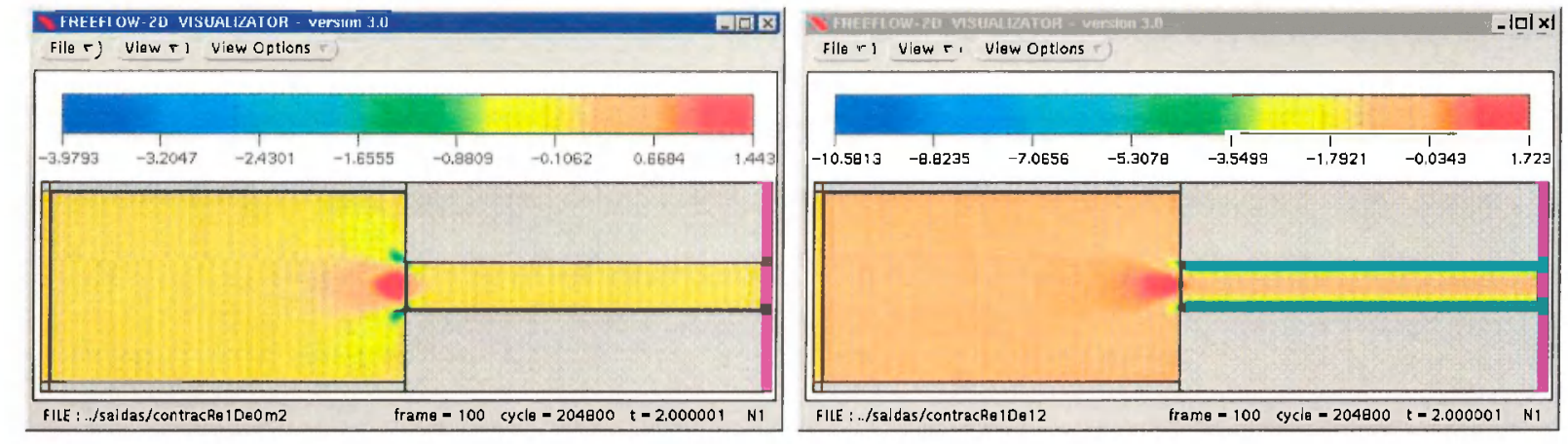

Figura 6.9: Diferença de tensão normal $N 1: \operatorname{Re}=1.0 \mathrm{e} \mathrm{t}=2.0 \mathrm{~s}$ com De $=0$ e 1.2 . 


\subsection{Inchamento do Extrudado}

O problema de inchamento do extrudado será resolvido utilizando um canal de comprimento $5.0 \mathrm{~cm}$ e largura $1.0 \mathrm{~cm}$, para estabilizar a solução, de acordo com a figura (6.10).

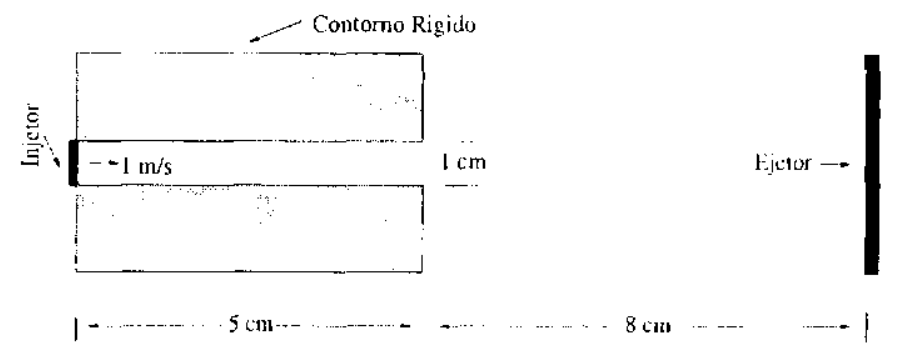

Figura 6.10: Modelo para a simulaçăo do inchamento do extrudado.

Para modelar o problema (6.10) utilizamos os seguintes dados:

Escala de comprimento $L=0.01 \mathrm{~m}$

Escala de velocidade $U-1.0 \mathrm{~m} / \mathrm{s}$

Força gravitacional : $\underline{g}_{x}=\underline{g}_{y}=0.0 \mathrm{~m} / \mathrm{s}^{2}$

Viscosidade $\eta / \rho=0.01 \mathrm{~m}^{2} / \mathrm{s}$

Tolerância para a equação de Poisson $=10^{-8}$

Fator de controle de passo $\zeta=0.1$

Número de Reynolds $=1.0$

Malha: $\delta x=\delta y=0.62510^{-3} \mathrm{~m}, 48 \times 624$ cólulas

No problema do inchamento do extudado acima, o número de Frouden é 3.19 se considerarmos a força gravitacional, contudo para esse caso podomos desprezar o efeito da força gravitacional

As figuras (6.11)-(6.16) mostram os resultados numéricos obtidos na simulação do problema de inchamento do extrudado para $R e=1.0$ em regime permanente. 


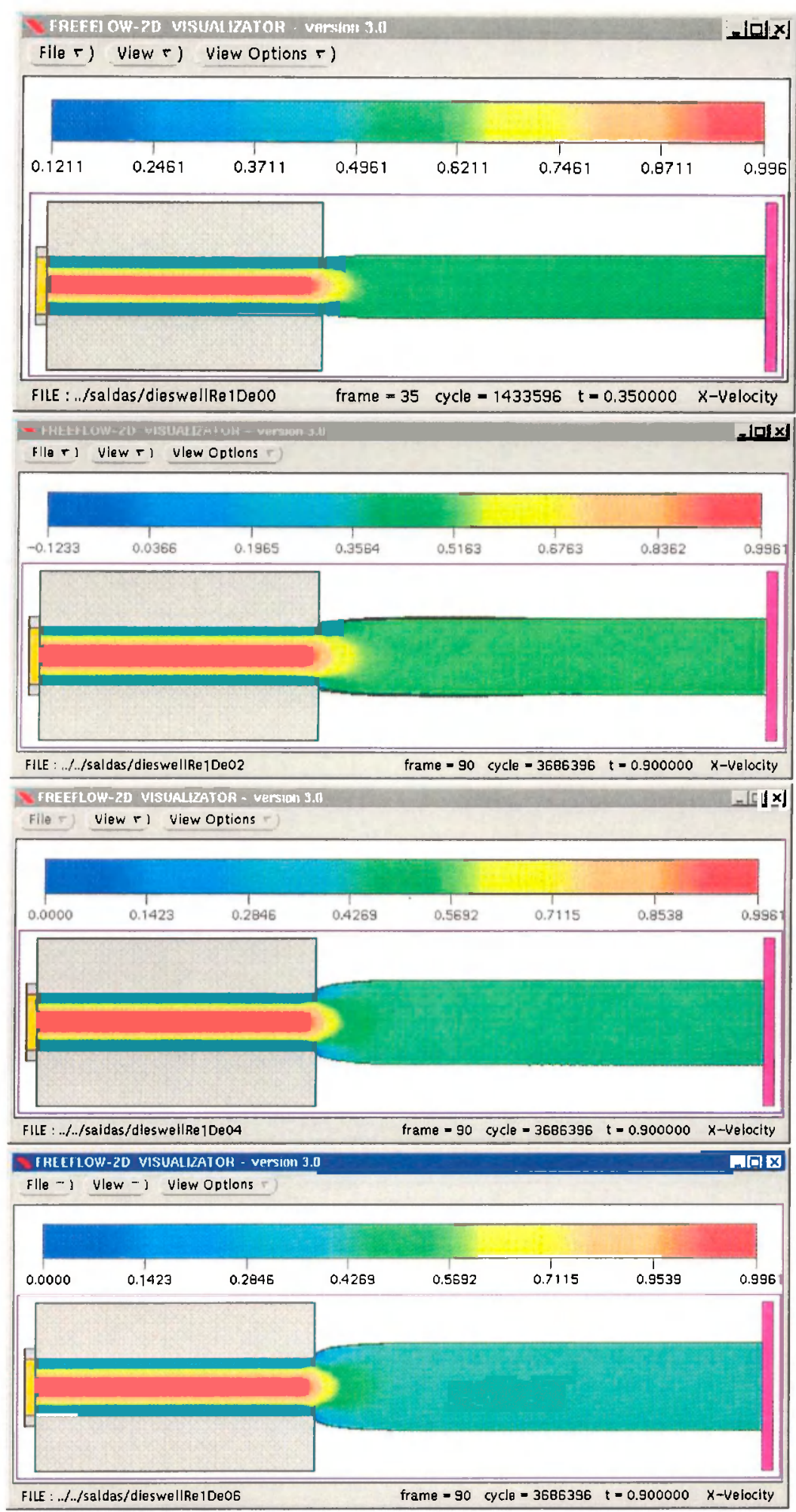

Figura 6.11: Componente $u$ em $t=0.9 s$ para $\mathrm{De}=0,0.2,0.4$ e 0.6 


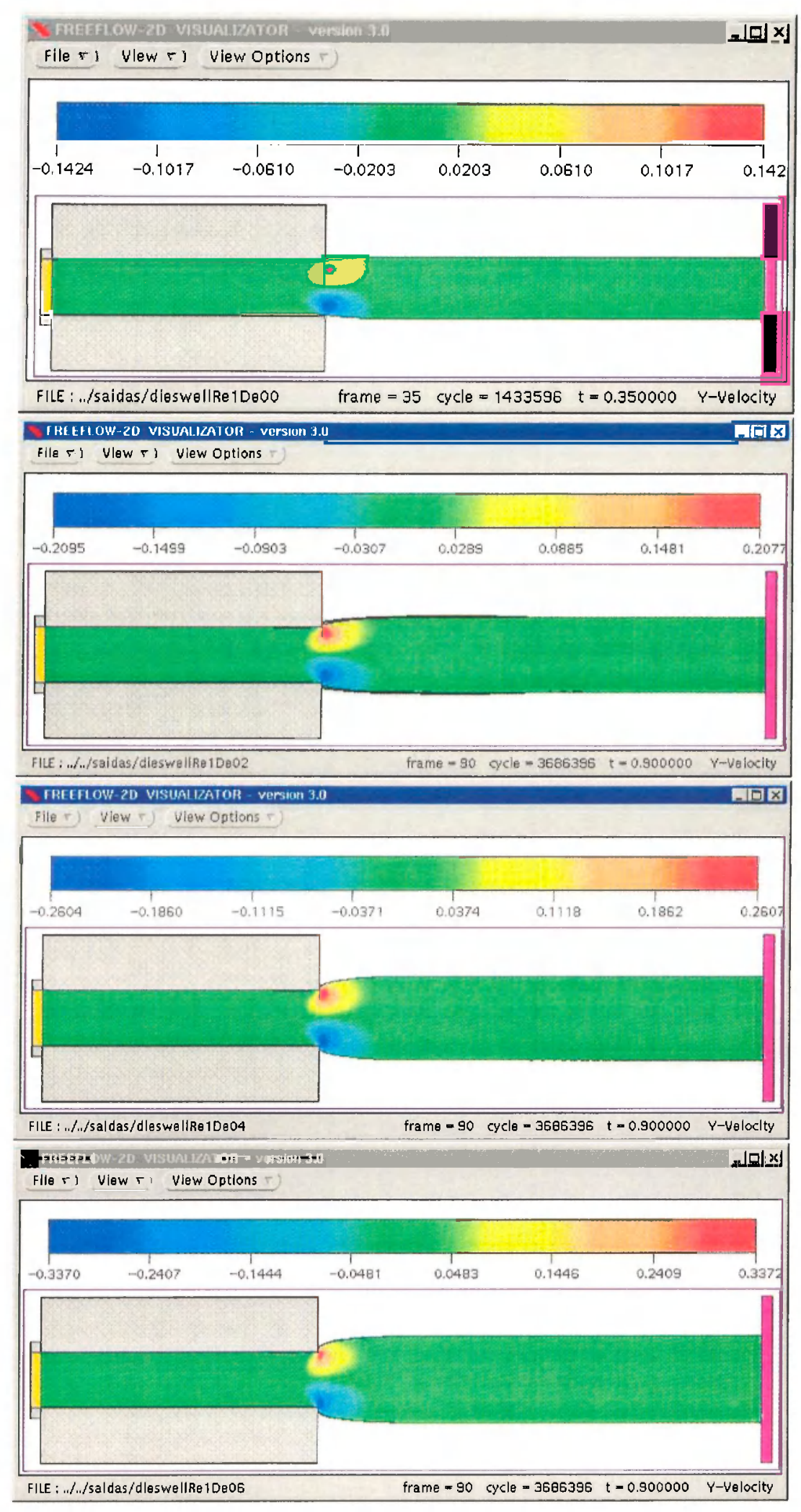

Figura 6.12: Componente $\vee$ em $1=0.9 \mathrm{~s}$ para $\mathrm{De}=0,0.2,0.4$ e 0.6. 


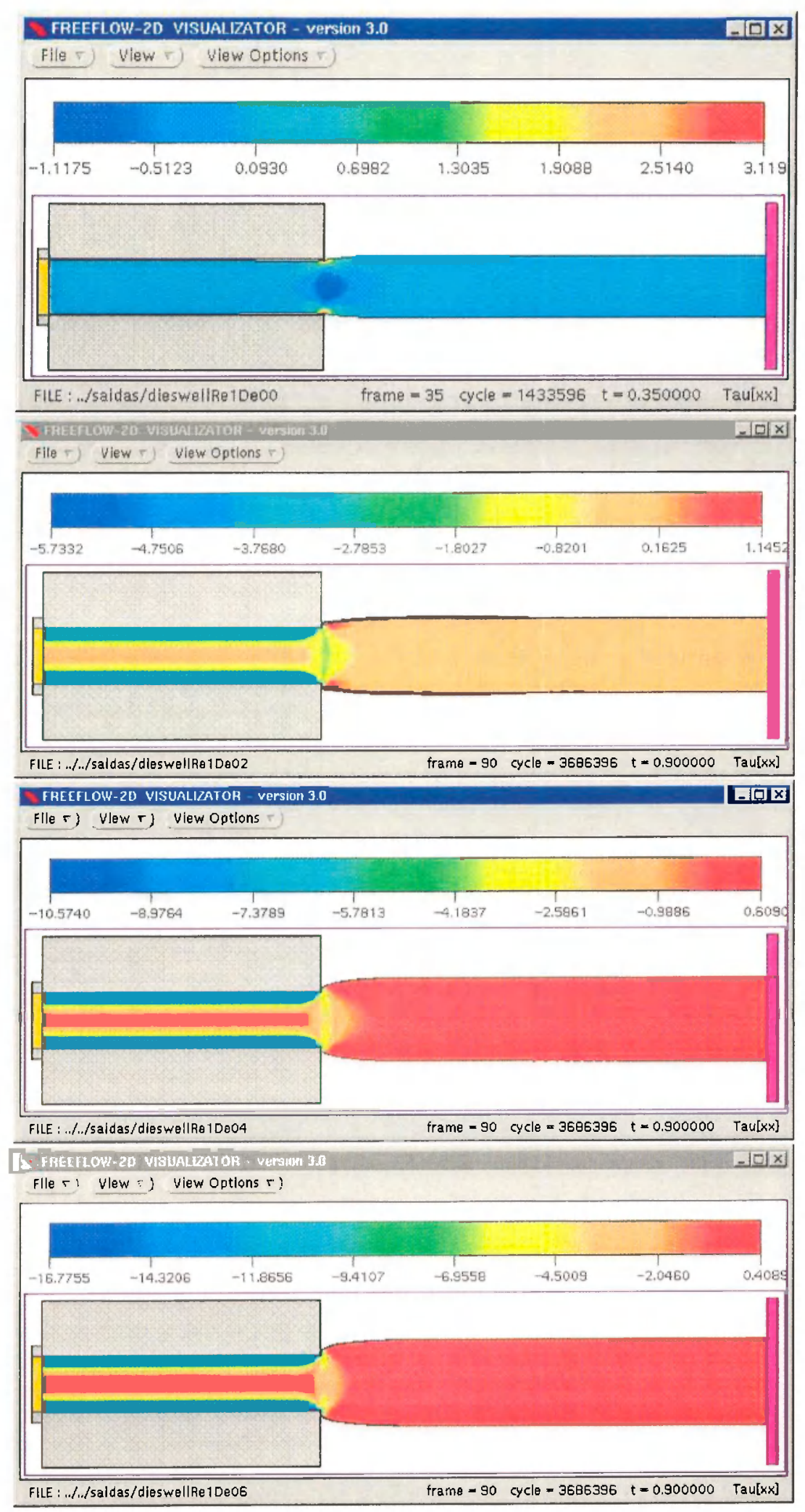

Figura 6.13: Componente $\tau^{x x}$ em $t=0.9 s$ para $\mathrm{De}=0,0.2,0.4$ e 0.6 . 


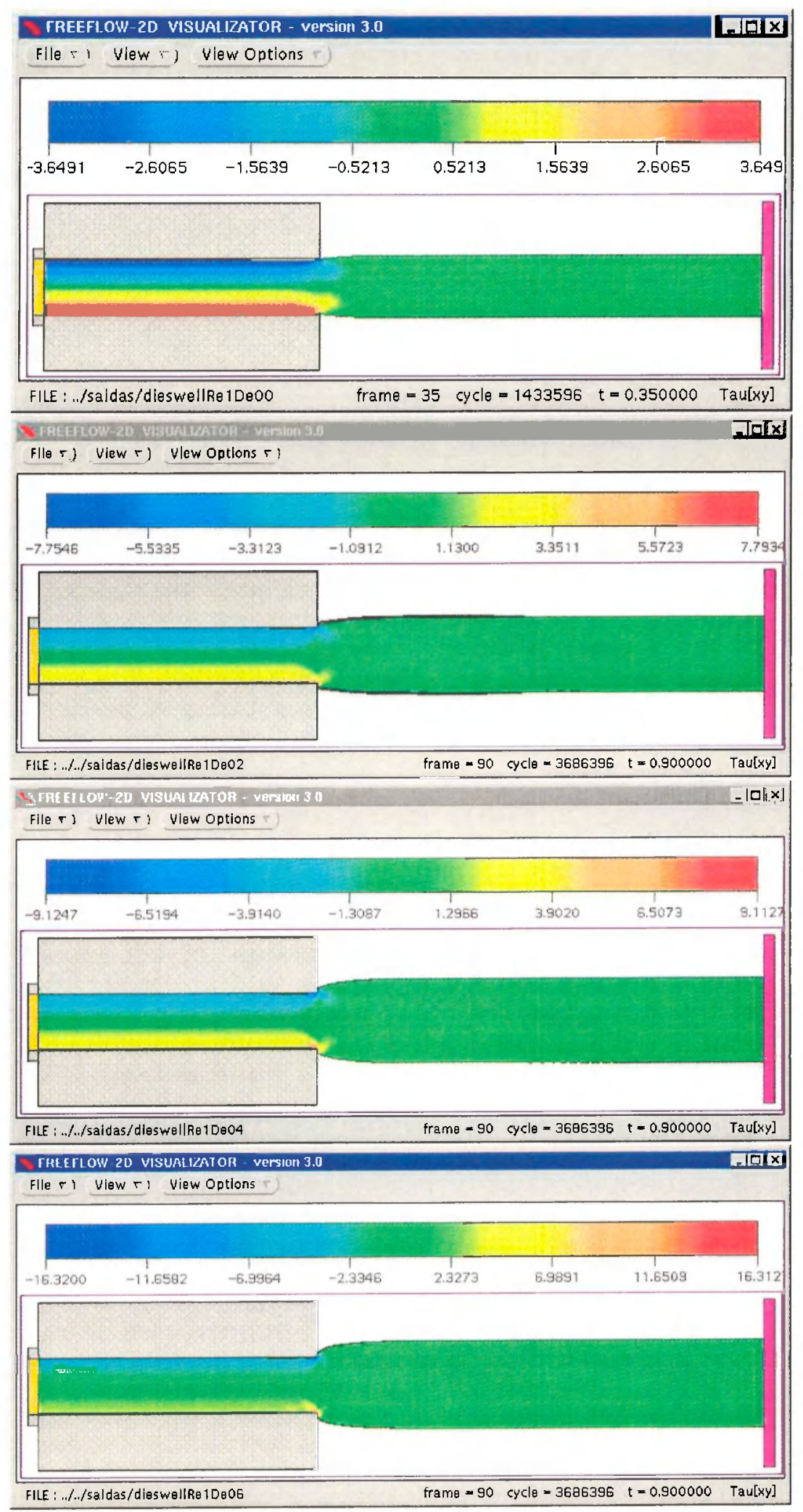

Figura 6.14: Componente $\tau^{x l}$ em $\uparrow=0.9 s$ para De $=0,0.2,0.4$ e 0.6. 


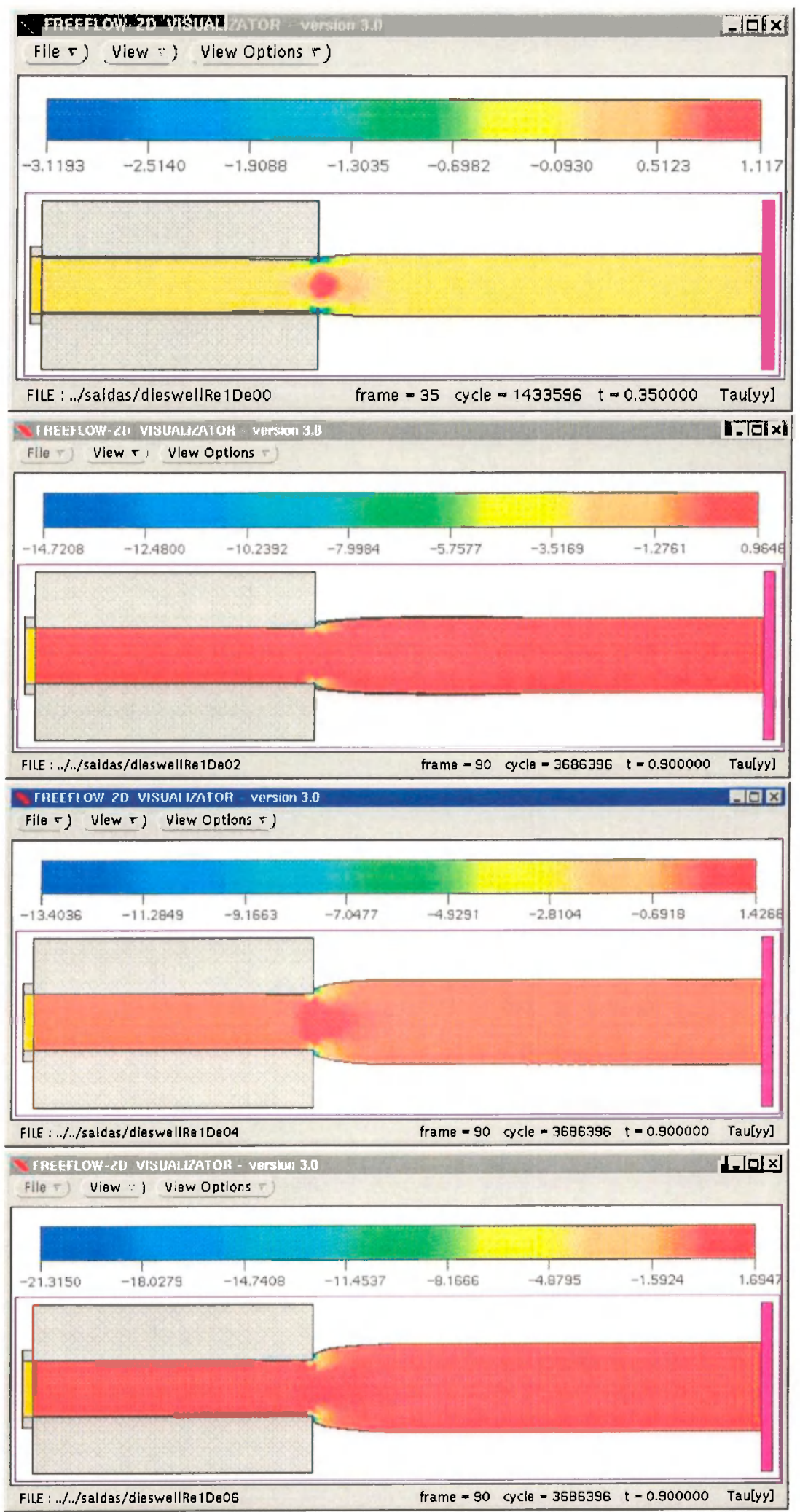

Figura 6.15: Componente $\tau^{y / 3}$ em $t=0.9 s$ para De $=0,0.2,0.4$ e 0.6. 


\section{Resultados Numéricos}

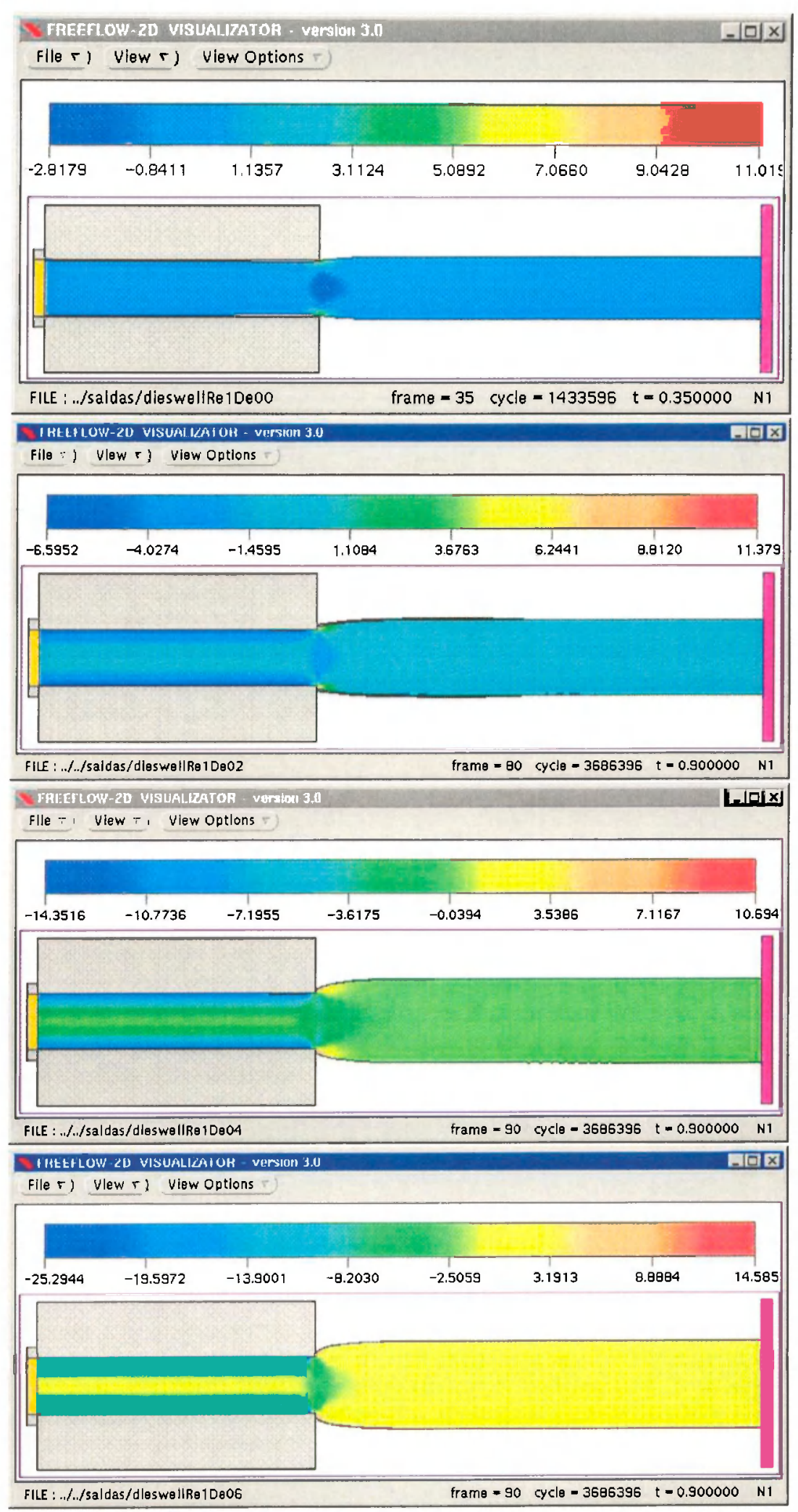

Figura 6.16: Diferença de tensão normal N1 em $t=0.9 \mathrm{~s}$ para De $=0,0.2,0.4$ e 0.6 
O inchamento do fluido ao deixar o canal no prohtema (6.10) será comparado com os trabalbos de Crochet et al. [1982] e com a Teoria de Tanner, conforme Tanner [1970;. Para realizarmos essa comparação é necessário utilizarmos o parâmetro adimensional $S_{h}$ definido abaixo:

$$
S_{R}=\frac{N_{1}}{2 \tau^{x y}}=\frac{\tau^{x x}-\tau^{y y y}}{2 \tau^{x y}} .
$$

Considerando o escoamento no canal completamente desenvolvido, o parâmetro $S_{H}$ e dado por:

$$
S_{R}: \cdots D e \frac{\partial u}{\partial y}
$$

Considerando a velocidade dada pela equação (5.2) na parede, $S_{R}=4 \mathrm{D}$ e.

De acordo com a Teoria de Tanner, a taxa de inchamento $S_{r}=\frac{D_{\text {maxi }}}{L_{r}}$ (onde $L$ é a largura do canal e $D_{\text {max }}$ é a largura máxima que o jato atinge ao deixar o canal) é dada por:

$$
S_{r}=\frac{D_{r u t u x}}{L}:-0.2+\left(1+\frac{\left(S_{R}\right)^{2}}{3}\right)^{\frac{1}{3}}
$$

O gráfico (6.17) mostra os resultados obtidos para o problema de inchamento do extrudado comparado com a 'eoria de Tamner e os dados de Crochet e Keunnings:

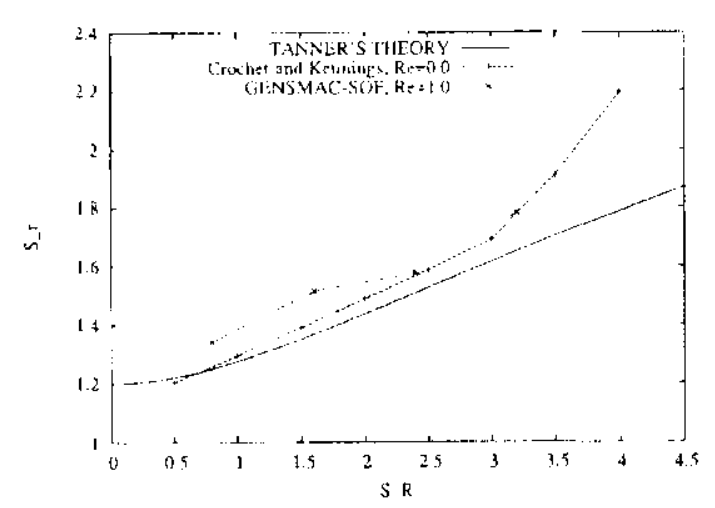

Figura 6.17: Taxa de inchamento do problema de inchamento do extrudaclo 


\section{Conclusões e Recomendações}

As simulaçōes numéricas realizadas nesse trabalho indicaram a eficiência do método numérico desenvolvido ao simular escoamentos incompressíveis em regime laminar e isotérmico de fluidos de Segunda Ordem com on sem superfícies livres. A validação no canal demonstrou que o método converge quadraticamente com o refinamento da malha de pontos. A simulação do escoamento através da contração $4: 1$ indicou a presença dos efcitos clásticos, previstos nos trabalhos de Nigen e Walters [2002], devido à redução do tamanho dos vórtices com o aumento do número de Deborah. O inchamento do jato, ao deixar o canal no problema do inchamento do extrudado, indicou a presença do efeito de tensão normal para problemas envolvendo superfícies livres. Fsse cfeito foi também relatado nos trabalhos de Mitsoulis [1999? e Liang e Özetkin [1999]. Além disso, os resultados concordaram com a teoria de 'lanner c com o trabalho de Crochet e Keunnings, conferir Crochet et al. [1982] e Tanner [1970]. O método numérico para escoamentos de fluidos de Segunda Ordem desenvolvido nesse trabalho consistiu em uma extensão do ambiente de simulação FreFlow-2D, ver Oliveira [1999].

Para o desenvolvimento de novos trabalhos, envolvendo escoamentos de fluidos de Segunda Orden, pretendemos incluir um método numérico para implementar a derivada substancial do tensor taxa de deformação e também recomendamos o cstudo de métodos de scegunda ordem para aproximar as derivadas em pontos próximos aos contornos. Sugerimos a implementação de escoamentos axissimćtricos e tridimensionais para fluidos de Segunda Ordem, além da implementação de um método para resolver escoamentos com troca de calor entre o fluido e o meio ambiente. 


\section{Referências Bibliográficas}

Acheson, D. J. (1990). Elementary Fluid Dynamics. Oxford University Press.

Amsden, A. e Harlow, F. H. (1970). The SMAC Method: A Numerical Technique for Calculating Incompressible Fluid Flows. Los Alamos Scientific Lab. Report LA-4370.

Armenio, V. (1997). The SMAC method: a numerical technique for calculating incompressible fluid flow. International Journal of Numerical Methods in Fluids, 24:185. 214.

Batchelor, G. K. (1967). An Introduction to Fluid Dynamics. Cambridge Univ. Press.

Bird, R. B. Armstrong, R. C. c IIassager, O. (1987). Dynamics of Polymeric Liquids. John Wiley \& Sons.

Castelo, A. Tome, M. F. Mckec, S. Cuminato, J. A. (2000). Freeffow: An Integrated Simulation System for Three-Dimensonal Free Surface Flows, Computing and Visualization in Science. 2:199-210.

Crochet, M. J. e Keunings, R. (1982). Finite element analysis of die-swell of a highly elastic: fluid. Journal of Non-Newtonian Fluid Mechanics, 10:339-356.

Crochet, M. J. e Walters, K. (1984). Numerical Simulation of Non-Newtonian Flow. Elsevier.

Ferreira, V. G., Tomé, M. F., Mangiavacchi, N. Castelo, A., Cuminato, J. A., Fortuna. A. O., e. Ackee, S. (2002). High Order Upwinding and the Hydraulic Jump. International Journal of Numerical Methods in Fluids, 39:549-583.

Ferziger, J. H. e Peric, M. (1999). Computational Methods for Fluid Dynamics. Springer. Second Edition. Tokyo. 
Fletcher, C. A. J. (1991). Computational T'chniques for Fluid Dynamics: Vol. I e Vol II. Springer Verlag.

Fortuna, A. (). (2000). Técnicas Computacionais para Dinâmica dos Fluidos. Edusp.

Fox, R. W. e.McIDonald, A. T. (1995). Introdução à Dinâmica dos Fluidos. Livros Técnicos e Científicos.

Gaskell, P. II. (: Lau, A. K. C. (1988). Curvature-compensated convective transport: $\mathrm{SMART}$, a new boundedness-preserving transport algorithm. International Journal of Numerical Methods in Fluids, 8:617-641.

Gast, L. e Ellingson, W. (1999). Die swell measurements of second-order fluids: numerical experiments. International Journal for Numerical Methods in Fluids, 29:1-18.

Harlow, F. H. o Welsh, J. E. (1965). Numerical calculation of a time dependent viscons incompressible flow with trec surface. Phys. Fluids, 8:2182 2189.

Kcunings, R. e Crochet, M. (1984). Numerical Simulation of the Flows of a Viscoelastic Fluid Through an Abrupt Contraction. Journal of Non-Newtonian Fluid Mechanics, 14:279.299.

Liang, Y. e Özetkin, A. Neti, S. (1999). Dynamics of viscoelastic jets of polymeric liquid extrudate. Journal of Non-Newtonian Fluid Mechanics, 81:105 132

Mitsoulis, E. (1999). Three-dimensional non-.Newtonian computations of extrudate swell with the finite Element Method. Compul. Methods Appl. Mech. Engrg., 180:333- 344.

Nigen, S. e Walters, K. (2002). Viscoelastic contraction flows: comparison of axisymmetric and planar configurations. Journal of Non-Newtonian Fluid Mechanics, 102:343 359.

Oliveira, J. (1999). Desenvolvimento de um Sistema de Sinulaçäo de Escoamentos de Fluidos com Superficies Livres Bidimensionais. Dissertação de mestrado, ICMC/USP.

Owens, R. G. e Phillips, T. N. (2002). Computational Rheology. Imperial College Press.

Papanastasiou, T. C. (1994). Applied fluid mechanics. Prentice-Hall.

Peyret, R. e Taylor, 'T. D. (1983). Computational Methods for Fluid Flow. Springer-Verlidg. 
Phillips, T. N. o Williams, A. (1999). Viscoclastic flow though a planar contraction using a semi-Lagrangian finite volume method. Journal of Non-Newtonian Fluid Mechanics, $87: 215 \cdot 246$.

Pontes, J. (1999). Fenômenos de Transferência. Technical Report, COPPE/LFRJ.

Purnode, B. e Crochet, M. (1987). Flows of polymer solutions through contractions. Part 1: Hows of polyacrylamide solutions through planar contractions. Journal of NonNewtonian Fluid Mechanics, 65:269-289.

Ralston, A. (1965). A first course in numerical analysis. McGraw-Hill, Tokio.

Ryan, M. E. e Dutta, A. (1981). A finite Difference simulation of Extrudate Swell. Proc. 2nd. World Congr. Chem. Eng., VI:277 281.

Tanner, R. I. (1970). A theory of die-swell. Journal of Polymer Science, 8:2067 2078.

Tanner, R. I. e Walters, K. (1998). Rheology: An Historical Perspective. Elsevier.

Tomé, M. F. (1993). GENSMAC: A Multiple Free Surface Fluid Flow Solver. Ph d. thesis, University of Strthclyde.

Tomé, M. F., Mangiavacchi, N. A., Cuminato, J. A., C Castelo, A. (2002). A Numerical Technique for Solving Unsteady Viscoelastic Free Surface Flows. Journal of NonNewtonian Fluid Mechanics, 106:61-106.

Tomé, M. F., Duffy, B., e McKee, S. (1996). A Numerical Method for Solving Unsteady Non-Newtonian Free Surface Flows. Journal of Non-Newtonian F'luid Mechanics, 62:9 34.

Tomé, M. F. e McKee, S. (1994). GENSMAC: A Computational Marker-and-Cell Method for Free Surface Flows in General Domains. Journal of Computational Physics, $110(1): 171 \cdots 189$.

Varonos, A. e Bergeles, G. (1998). Development and assessment of a variable-order nonoscillatory scheme for convection term discretization. International Journal For $\mathrm{Nu}$ merical Methods in Fluids, 26:1-16. 
Yoo, 1. . Na, Y. (1991). A numerical study of the planar contraction flow of a viscoclastice fluid using the SIMPLLR algorithm. Jonmal of Non-Newtonian Flud Mechanics, 30:89 106

Zhu. J. (1992). On the higher-order bounded discretization schemes for finite volume computations of incompressible flows. Comput. Methods Appl. Mech. Eng, 98:345-360. 


\section{Anexo A: Métodos de Runge-Kutta}

Métodos de Runge-Kutta para Equações Diferenciais Ordinárias

Os Métodes de Runge-Kutta, conferir Ralston [1965], foram desenvolvidos parat resolver numericamente as equaçóes diferenciais ordinárias da forma:

$$
\begin{aligned}
& \frac{\partial y}{\partial x}=f(x, y) \\
& y\left(x_{0}\right)=y_{0}
\end{aligned}
$$

sob as hipóteses:

1. $f(x, y)$ é definida o contínua no intervalo $x_{0} \leq x \leq b,-\infty<y<\infty$ com $x_{0}$ e $b$ finitos.

2. Existe uma constante $L$ tal que para qualquer $x \in\left[x_{0}, b\right]$ e quaisquer $y$ e $y^{*}$ tem-se:

$$
\left|f(x, y)-f\left(x, y^{*}\right)\right| \leq L\left|y-y^{*}\right|
$$

Os Métodos de Runge-Kutta expressão a diforença entre os valores de $y$ em $x_{n+1} \mathrm{e}$ $x_{n}$ como:

$$
y_{n+1}-y_{n}=\sum_{i=1}^{m} w_{i} k_{i}
$$

onde os $w_{i}^{\prime}$ s são constantes e

$$
k_{i}=h_{n} f\left(x_{n}+\alpha_{i} h_{n}, \quad y_{n}+\sum_{j-1}^{i \cdot 1} \beta_{i j} k_{j}\right),
$$


$\operatorname{com} h_{n}=x_{n, 1} \quad x_{n} \rho \alpha_{1}-0$.

Para Métodos de Runge-Kutta de até $4^{a}$ ordem, $v_{i}, \alpha_{i}$ o $\beta_{i j}$ devem satisfazer as seguintes rquaçoes:

$$
\begin{aligned}
& w_{1}+w_{2}+w_{3}+w_{4}=1, \\
& w_{2} \alpha_{2}+w_{3} \alpha_{3}+w_{4} \alpha_{4}=\frac{1}{2}, \\
& w_{2} \alpha_{2}^{2}+w_{3} \alpha_{3}^{2}-w_{4} \alpha_{4}^{2}=\frac{1}{3}, \\
& w_{3} \alpha_{2} \beta_{32}+w_{4}\left(\alpha_{2} \beta_{42}+\alpha_{3} \beta_{43}\right)=\frac{1}{6}, \\
& w_{2} \alpha_{2}^{3}+w_{3} \alpha_{3}^{3}+w_{4} \alpha_{4}^{3}=\frac{1}{4}, \\
& w_{3} \alpha_{2}^{2} \beta_{32}+w_{4}\left(\alpha_{2}^{2} \beta_{42}+\alpha_{3}^{2} \beta_{43}\right)=\frac{1}{12}, \\
& w_{3} \alpha_{2} \alpha_{3} \beta_{32}+w_{4}\left(\alpha_{2} \beta_{42}+\alpha_{3} \beta_{43}\right) \alpha_{1}=\frac{1}{8}, \\
& w_{4} \alpha_{2} \beta_{32} \beta_{43}=\frac{1}{24} .
\end{aligned}
$$

- Métodos de Scgunda Ordem: Apresentaremos três métodos importantes de segunda ordem: aøueles em que $\alpha_{2}=\frac{1}{2}, \frac{2}{3}$ e 1 . Ltilizando as equações (2)-(9) determinamos $u_{i}$ e $\beta i j$ e substituindo-os na equação (1) temos:

$$
\begin{aligned}
& y_{n-1}-y_{n}=h_{n} f\left(x_{n}+\frac{1}{2} h_{n_{n}}, y_{n}+\frac{1}{2} h_{n} f_{n}\right), \\
& y_{n+1}-y_{n}=\frac{1}{4} h_{n}\left[f\left(x_{n}, y_{n}\right)+3 f\left(x_{n}+\frac{2}{3} h_{n}, \quad y_{n}+\frac{2}{3} h_{n} f_{n}\right)\right], \\
& y_{n+1}-y_{n}=\frac{1}{2} h_{n}\left[f\left(x_{n}, y_{n}\right)+f\left(x_{n}+h_{n}, \quad y_{n}+h_{n} f_{n}\right)\right] .
\end{aligned}
$$

- Dois métodos de Terceira Ordem:

$$
\begin{aligned}
& y_{n+1}-y_{n}=\frac{2}{9} k_{1}+\frac{1}{3} k_{2}+\frac{4}{9} k_{3}, \\
& k_{1} \cdots h_{n} f\left(x_{n}, \quad y_{n}\right), \\
& k_{2}=h_{n} f\left(x_{n}+\frac{1}{2} h_{n}, y_{n}+\frac{1}{2} k_{1}\right), \\
& k_{3}=h_{n} f\left(x_{n}+\frac{3}{4} h_{n}, \quad y_{n}+\frac{3}{4} k_{2}\right) .
\end{aligned}
$$




$$
\begin{aligned}
& y_{n+1}-y_{n}=\frac{1}{6}\left(k_{1}+k_{2}+k_{3}\right), \\
& k_{1}=h_{n} f\left(x_{n}, y_{n}\right), \\
& k_{2}=h_{n} f\left(x_{n}+\frac{1}{2} h_{n}, y_{n}+\frac{1}{2} k_{1}\right), \\
& k_{3}=h_{n} f\left(x_{n}+h_{n}, \quad y_{n}-k_{1}+2 k_{2}\right) .
\end{aligned}
$$

- Dois métodos de Quarta Ordem:

$$
\begin{aligned}
& y_{n+1}-y_{n}=\frac{1}{6}\left(k_{1}+2 k_{2}+2 k_{3}+k_{1}\right), \\
& k_{1}=h_{n} f\left(x_{n}, \quad y_{n}\right), \\
& k_{2}=h_{n} f\left(x_{n}+\frac{1}{2} h_{n}, \quad y_{n}+\frac{1}{2} k_{1}\right) \\
& k_{3}=h_{n} f\left(x_{n}+\frac{1}{2} h_{n}, \quad y_{n}+\frac{1}{2} k_{2}\right) \\
& k_{4}=h_{n} f\left(x_{n}+h_{n}, \quad y_{n}+k_{3}\right) \\
& y_{n+1}-y_{n}=0.17476028 k_{1}-0.55148053 k_{2}+1.20553547 k_{3}+0.17118478 k_{1}, \\
& k_{1}=h_{n} f\left(x_{n}, \quad y_{n}\right), \quad \\
& k_{2}=h_{n} f\left(x_{n}+0.4 h_{n}, \quad y_{n}+0.4 k_{1}\right), \\
& k_{3}=h_{n} f\left(x_{n}+0.45573726 h_{n}, \quad y_{n}+0.29697760 k_{1}+0.15875966 k_{2}\right) \\
& k_{1}=h_{n} f\left(x_{n}+h_{n}, \quad y_{n}+0.21810038 k_{1}-3.050966470 k_{2}+3.83286432 k_{3}\right) .
\end{aligned}
$$




\section{Anexo B: Linhas de Corrente}

\section{Cálculo das Linhas de Corrente}

Para a visualização dos vórtices, no problema da contração planar, foi implementada a equação de função de corrente bidimensional. A relação entre a velocidade e a função de corrente $e^{2}$ é definida por:

$$
u=\frac{\partial \psi}{\partial y} \quad v \quad v=-\frac{\partial \psi}{\partial x}
$$

A vorticidade é definida como:

$$
\omega=\frac{\partial u}{\partial y} \cdot \frac{\partial v}{\partial x}
$$

Substituindo as definiçōes (17) para $u$ e $v$ na definiçāo da vorticidade (18), obteremos:

$$
\omega=\frac{\partial^{2} \dot{\psi}}{\partial y^{2}}+\frac{\partial^{2} \dot{\psi}}{\partial x^{2}}
$$

A equação de corrente e vorticidade é discretizada no centro das cólulas cheias. Assumindo que $\delta x=\delta y$ obtcmos:

$$
-\psi_{i-1, j}-\psi_{i, j} \quad 1+4 \psi_{i, j}-\psi_{i+1, j}-\psi_{i, j+1}=-\delta x^{2} \omega_{i, j}
$$

2 Utilizamos a notaçăo de sintais de acordo com Fortuna [2000]. 
A aplicação da equaçào (20) sobre a malha resulta em um sistema linear da forma $\underline{\underline{A}} \underline{x}=\underline{b}$. Onde $\underline{\underline{A}}$ ć uma matriz simétrica definida positiva, $\underline{x}$ ć o vetor solução e $\underline{b}$ é o vetor que representa o lado direito da equação (20).

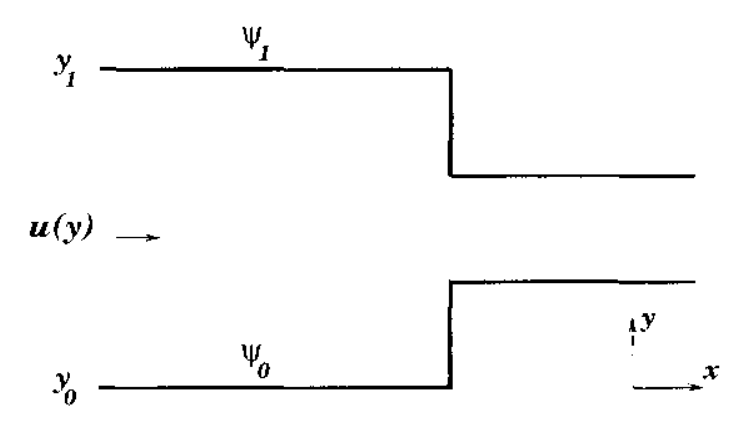

Figura 1: Esquema para o cálculo da funçăo de corrente?

Montamos a matrì A aplicando a equação (20) em cada célula cheia da malha. Portanto, para a montagem da matriz é necessário conhecermos as condições de contorno para a função de corrente no injetor, no ejetor e na fronteira rígida, conferir figura (1). A função de corrente no injetor é calculada a partir da relação (17) da seguinte forma:

$$
\frac{\partial \psi}{\partial y}=u \Rightarrow \int_{\psi_{0}}^{\psi_{1}} \partial \psi=\int_{y_{i}}^{y_{1}} u \partial y=\psi_{1}-\psi_{0}
$$

O perfil de velocidades no injetor é dado pela equação (5.1): $u(y)=u_{0}-\frac{1 u_{0}}{L^{2}}\left(y-\frac{L}{2}\right)^{2}$. Nesse caso podemos verificar que $\psi_{\text {total }}=\psi_{1}-\psi_{0}=\frac{2}{3} u_{0} L$, tomando $y_{0}=0$ e $y_{1}=L$. Devido ao fato da contração planar ter simetria em relação ao cixo contral, defino-se:

$$
\begin{aligned}
& \psi_{0}=-\frac{1}{2} \psi_{\text {total }} \\
& \psi_{1}=\frac{1}{2} \psi_{\text {total }} .
\end{aligned}
$$

Assim, as condiçōes de contorno adequadas para a $\psi$ são:

- Na vizinhança de células cheias com cólulas injetoras ou ejetoras aplicamos a condição homogênea de Nenmann: 


$$
\frac{\partial \psi}{\partial n}-0
$$

- Na vizinhança de células cheias com células de fronteira rígida aplicamos a condição homogenea de Dirichlet. A fungăo de corrente á calculada como a média entre o valor da função de corrente na célula cheia com o valor cla função de corrente na célula de fronteira. Conforme a geometria apresentada na figura (1), dois casos devem ser analisados:

1. Célula cheia com lace superior en contato com cólula de fronteira:

$$
\frac{\psi_{i, j+1}+\psi_{i, j}}{2}=\dot{\psi}_{1} \quad \Rightarrow \quad \psi_{i, j 11}=-\dot{\psi}_{i, j}+2 \psi_{1}
$$

2. Célula cheia com face inferior em contato com célula de fronteira:

$$
\frac{\psi_{i, j-1}+\psi_{i, j}}{2}=\psi_{0} \quad \rightarrow \quad \psi_{i, j, 1}=-\psi_{i, j}+2 \psi_{1\}}
$$

Montado o sistema linear $\underline{\underline{A}} \underline{x}=\underline{b}$, aplicamos o método dos gradicntes conjugados para resolvê-lo. O vetor $x$ é inicializado como o vetor de funçäo de corrente no tempo anterior. 


\section{Anexo C: Ambiente FreeFlow}

\section{O Ambiente de Simulação FreeFlow-2D}

() FrefFlow-2D é um ambiente de modelagem, simulação e visualização para cscoamentos incompressiveis isotérmicos e com superfícies lives bidimensional. Esse ambiente é composto de quatro módulos distintos:

- Modllow-2d: Esse módulo consiste de uma ferramenta gráfica que permite a construção de modelos bidimensionais para a simulação.

- Simflow-2d: Esse módulo permite a simulação do modelo gerado através do módulo Modflow-2d.

- Visflow-2d: A visualização dos resultados gerados pelo Simflow-2d pode ser efetuada através desse módulo. O Visflow-2d permite a visualização das componentes do campo de velocidades, as tensöes totais e não-Newtonianas, da viscosidade c taxa de cisalhamento, bem como a primeira diferença de tensões normajs.

- Resimflow-2d: Ésse módılo é responsável pela reinicialização da simulação caso aconteça queda no fornecimento de energia elétrica. Esse módulo também permite alteraçoes de alguns parâmetros da simulação, como por exemplo, o tempo final de simulação, o número máximo de ciclos, a tolerância do método dos gradientes conjugados, entre outros.

Maiores detalhes sobre esse ambiente de simulação podem ser encontrados no trabalho de Oliveira [1999]. 